\author{
UNIVERSIDADE DE SÃO PAULO \\ FFCLRP - DEPARTAMENTO DE FÍSICA E MATEMÁTICA \\ PROGRAMA DE PÓS-GRADUAÇÃO EM FÍSICA APLICADA À \\ MEDICINA E BIOLOGIA
}

\title{
Propriedades Ópticas de Absorção e Emissão \\ Fluorescente do Ácido orto-Aminobenzóico e seus \\ Derivados em meio solvente
}

Marcelo Takara

Tese apresentada à

Faculdade de Filosofia, Ciências e Letras de Ribeirão

Preto da USP, como parte das exigências para a obtenção do título de Doutor em Ciências, Área: Física Aplicada à Medicina e Biologia.

(versão corrigida)

RIBEIRÃO PRETO -SP

2006 
FFCLRP - DEPARTAMENTO DE FÍSICA E MATEMÁTICA PROGRAMA DE PÓS-GRADUAÇÃO EM FÍSICA APLICADA À MEDICINA E BIOLOGIA

\section{Propriedades Ópticas de Absorção e Emissão Fluorescente do Ácido orto-Aminobenzóico e seus Derivados em meio solvente}

\section{Marcelo Takara}

Tese apresentada à

Faculdade de Filosofia, Ciências e Letras de Ribeirão Preto da USP, como parte das exigências para a obtenção do título de Doutor em Ciências, Área: Física Aplicada à Medicina e Biologia.

Orientador: Prof. Dr. Amando Siuiti Ito

RIBEIRÃO PRETO -SP 
AUTORIZO A REPRODUÇÃO E DIVULGAÇÃO TOTAL OU PARCIAL DESTE TRABALHO, POR QUALQUER MEIO CONVENCIONAL OU ELETRÔNICO, PARA FINS DE ESTUDO E PESQUISA, DESDE QUE CITADA

Ficha Catalográfica

Takara, Marcelo.

Propriedades Ópticas de Absorção e Emissão Fluorescente do Ácido orto-Aminobenzóico e Derivados em meio solvente/ Marcelo Takara; orientador

Amando Siuiti Ito.

Ribeirão Preto, 2006.

132 f. :g.

Tese (Doutorado - Programa de Pós Graduação da Faculdade de Filosofia, Ciências e Letras de Ribeirão Preto - Ârea de Concentração: Física Aplicada a Medicina e Biologia) - Faculdade de Filosofia, Ciências e Letras de Ribeirão

Preto da Universidade de São Paulo.

1. Espectroscopia - Fluorescência - Absorção Óptica. 2. Ácido Antranílico- Aminobenzóico - Efeitos de solventes. 3. Simulação computacional - Monte Carlo - Ab-Initio - QM/MM. 
Dedico esta tese

ao meu pai,

Seisaburo Takara

(in memoriam) 


\section{Agradecimentos}

Agradeço à FAPESP por haver concedido a bolsa de doutorado que me permitiu realizar este projeto.

Ao Professor Amando não somente pela orientação, mas também pela amizade, atenção e compreensão, sobretudo nos momentos de dificuldades de ordem pessoal.

À Professora Kaline Coutinho pela orientação quanto às metodologias de simulação computacional, assim como pelo direito de uso do DICE.

À Izaura Hirata do Departamento de Biofísica da Unifesp por sintentizar as amostras.

À Professora Maria Teresa Lamy, por ceder o uso das instalações e equipamentos do Laboratório de Biofisica-IFUSP, nas minhas estadias em São Paulo.

Aos técnicos do Laboratório de Biofísica do IFUSP, Tiago e Evandro, pela acolhida e pela ajuda no laboratório.

Aos técnicos Júlio e Aziani da oficina do departamento, pelo grande profissionalismo e presteza que sempre demonstraram ante as necessidades do grupo.

Ao amigo Prof. Pablo, pelos esclarecimentos acerca de espectroscopia e lasers, e também pela sólida amizade e a ótima convivência, sobretudo nos momentos dificeis.

À amiga Cássia, colega desde os tempos de mestrado, pela ajuda nos experimentos de laboratório e também pela amizade de longa data.

Ao amigo Fábio pela amizade e pelas intermináveis discussões frutificantes ou não, mas que faziam pensar bastante.

À Giuse, esposa do Prof. Amando, pelos deliciosos almoços de domingo, em Ribeirão Preto e em São Paulo.

Ao Prof. Iouri pelas valiosas discussões e a amizade e também à sua esposa Profa. Galina.

Aos amigos que vieram depois, Luciana, Marina, Ernando e Moisés, pela ótima convivência nos meus últimos dias de doutorado, e pelas agradáveis "bandejadas" diárias. 
Às irmãs do pensionato do Vita et Pax, Irmãs Maura, Luca e outras, pelo carinho e hospitalidade nos meus primeiros meses em Ribeirão Preto.

À Dra. Paula, que me ajudou a encontrar o meu "eixo" e a serenidade e aos irmãos "companheiros da jornada evolutiva" que fiz em Ribeirão Preto, enquanto freqüentei o CEAE da Vila Tibério.

A Marina Gold, pelos preciosos conselhos.

Aos meus irmãos Nelson, Hélio e Cristiane que sempre acreditaram em mim, e pela forte sentimento fraterno que sempre nos manteve unidos, mesmo nas dificuldades.

À minha Mãezinha mui amada D. Ana (Oka-chan), pelas constantes orações e pelos exemplos de amor e dedicação.

Ao Deus Pai Criador, pelo que sou e por tudo que consegui até hoje. 
"Olhai os lírios do campo, como eles crescem; não trabalham nem fiam; eEu vos digo que nem mesmo Salomão, em toda a suaglória, se vestiu como qualquer um deles. Pois se Deus assim veste a erva do campo, que hoje existe e amanhã é lançada no forno, não vos vestirá muito mais a vós, homens de pouca fé?”

Mateus, 6: 28-30 


\section{RESUMO}

Nesta tese, apresentamos estudos experimentais e teóricos realizados com o Ácido orto-Aminobenzóico (o-Abz) e seus derivados 2-amino-benzamida (o-Abz- $\left.\mathrm{NH}_{2}\right)$, 2-amino-metil-benzamida (o-Abz-NH( $\left.\mathrm{CH}_{3}\right)$ ) e 2-amino -dimetilbenzamida (o-Abz-N $\left.\left(\mathrm{CH}_{3}\right)_{2}\right)$. Foram feitas medidas de absorção óptica, fluorescência estática e resolvida no tempo e anisotropia de fluorescência em solventes com diferentes graus de polaridade e diferentes capacidades de doar e aceitar prótons. Os resultados experimentais foram comparados aos resultados de simulações computacionais que simularam o sistema solventesoluto. Restrições impostas pelas limitações computacionais impedem cálculos totalmente quânticos via métodos ab-initio, porém uma metodologia que tem apresentado resultados satisfatórios é o método híbrido que envolve a mecânica quântica associada à mecânica molecular (QM/MM). No presente trabalho, foram combinados cálculos quânticos ab-initio e semi-empíricos na otimização de geometrias de moléculas isoladas e no cálculo de energias de transições respectivamente. Foram simulados os sistemas soluto+solvente via Método de Monte Carlo. Os espectros de absorção ótica obtidos via simulação demonstraram boa concordância com os resultados experimentais, identificando-se as bandas como oriundas das transições $\pi-\pi^{*}$. Verificamos que a forma ácida aniônica do o-Abz é responsável pelo deslocamento para o azul, observado em solvente aquoso. A forma aniônica incrementa a eletronegatividade dos átomos de Oxigênio, aumentando a energia das ligações de hidrogênio. Essas ligações mais intensas estabilizam o estado excitado do o$\mathrm{Abz}$, e isso se reflete no deslocamento para azul. Da simulação, verificou-se também que na forma aniônica há uma inibição das ligações de hidrogênio do tipo doadoras por parte do grupo amina. Os derivados do o-Abz apresentam aumento na capacidade do grupo amina atuar como doador em ligações de hidrogênio e diminuição na soma de todas as ligações de hidrogênio entre soluto-solvente. Os derivados amida e monometilamida mantiveram elevado rendimento quântico e sensibilidade à polaridade ambiente. Por outro lado, o derivado o-Abz-N( $\left(\mathrm{CH}_{3}\right)_{2}$ mostra sensibilidade à presença de metilas que incrementam as vias de desexcitação não radiativa. 


\begin{abstract}
In the present, we report experimental and theoretical studies on orthoaminobenzoic acid (o-Abz) and its derivatives 2 amino-benzamide (o-Abz- $\mathrm{NH}_{2}$ ), 2 amino-monomethyl-benzamide (o-Abz- $\left.\mathrm{NH}\left(\mathrm{CH}_{3}\right)\right)$ and 2 amino-dimethyl-benzamide (o-Abz-N $\left(\mathrm{CH}_{3}\right)_{2}$. We measured optical absorption, steady state and time-resolved fluorescence and fluorescence anisotropy of the compounds in solvents with different donor/acceptor character. The experimental results were compared with results of computational calculations which simulated solvent-solute systems. Due to the restrictions imposed by the computer limitations, it was not possible to do entire quantum calculations by ab-initio methods. We used then $Q M / M M$ methods, which involves quantum calculation with molecular mechanics simulations. In this work, ab-initio and semi-empiric quantum calculations were combined in the single molecule geometry optimization and energy transitions calculus, respectively. The solute-solvent system was simulated by Monte Carlo method. The optical absorption spectra obtained from simulations showed good agreement with experimental results, identifying the bands relative to $\pi-\pi^{*}$ transitions. It was observed that the anionic acid form of the o-Abz is responsible for the blue shift when it is in aqueous solution. Anionic form increases the electronegativity of Oxygen atoms, rising the energy of the hidrogen bonds. These strong bonds stabilize the fundamental state of o-Abz, resulting in a blue shift in absorption spetrum. From simulation, it was verified that in the anionic form of $\mathrm{o}-\mathrm{Abz}$ there is also an inhibition of hidrogen bonds of the donor type by the amine group. Compared to o-Abz alone, the derivatives present an increase in the amine group capacity to act as a hidrogen bond donor. The o-Abz-NH2 and o-Abz$\mathrm{NH}(\mathrm{CH} 3)$ derivatives preserved the high quantum yield and the sensitivity for the environment polarity, while in the dimethyl amide derivative, the presence of methyl groups increases the deexcitation by non-radiactive pathways.
\end{abstract}




\section{Conteúdo}

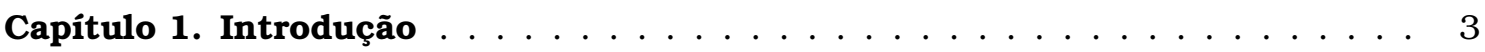

1.1. Motivação .......................... 3

1.2. Ácido orto-Aminobenzóico e derivados . . . . . . . . . . . . . . . . . . 4

1.3. Efeitos de solventes em espectros de absorção óptica e emissão fluorescente 7

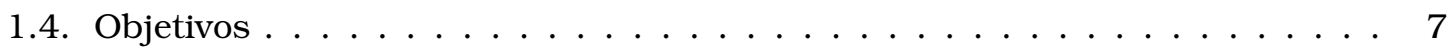

Capítulo 2. Bases Experimentais $\ldots \ldots \ldots \ldots \ldots \ldots$

2.1. Espectroscopias de Absorção Ótica e Fluorescência . . . . . . . . . . . . . . . 9

2.1.1. Absorção Óptica e Fluorescência . . . . . . . . . . . . . . . . . . . . . 9

2.1.2. Espectroscopia de Fluorescência com resolução temporal . . . . . . . 17

2.1.3. Anisotropia de Fluorescência ． . . . . . . . . . . . . . . 22

2.1.4. Modelo de solvatação: Önsager e equação de Lippert-Mataga . . . . . 26

2.2. Descrição experimental . . . . . . . . . . . . . . . . . . . 33

2.2.1. Espectrofotômetro de Absorção Óptica . . . . . . . . . . . . . . . . 33

2.2.2. Espectrofluorímetro Estático . . . . . . . . . . . . . . . 34

2.2.3. Espectrofluorímetro de resolução temporal . . . . . . . . . . . . . 36

Capítulo 3. Fundamentos e Métodos Computacionais . . . . . . . . . . . . . 41

3.1. Funções de Ondas para vários elétrons . . . . . . . . . . . . . . . . 41

3.1.1. Aproximação de Born-Oppenheimer . . . . . . . . . . . . . . . . . 42

3.1.2. Anti-simetria ou Princípio de Exclusão de Pauli . . . . . . . . . . . . 43

3.1.3. Orbitais espaciais, orbitais de spin e Determinante de Slater . . . . . 45

3.2. Hartree-Fock, CI e DFT . . . . . . . . . . . . . . . . . . . . . 50

3.2.1. Método Hartree-Fock e as equações de Roothan . . . . . . . . . . . . . 50

3.2.2. Interação de Configurações e Energia de Correlação Eletrônica . . . . 56 
3.2.3. Teoria do Funcional Densidade . . . . . . . . . . . . . . . . . 58

3.3. Dinâmica Molecular e método de Monte Carlo . . . . . . . . . . . . . . . . . . 62

3.3.1. O Potencial de Interação . . . . . . . . . . . . . . . . . . . . 62

3.3.2. Dinâmica Molecular . . . . . . . . . . . . . . . . . . . . . 66

3.3.3. Método de Monte Carlo . . . . . . . . . . . . . . . . . . . . . . 68

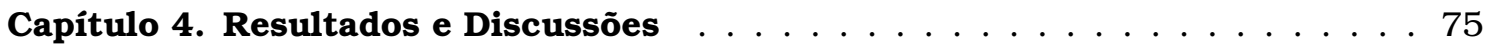

4.1. Espectros de Absorção e Emissão Fluorescente . . . . . . . . . . . . . 75

4.1.1. Efeitos Gerais . . . . . . . . . . . . . . . . . . 77

4.1.2. Efeitos Específicos . . . . . . . . . . . . . . . 81

4.2. Polarização da fluorescência do o-Abz: determinação de volume molecular . 95 4.2.1. Abz em mistura água + glicerina . . . . . . . . . . . . . . 96

4.2.2. Abz-Bradicinina em mistura água + glicerina . . . . . . . . . . . . 99

4.2.3. Abz ligado a aminoácidos . . . . . . . . . . . . . . . . . . . 100

4.3. Cálculos ab-initio . . . . . . . . . . . . . . . . . . . 103

4.3.1. Otimização de estrutura do o-Abz e seus derivados . . . . . . . . . 103

4.4. Simulação de Monte Carlo do Espectro de absorção do o-Abz em água . . 107

4.4.1. Termalização e Equilíbrio . . . . . . . . . . . . . . . . . . . 107

4.4.2. Solvatação do o-Abz . . . . . . . . . . . . . . . . . . 110

4.4.3. Solvatação de derivados do o-Abz . . . . . . . . . . . . . . 119

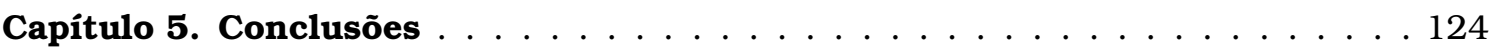

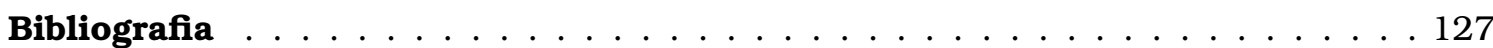




\section{Capitulo 1}

\section{Introdução}

\subsection{Motivação}

Nos estudos acerca de proteínas e peptídeos que fazem uso da espectroscopia de fluorescência, há uma questão muito importante, relativa à escolha da sonda fluorescente mais adequada ao tipo de experiência realizada. A situação ideal é aquela em que podemos contar com uma sonda intrínseca à molécula em estudo, como é o caso dos aminoácidos triptofano e tirosina [1, 2]. Por serem componentes naturais de algumas proteínas e peptídeos, podemos dispor da estrutura na sua conformação nativa, livre de qualquer agente exógeno, o que melhor reflete o seu comportamento natural. Entretanto, como nem sempre esta situação ideal se faz presente, geralmente se faz necessário agregar uma sonda exógena à molecula em estudo. Assim, a caracterização de uma sonda fluorescente ideal para estudos envolvendo técnicas de fluorescência assume um importante papel, ao se constituir um novo instrumento de pesquisas em estudos biológicos. O Ácido orto-Aminobenzóico (o-Abz ou OABA), também conhecido como Ácido Antranílico, tem sido estudado como sonda fluorescente [3, 4], e o presente trabalho busca compreender os efeitos de solventes sobre as características de absorção óptica e emissão fluorescentes. Tal compreensão acerca dos efeitos de solvente é muito importante, uma vez que o papel principal de uma sonda constitui em enviar informações acerca do meio em que se encontra. O presente trabalho é também uma seqüência a um estudo iniciado no mestrado, onde os efeitos 
de solvente sobre o o-Abz foram estudados experimentalmente apenas na forma isolada[5]. Esta seqüência agora inclue os derivados aminados e metilados do o-Abz, além de alguns compostos com peptídios, onde se mostra também uma aplicação prática do seu uso como sonda. Além das observações experimentais, este trabalho faz o uso de cálculos de simulação computacional do fluoróforo em meio solvente. Assim, aliando resultados experimentais aos cálculos teóricos foi possível chegar a conclusões mais consistentes acerca da caracterização do o-Abz como sonda fluorescente.

\section{2. Ácido orto-Aminobenzóico e derivados}

Também conhecido como Ácido Antranílico na sua conformação orto, o ácido Aminobenzóico basicamente se constitui de um anel benzênico que possui grupos amina e ácido carboxílicos tal qual um aminoácido, favorecendo a sua inserção em terminais de cadeias peptídicas, ou mesmo em posições intermediárias dentro da seqüência. Na configuração orto, os terminais amina e ácido carboxílico se encontram ligados à átomos de carbonos adjacentes no anel benzênico, como os carbonos 1 e 2 (vide figura 1.1). As outras configurações, meta e para, envolvem esses mesmos carbonos intercalados por outro carbono (carbonos $1 \mathrm{e}$ 3) e em posições opostas (carbonos 1 e 4), respectivamente.

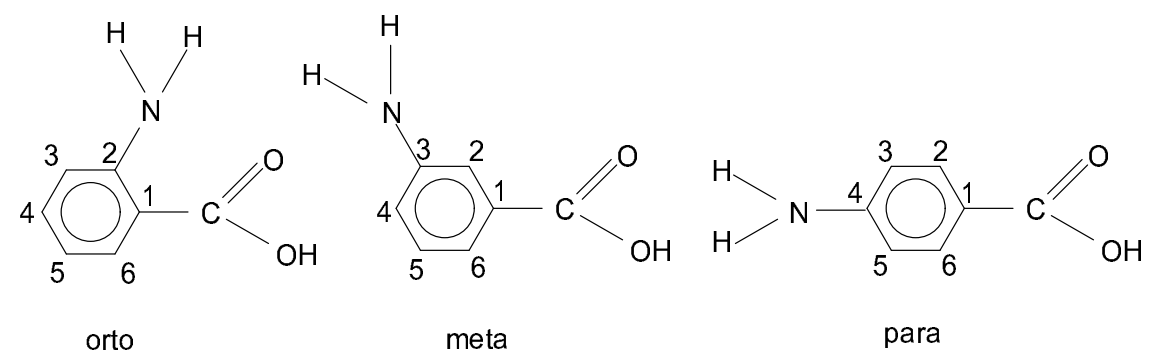

Figura 1.1. Abz nas formas orto, meta e para. 
Estudos foram feitos por Souza et al [6], usando-se o modelo de transferência de energia por ressonância de Förster (FRET) na determinação de distâncias intramoleculares dos terminais da bradicinina, ligados ao doador Etileno- dinitrofenilfosfato (Eddnp) e ao receptor o-Abz. Por apresentarem uma boa sobreposição entre as bandas de emissão fluorescente e absorção óptica, o Eddnp e o o-Abz respectivamente formam um bom par doador-aceitador em aplicações envolvendo FRET. Outros trabalhos envolvendo o grupo fluorescente do o-Abz como sonda foram feitos junto a peptídeos [3] e a cadeias hidrofóbicas de carbono inseridas em micelas e vesículas [7]. Na presente tese é apresentado também uma aplicação do o-Abz como sonda fluorescente na determinação aproximada do volume molecular de um peptídeo. O o-Abz possui ainda dimensões relativamente reduzidas, e quando isolado e em solução aquosa com pH neutro, seu espectro de excitação apresenta um máximo em $310 \mathrm{~nm}$ e a sua emissão fluorescente ocorre com o máximo por volta de $398 \mathrm{~nm}[8,5]$. Quando ligado ao terminal carboxílico (amino) de um peptídeo e na mesma solução, tais comprimentos de onda tendem a se deslocar para 330 (320) nm e $\sim 420 \mathrm{~nm}$, respectivamente. Na sua forma isolada, observam-se ainda deslocamentos espectrais também ante variações no $\mathrm{pH}$ da solução, semelhantes àqueles observados em aminoácidos devido aos diferentes estágios de protonação dos grupos amino e ácido carboxílico $[9,10]$. Assim, o o-Abz isolado exige uma certa atenção quanto a seus possíveis estados de protonação, tal qual os aminoácidos.

O seu rendimento quântico, em um solvente prótico como o etanol é de cerca de 60\% [11], valor elevado para um fluoróforo. Esta característica, aliada à sua dimensão reduzida e ao seu significativo deslocamento de Stokes fazem do o-Abz uma boa opção como sonda fluorescente e estudos têm sido feitos no intuito de caracterizar o seu comportamento em diferentes meios ambientes. A única restrição quanto ao seu uso se dá quando o o-Abz se liga diretamente à Prolina, formando a não fluorescente pyrrobenzodiazepine-5,11-dione [12]. Cálculos de 
simulação computacional e medidas experimentais envolvendo a técnica de Jet Cooling [13] mostram que o o-Abz em vácuo apresenta duas conformações distintas devido à rotação do grupo ácido carboxílico. Por possuir grupos aceitadores e doadores de prótons próximos, o o-Abz tende ainda a formar ligações de hidrogênio intramoleculares entre a amina e a carboxila [58].

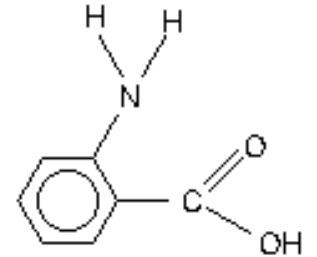

rotâmero 1

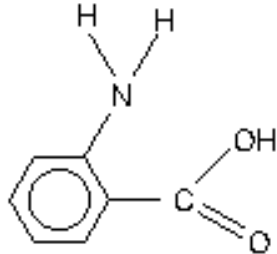

rotâmero 2

Figura 1.2. Abz-normal nos rotâmeros 1 e 2 .

Como o-Abz isolado apresenta um comportamento ácido através do grupo ácido carboxílico, uma vez que forme uma ligação peptídica através desse grupo, ele perde esse caráter de doador de prótons, o que deve se refletir nas suas características espectroscópicas. Assim, para estudá-lo na forma de sonda ligada, foram sintetizados três derivados : $\mathrm{Abz}-\mathrm{NH}_{2}, \mathrm{Abz}-\mathrm{NH}\left(\mathrm{CH}_{3}\right)$ e $\mathrm{Abz}-\mathrm{N}\left(\mathrm{CH}_{3}\right)_{2}$. No derivado $\mathrm{Abz}-\mathrm{NH}_{2}$, o terminal carboxila do o- $\mathrm{Abz}$ liga-se a um grupo amina, enquanto nos compostos $\mathrm{Abz}-\mathrm{NH}\left(\mathrm{CH}_{3}\right)$ e $\mathrm{Abz}-\mathrm{N}\left(\mathrm{CH}_{3}\right)_{2}$ os mesmos terminais se acham ligados aos grupos monometil amida e dimetil amida, respectivamente. São derivados relativamente simples e a escolha se deu porque servem como modelos simples para o estudo das propriedades óticas de Abz-peptídeos nos quais a sonda liga-se à macromolécula de interesse através da ligação formada entre a carboxila do o-Abz e terminal amina do peptídeo. Poucos átomos: é possivel fazer calculos computacionais. 


\subsection{Efeitos de solventes em espectros de absorção óptica e emissão fluorescente}

Os efeitos de solvente na espectroscopia UV-Visível são classificados em efeitos gerais e efeitos específicos. Os efeitos gerais, como o próprio nome sugere, estão presentes em todas as situações e decorrem da interação entre os momentos de dipolo das moléculas dos cromóforos e dos solventes e tem por base o modelo de solvente contínuo de Önsager, com aplicações através da equação de Lippert-Mataga no estudo do Deslocamento de Stokes na emissão fluorescente[14, 15, 16]. Em solventes apróticos, verificamos deslocamentos para o vermelho em solventes mais polares, e fazendo uso da equação de Lippert-Mataga para um solvente contínuo baseado no modelo de Onsager e Kirkwood [17, 18], foi calculada uma aproximação para a variação dos momentos de dipolo nos estados fundamental e excitado, por volta de 2,3 D [8]. Já os efeitos específicos dependem das características particulares de cada solvente e podem envolver efeitos oriundos da presença de ligações de hidrogênio [19, 20], da variação de pH do meio, assim como indução de alterações estruturais na molécula do soluto, formação de agregados e qualquer outro efeito que não possa ser classificado como efeito geral. Deve-se ressaltar que os efeitos gerais estão sempre presentes em todas as situações indistintamente, mesmo quando se presencie efeitos específicos. Comumente estes últimos, quando presentes sempre se mostram mais intensos do que os primeiros, mormente quando são observadas ligações de hidrogênio do solvente para o soluto, de forma que ao se estudar os efeitos gerais é conveniente evitar os solventes próticos.

\subsection{Objetivos}

No intuito de melhor compreender o comportamento do o-Abz e de seus derivados ante diferentes meios solventes, fez se o seu estudo da absorção óptica 
e da emissão fluorescente, bem como a simulação computacional desses efeitos solventes-cromóforo. Nesta tese, a parte experimental consistiu em fazer medidas de espectros de absorção óptica e emissão fluorescente, bem como dos tempos de vida da fluorescência do o-Abz e seus derivados, submetidos a diferentes condições de meio solventes. Foram utilizados solventes conforme o grau de polaridade e o caráter prótico. Também foram feitas medidas da anisotropia de fluorescência em meios de viscosidade variável, o que permitiu estimativas das dimensões moleculares.

Complementando os resultados experimentais, entraram em cena também os cálculos de simulações computacionais que permitiram simular o sistema solvente-soluto. Pode-se através da simulação criar uma configuração particular que permite ou não corroborar hipóteses levantadas experimentalmente acerca de tal configuração. Tal configuração, comumente chamada "caixa d'água” basicamente constitui-se de uma ou mais moléculas do soluto rodeadas pelas moléculas de solvente, numa espécie de caixa. Teoricamente é possível se chegar a resultados exatos através de cálculos quânticos ab-initio; na prática, as restrições são impostas pelas limitações computacionais. Uma metodologia que tem apresentado resultados satisfatórios é o método híbrido que envolve a mecânica quântica associada à mecânica molecular (QM/MM). No presente trabalho, foram combinados cálculos quânticos ab-initio e semi-empíricos na otimização de geometrias de moléculas isoladas e no cálculo de energias de transições respectivamente; e foram simulados os sistemas soluto+solvente (caixa d'água) através da geração aleatória de configurações via Método de Monte Carlo, onde as interações se dão pela mecânica clássica, através de potenciais de interações empíricos. 


\section{Capítulo 2}

\section{Bases Experimentais}

Este capítulo versa sobre a parte experimental do trabalho e basicamente se divide na descrição das técnicas de espectroscopias de absorção óptica e emissão fluorescente, bem como todo o seu embasamento teórico e a segunda parte se volta para a descrição dos equipamentos e dos procedimentos adotados no uso de cada equipamento.

\subsection{Espectroscopias de Absorção Ótica e Fluorescência}

\subsubsection{Absorção Óptica e Fluorescência}

No processo de absorção de radiação por uma molécula[21], a energia a ser absorvida deve se relacionar com a freqüência da radiação $\nu$ por :

$$
E=h \nu,
$$

onde h é a constante de Planck ( $6,67 \times 10^{-27}$ erg.s ) e assim, impõe-se à radiação o aspecto corpuscular. A outra exigência da física quântica diz respeito aos níveis de energia do átomo ou molécula, que devem existir em valores determinados, não sendo mais uma distribuição contínua. Não iremos aqui nos ater à dedução dos níveis de energia permitidos, mas podemos recorrer a um modelo simplificado de uma molécula diatômica para uma melhor compreensão do ponto de vista qualitativo. Para um dado estado, a energia potencial dependerá da distância entre os núcleos, tal qual mostrada pelas curvas representadas na 
figura 2.1. Em cada estado eletrônico, a molécula possui um conjunto de níveis de energia vibracional permitidos. Entre estes últimos, encontramos ainda os níveis de energia rotacionais.

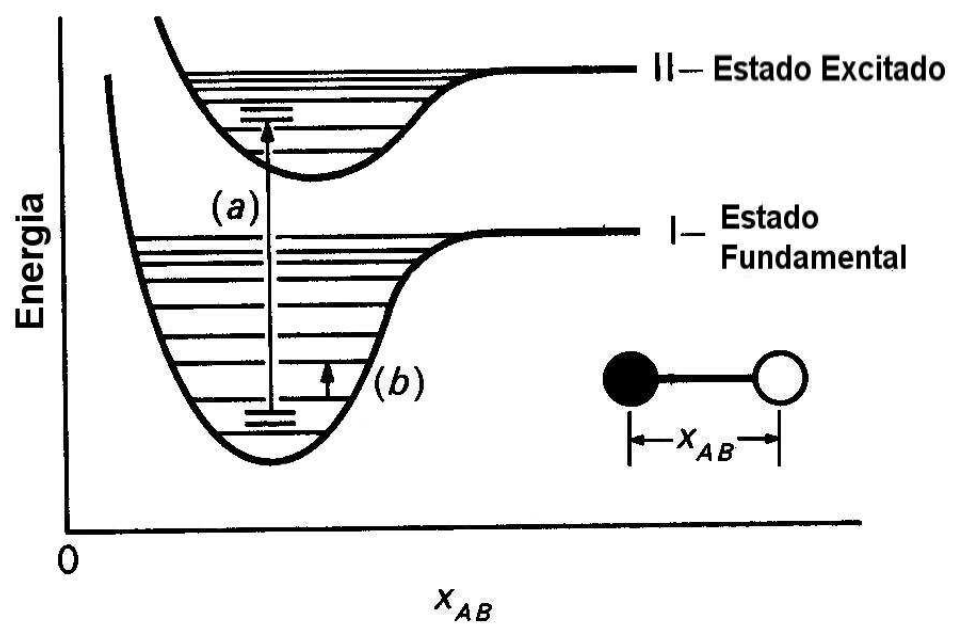

Figura 2.1. Níveis de energia de uma molécula diatômica simples.

Este sistema simples então nos permite demonstrar aspectos mais importantes da espectroscopia de absorção óptica. As transições podem ocorrer entre os níveis eletrônicos, vibracionais e rotacionais da molécula. As transições que envolvem somente os níveis rotacionais se relacionam com a faixa das microondas, e as vibracionais envolvem o espectro infravermelho. Já as transições eletrônicas abrangem o espectro UV visível e constituem o objeto de estudo das técnicas espectroscópicas de fluorescência e absorção óptica. Uma transição eletrônica ocorre quando um elétron é promovido do orbital ocupado de mais alta energia, HOMO (Highest occupied molecular orbital) para o orbital desocupado de mais mais baixa energia LUMO (Lowest unoccupied molecular orbital). Os orbitais moleculares geralmente são descritos como uma combinação linear de orbitais atômicos e são classificados como $\sigma$ e $\pi$, quando participam de uma ligação. O orbital $\sigma$ possui seu eixo de simetria paralelo à direção da ligação, enquanto o orbital $\pi$ possui eixo de simetria perpendicular à ligação. Formados pela combi- 
nação linear dos orbitais atômicos $2 \mathrm{p}_{\mathrm{x}}, 2 \mathrm{py}$ e $2 \mathrm{p} z$, as ligações podem ser do tipo ligantes $(\sigma, \pi)$ ou anti-ligantes $\left(\sigma^{*}, \pi^{*}\right)$, sendo que estes últimos protagonizam os estados excitados nas transições. Um outro tipo de orbital é o não-ligante $(n)$, que como o próprio nome sugere, não participa de ligações. A energia de um orbital não ligante $n$ é geralmente maior do que a de orbitais $\sigma$ e $\pi$, mas menor do que de orbitais anti-ligantes. Basicamente, a espectroscopia de UV-VIS se assenta nas transições de elétrons que ocupam orbitais $n$ ou $\pi$ para estados excitados $\pi^{*}$. As transições $\sigma-\sigma^{*}$, embora possíveis, tendem a ocorrem para energias bem maiores, ou seja, envolvem comprimentos de onda menores.

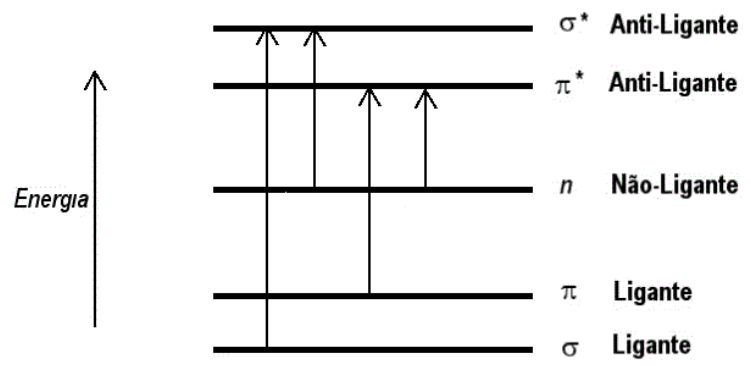

Figura 2.2. Transições eletrônicas envolvidas na espectroscopia UV-vis.

Como se observa da figura 2.2, as transições do tipo $n \rightarrow \pi^{*}$ geralmente envolvem energias menores do que as do tipo $\pi \rightarrow \pi^{*}$, e por serem proibidas apresentam baixa intensidade, com coeficiente de extinção molar $\epsilon_{\max }$ abaixo de 100. Além disso, bandas de absorção relativas às transições $n \rightarrow \pi^{*}$ geralmente costumam sofrer um deslocamento para azul (deslocamento hipsocrômico) ante o aumento de polaridade do solvente. Já para as transições $\pi \rightarrow \pi^{*}$, costuma-se observar o inverso, i.e. verifica-se deslocamentos para o vermelho nas bandas de absorção (deslocamento batocrômico), ante aumento da polaridade do solvente (figura 2.3). Tal fato se deve à estabilização dos níveis ocupados e virtuais, onde o nível virtual (excitado) é mais estabilizado do que o ocupado (fundamental), resultando numa menor energia de excitação. 


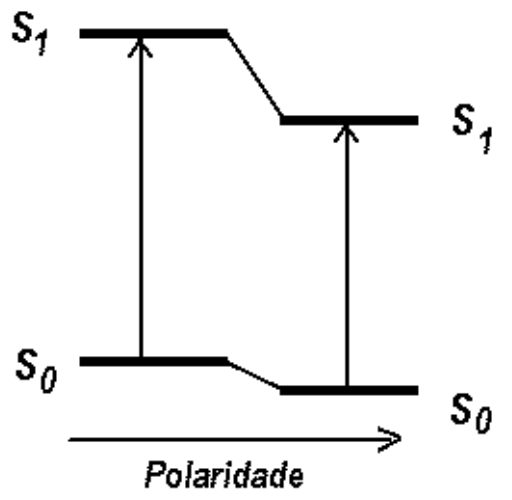

Figura 2.3. Efeito de solvente sobre transições $\pi-\pi^{*}$, onde $\Delta \mu>0$. Aumento na polaridade do solvente diminui a energia de excitação.

\section{Princípios Básicos de Fluorescência}

Consideremos uma molécula hipotética com dois níveis de energia, $S_{b}$ e $S_{a}$ :

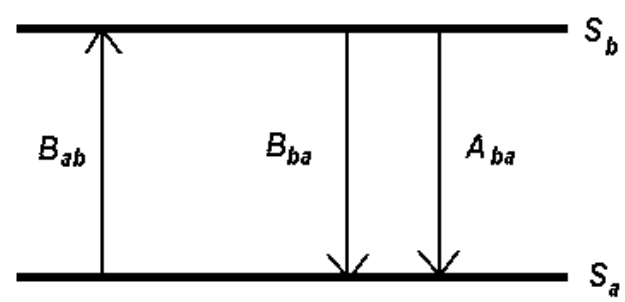

Figura 2.4. Niveis de energia de uma molécula hipotética.

Uma luz com densidade de radiação $I(\nu)$ induz a transição de $S_{a}$ a $S_{b}$ a uma taxa $B_{a b}$ por molécula. O processo de radiação induzida $S_{b}-S_{a}$ ocorre exatamente sob a mesma taxa, logo $B_{a b}=B_{b a}$. Se originariamente o sistema contém $n_{a}$ moléculas no estado $S_{a}$ e $n_{b}$ no estado $S_{b}$, então a taxa líqüida de conversão é $n_{a} B_{a b} I(\nu)$ e $n_{b} B_{b a} I(\nu)$, respectivamente. No equilíbrio, estas taxas devem ser iguais, logo $n_{a} B_{a b} I(\nu)=n_{b} B_{b a} I(\nu)$, ou $n_{a}=n_{b}$, independentemente da densidade de radiação. Entretanto, tal resultado é um absurdo, pois sem luz, virtualmente todas as moléculas deveriam estar no estado fundamental $S_{a}$, conforme se verifica pela Equação de Boltzmann: 


$$
n_{a} / n_{b}=e^{-\left(E_{a}-E_{b}\right) / k T}=e^{+h v / k T}
$$

onde $h$ é a constante de Planck.

Para resolver a discrepância, Albert Einstein postulou uma taxa de emissão espontânea de fótons a partir do estado $S_{b}$. A taxa deste processo $\left(A_{b a}\right)$ deveria ser independente de $I(\nu)$. Quando a taxa de emissão espontânea é incluída e as taxas de interconversão de $S_{a}$ e $S_{b}$ são mantidas iguais no equilíbrio, o resultado é

$$
n_{a} / n_{b}=\left[B_{a b} I(\nu)+A_{b a}\right] / B_{a b} I(\nu)=1+A_{b a} / B_{a b} I(\nu)
$$

Igualando as equações 2.1 e 2.2 podemos obter $A_{b a}$. Para fazê-lo, precisamos primeiro inserir em $I(\nu)$ a densidade de radiação esperada para um corpo negro sob temperatura $\mathrm{T}$ :

$$
I(\nu)=8 \pi h \nu^{3} / c^{3}\left(e^{h \nu / k T}-1\right)
$$

Com esta substituição, a equação 2.2 se torna

$$
n_{a} / n_{b}=1+A_{b a} / B_{a b} I(\nu)=1+A_{b a}\left(e^{h \nu / k T}-1\right) / 8 \pi h \nu^{3} c^{-3} B_{a b}
$$

Quando este valor é igualado a $e^{h \nu / k T}$ (da equação 2.1), o resultado para $A_{b a}$ é

$$
A_{b a}=8 \pi h \nu^{3} c^{-3} B_{a b}
$$

Notemos que esta equação possui uma dependência cúbica da freqüência, o que significa que sob comprimentos de onda curtos, $A_{b a}$ é muito maior do que $B_{a b}$. Essencialmente toda emissão é espontânea. Sendo $B_{a b}=\left(2 \pi / 3 \hbar^{2}\right) D_{a b}$, onde $D_{a b}$ é a força de dipolo [22] e é dada por 
integral de dipolo

$$
D_{a b}=\left|\left\langle\Psi_{a}|\tilde{\mu}| \Psi_{b}\right\rangle\right|^{2}
$$

Assim, podemos obter

$$
A_{b a}=\left(32 \pi^{3} \nu^{3} / 3 c^{3} \hbar\right) D_{a b}
$$

Como a força de dipolo $\left(D_{a b}\right)$ e a freqüência $(\nu)$ geralmente podem ser observados de espectros de absorção, a taxa de emissão espontânea pode ser determinada sem que se faça uma medida da emissão fluorescente. Na ausência da radiação ou quaquer outra perturbação ou interações, a taxa de desexcitação de moléculas inicialmente no estado $S_{b}$ será

$$
d n_{b} / d t=-A_{b a} n_{b}
$$

onde a solução desta equação diferencial será $n_{b}(t)=n_{b}(0) e^{-A_{b a} t}$ onde $n_{b}(0)$ é a concentração de estados excitados no instante zero. Podemos então definir o tempo de vida radiativo do estado $S_{b}$ como

$$
\tau_{R}=1 / A_{b a}
$$

A força de dipolo $D_{a b}$ é uma medida direta da intensidade de uma absorção espectral. Da equação 2.7 vemos que $D_{a b}$ e $A_{b a}$ são proporcionais, logo a equação 2.9 indica que quanto maior a absorção de uma dada molécula isolada, mais rápida a emissão fluorescente. Notemos no entanto, que a equação 2.9 é válida somente quando se o mesmo estado que absorveu a radiação está subseqüentemente emitindo-a, o que não é sempre o que ocorre. Na verdade, o tempo de vida realmente observado para um estado singleto raramente é como o tempo de vida computado pela equação 2.9 , pois o estado excitado pode perder a energia através de vários outros processos, a serem descritos através do diagrama de 
Jablönski logo adiante. A taxa de fluorescência intrínseca $\left(k_{F}\right)$ pode então ser avaliada como

$$
k_{F}=A_{b a}=1 / \tau_{R}
$$

\section{Diagrama de Jablonski}

Embora a figura 2.1 não indique, vários outros processos podem influenciar a emissão fluorescente, como efeitos de solventes, relaxação de solventes, supressão e uma variedade de reações de estado excitado [24]. No presente trabalho, em particular, examinaremos alguns detalhes acerca dos processos que envolvem a ação dos solventes.

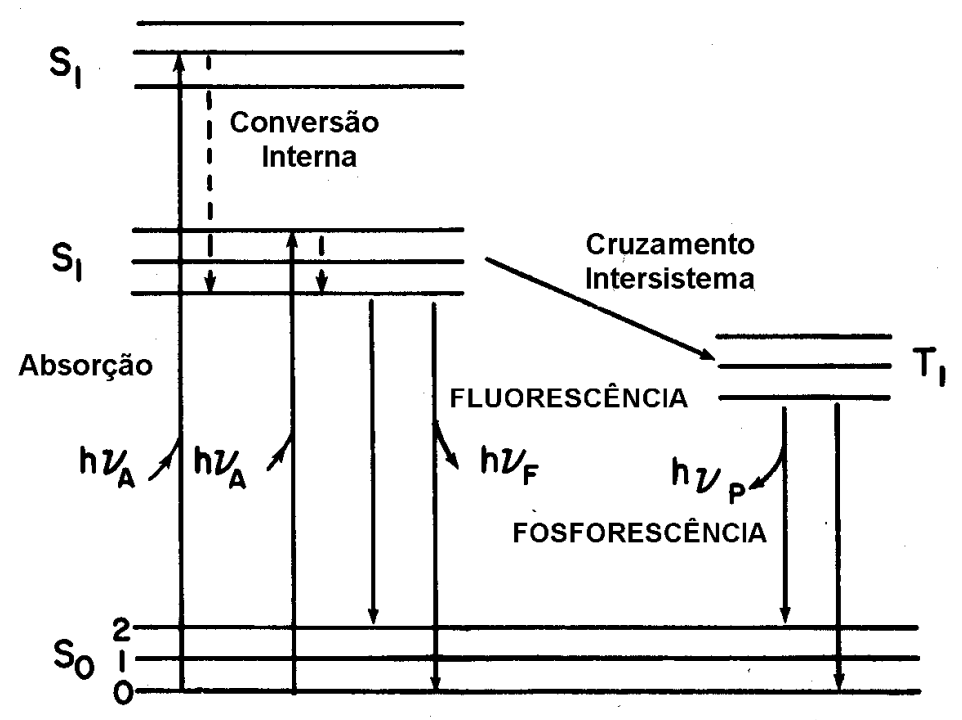

Figura 2.5. Diagrama de Jablonski.

A configuração básica de uma molécula se constitui de núcleos carregados positivamente com os elétrons ocupando os orbitais moleculares. Uma vez que os elétrons possuem spin semi inteiro $1 / 2$, são caracterizados como férmions e devem obedecer ao Princípio de Exclusão de Pauli, onde um estado eletrônico não pode ser ocupado simultaneamente por mais de um elétron. Numa transi- 
ção eletrônica entre diferentes estados uma nova distribuição de cargas deveria modificar as posições dos nucleos dos átomos constituintes da molécula, mas devido ao tempo de vida do estado excitado e à diferença das massas dos núcleos em relação aos elétrons, tal ocorrência é desprezada. Quando um elétron é excitado, os outros elétrons prontamente percebem a mudança e imediatamente promovem a sua redistribuição, enquanto os núcleos, devido à suas massas que são cerca de três ordens de grandeza maior, levam um tempo muito maior do que o próprio tempo de vida do novo estado para se locomoverem em resposta à nova configuração eletrônica. Tal é o Princípio de Frank Condon, e assim, no estudo das transições eletrônicas, considera-se os núcleos fixos e volta-se a atenção unicamente aos elétrons.

No Diagrama de Jablonski (figura 2.5) observamos a forma como se dão as transições eletrônicas. Ao incidir um fóton sobre a molécula ocorre a excitação de elétron do estado fundamental $S_{0}$ para o estado excitado $S_{1}$, numa escala de tempo da ordem de $10^{-15} \mathrm{~s}$. Ainda neste nível eletrônico, ocorre um processo de relaxação interna entre os subniveis vibracionais e rotacionais ao qual se denomina conversão interna, em um tempo da ordem de $10^{-12} s$. Assim, o elétron ainda tende a permanecer nesse estado até o seu retorno ao estado fundamental com a emissão de fóton, após um tempo da ordem de $10^{-9} s$, caracterizando então a emissão fluorescente, ou pode também retornar ao seu estado fundamental sem que ocorra tal emissão. Nesse caso, a energia seria dissipada por processos não-radiativos, seja por colisões com outras moléculas, ou por processos de transferência de energia, como o $\operatorname{FRET}^{1}[6]$. Outra possibilidade é o cruzamento inter-sistema, onde a transição pode ocorrer entre o estado singleto para o estado tripleto, com a mudança do spin do elétron.

De acordo com as regras de seleção para as transições eletrônicas segundo a qual $\triangle S=0$, uma tal transição é dita proibida, e o que se observa então é a

\footnotetext{
1 Transferência de energia de fluorescência por ressonância.
} 
sua baixíssima probabilidade de ocorrência. Mas uma vez que ela ocorre, devido à essa baixa taxa de transição o seu retorno ao estado fundamental ocorre em uma escala de tempo extremamente alta quando comparada à da fluorescência, da ordem de $10^{-3} s$ ou até unidades de segundos.

Assim, os processos não radiativos que competem com a fluorescência (e as taxas que as caracterizam) incluem a conversão interna $\left(k_{i c}\right)$, cruzamento interssistemas $\left(k_{i s}\right)$ e supressões de vários tipos $\left[k_{q}(Q)\right]$. Todos estes processos competem diretamente para despopular o estado singleto excitado. Portanto, a fração de estados singletos excitados que decaem através da fluorescência é dada por

$$
\phi_{F}=k_{F} /\left[k_{F}+k_{i c}+k_{i s}+k_{q}(Q)\right]
$$

Denominada rendimento quântico, $\phi_{F}$ é a razão entre fótons emitidos e o número de fótons absorvidos.

\subsubsection{Espectroscopia de Fluorescência com resolução temporal}

O tempo de vida de fluorescência de uma substância usualmente representa o tempo médio em que a molécula permanece no estado excitado, antes de retornar ao estado fundamental. Tal informação nos revela a freqüência de encontros colisionais com agentes supressores, as taxas de transferência de energia e de reações dos estados excitados, além das taxas de transições entre os estados. A natureza precisa dos decaimentos fluorescentes pode ainda revelar detalhes acerca das interações do fluoróforo com seu meio, bem como indicar possíveis alterações estruturais da molécula.

Existem dois métodos largamente utilizados nas medidas dos tempos de vida de fluorescência. Estes são o método pulsado e o método harmônico ou fase-modulado. No método pulsado, a amostra é excitada com um breve pulso de luz e o decaimento da intensidade da fluorescência é medido. No método harmô- 
nico, a amostra é excitada com uma luz senoidalmente modulada, e utiliza-se o deslocamento de fase e a demodulação da emissão relativas à luz incidente, no cálculo do tempo de vida. No presente trabalho utilizamos o método pulsado, de forma que maiores detalhes são apresentados mais adiante.

\section{Medidas de tempos de vida no método pulsado}

Consideremos a excitação de um fluoróforo com um pulso de luz infinitamente curto (no tempo), resultando em uma população inicial $\left(\mathrm{N}_{0}\right)$ de fluoróforos nos estado excitado.

A taxa de decaimento da população inicialmente excitada é:

$$
\frac{d N(t)}{d t}=-(\gamma+k) N(t)
$$

onde

$\mathrm{N}(\mathrm{t})=\mathrm{n}^{\mathrm{o}}$ de moléculas excitadas em um tempo de $\tau$ após a excitação

$\gamma=$ taxa de emissão

$\mathrm{k}=$ taxa de decaimento não-radiativo

Sendo $\mathrm{N}(\mathrm{t})=\mathrm{N}_{0}$ quando $\mathrm{t}=0$, integramos (2.12):

$$
N(t)=N_{0} e^{-t / \tau}
$$

Onde $\tau=(\gamma+k)^{-1}$ é o tempo de vida do estado excitado.

Esperamos que a intensidade de Fluorescência $\mathrm{F}(\mathrm{t})$ seja proporcional à população do estado excitado

$$
F(t)=\gamma N(t)
$$

O tempo de vida da fluorescência geralmente é igualado ao tempo necessário para que a intensidade decaia para 1/e de seu valor inicial, que é $(\gamma+k)^{-1}$. 
Alternativamente, o tempo de vida pode ser determinado da curva $\log F(t)$ versus t.

O tempo de vida pode também ser considerado como o tempo médio que um fluoróforo despende no estado excitado. Tal média é dada por

$$
\langle t\rangle=\frac{\sum_{i} t_{i} N_{i}(t)}{\sum_{i} N_{i}(t)}
$$

Para um grande número de fluoróforos e pequenos intervalos de tempo, esta soma se torna:

$$
\langle t\rangle=\frac{\int_{0}^{\infty} t N(t) d t}{\int_{0}^{\infty} N(t) d t}=\frac{\int_{0}^{\infty} t e^{-t / \tau} d t}{\int_{0}^{\infty} e^{-t / \tau} d t}
$$

O denominador é igual $\tau$, e realizando a integração por partes, encontramos o numerador como sendo $\tau^{2}$. Portanto, para um decaimento exponencial, o tempo médio que um fluoróforo permanece no estado excitado é igual ao tempo de vida

$$
\langle t\rangle=\tau
$$

É importante notar que 2.17 não é verdadeiro para decaimentos mais complexos, tais como decaimentos multi-exponenciais ou não-exponenciais. Freqüentemente, os decaimentos não são adequadamente descritos por uma forma monoexponencial. Nestes casos, os decaimentos observados geralmente são ajustados a uma soma de exponenciais.

$$
F(t)=\sum_{i} \alpha_{i} e^{-t / \tau_{i}}
$$

Onde $\alpha_{i}$ é um fator pré-exponencial representando a contribuição fracional para o decaimento temporalmente resolvido da componente com o tempo de vida $\tau_{i}$. É importante perceber que dependendo da situação, as quantidades $\alpha_{i}$ e $\tau_{i}$ podem não ter significado físico. Um exemplo são os decaimentos 
não-exponenciais, comumente observados em fluoróforos suprimidos por transferência de energia e que sofrem relaxação de solvente. Assim, nem sempre podemos considerar $\alpha_{i}$ e $\tau_{i}$ como componentes isoladas da amostra, a menos que haja indicações que corroborem tal interpretação. Uma circunstância onde isso ocorre é aquela que envolve uma mistura de fluoróforos não interagentes. A mistura pode ser o resultado de vários fluoróforos diferentes ou um fluoróforo em diversos solventes. Cada valor $\tau_{i}$ representaria então uma espécie individual, e a intensidade fracional $f_{i}$ de cada espécie é dada por

$$
f_{i}=\frac{\alpha_{i} \tau_{i}}{\sum_{i} \alpha_{i} \tau_{i}}
$$

\section{Análise do decaimento resolvido no tempo da Intensidade de Fluorescência}

O objetivo das medidas dos decaimentos resolvidos no tempo é determinar a função $\mathrm{F}(\mathrm{t})$. Tal objetivo seria plenamente atingido, caso a excitação se desse através de um pulso infinitamente estreito, ou que cuja largura fosse muito menor do que o tempo de decaimento da amostra. Infelizmente, as larguras dos pulsos freqüentemente são comparáveis às dos tempos de decaimento. Devido a largura do pulso de excitação, o tempo zero não é definido, de forma que não podemos determinar o início da contagem do tempo de vida.

Geralmente mede-se a distribuição temporal L(t) do pulso em uma experiência separada. Desde que o perfil da lâmpada varia com o tempo, tal medida dever ser feita dentro de um curto espaço de tempo antes ou após a medida do decaimento fluorescente. Utiliza-se para tanto, uma solução que espalha a luz. Podemos considerar o pulso da lâmpada como um grande número de pulsos estreitos a cada tempo $t_{i}$, com iguais larguras $\Delta t$, onde $\Delta t$ é muito menor do que o tempo de decaimento observado. Cada pulso individual gera um outro pulso como resposta 


$$
R_{i}(t)=L\left(t_{i}\right) \Delta t F\left(t-t_{i}\right) \quad\left(t>t_{i}\right)
$$

O tempo $\left(t-t_{i}\right)$ serve para nos lembrar que o tempo do decaimento é contado a partir do instante da excitação, que é $t_{i}$. Para $t<t_{i}$, subentende-se que $R_{i}(t)=0$. Faz se aqui uma mudança de variáveis $\mu=t-t_{i}$. O total do decaimento é somado sobre todos os pulsos:

$$
R(t)=\sum_{t=o}^{t=t_{i}} L(t-\mu) F(\mu) \Delta \mu
$$

Conforme $\Delta t$ se aproxima de zero, tal soma se torna uma integral de convolução:

$$
R(t)=\int_{t=o}^{t=t_{i}} L(t-\mu) F(\mu) \Delta \mu
$$

Nas medições experimentais, são obtidas as curvas de decaimento total R(t) e a do perfil da lâmpada L(t). Como o interesse é observar a curva de decaimento "líqüido" $\mathrm{F}(\mathrm{t})$, sem o efeito causado pelo pulso de excitação, se torna necessário fazer a deconvolução da integral 2.22. A figura 2.6 exemplifica uma típica medida de decaimento de fluorescência. 

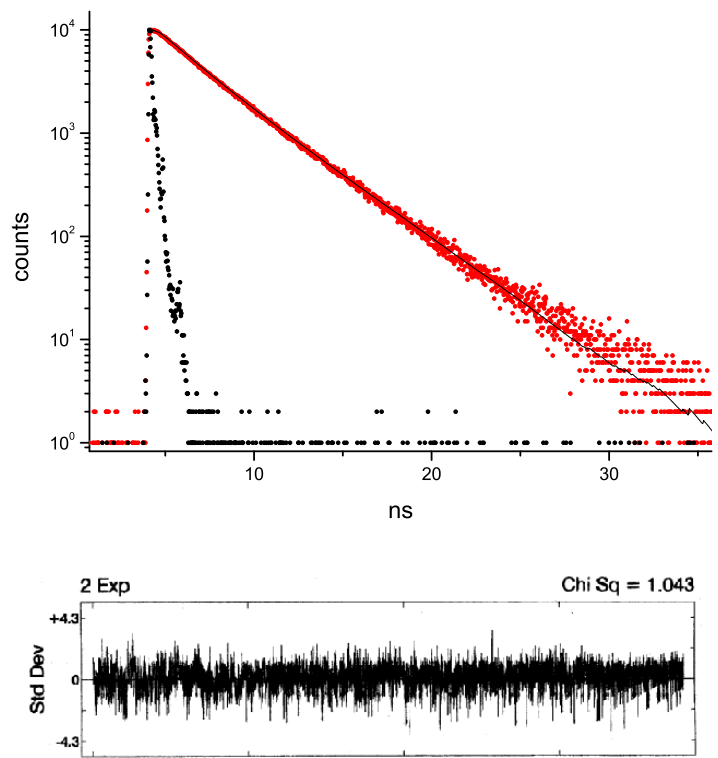

Figura 2.6. Decaimento temporal de Fluorescência do o-Abz e função de autocorrelação residual.

A deconvolução da integral $\mathrm{R}(\mathrm{t})$ para a obtenção de $\mathrm{F}(\mathrm{t})$ é feita pelo próprio software de aquisição de dados e permite obter não só a curva $F(t)=\sum_{i} \alpha_{i} e^{-t / \tau_{i}}$ com seus respectivos parâmetros ajustados $\alpha_{i}$ e $\tau_{i}$, como também visualizar a função de autocorrelação residual (fig.2.6). Esta última função nos possibilita avaliar a qualidade do ajuste feito, pois apresenta os desvios observados entre os dados experimentais e a curva ajustada. Um valor de $\chi_{\text {red }}^{2}$ próximo a 1.0 e uma distribuição aleatória nos valores de resíduos como na figura 2.6 serviram como critérios para o julgamento da qualidade do ajuste.

\subsubsection{Anisotropia de Fluorescência}

Muitas amostras, ao serem excitadas por uma luz polarizada, apresentam a emissão de luz também polarizada. O grau de polarização desta emissão é descrito em termos da anisotropia (r). A origem de tais fenômenos baseia-se na existência de momentos de absorção e emissão posicionados em direções específicas da estrutura do fluoróforo. Em uma solução homogênea, fluoróforos 
no estado fundamental se encontram todos orientados aleatoriamente. Quando expostos à luz polarizada, aqueles que apresentam seus momentos de transição orientados na mesma direção do vetor elétrico da luz incidente são preferencialmente excitados. Logo, a população no estado excitado não é aleatoriamente orientada, pois há um número maior de moléculas excitadas que possuem seus momentos de transição orientados ao longo do vetor elétrico da luz polarizada. A despolarização da emissão pode ser causada por vários fenômenos, que dependem do tipo de amostra investigada. A causa mais comum é a difusão rotacional, e medidas de anisotropia revelam o deslocamento angular médio que ocorre entre a absorção e conseqüente emissão de um fóton. Tais movimentos de rotação, por sua vez, dependem da viscosidade do solvente e da dimensão da molécula. Assim uma variação na viscosidade do solvente tende a alterar a anisotropia de fluorescência. Para pequenas moléculas em soluções de baixa viscosidade, a taxa de difusão rotacional é tipicamente mais rápida do que a taxa de emissão. Sob tais condições, a emissão é despolarizada e a anisotropia é próxima de zero.

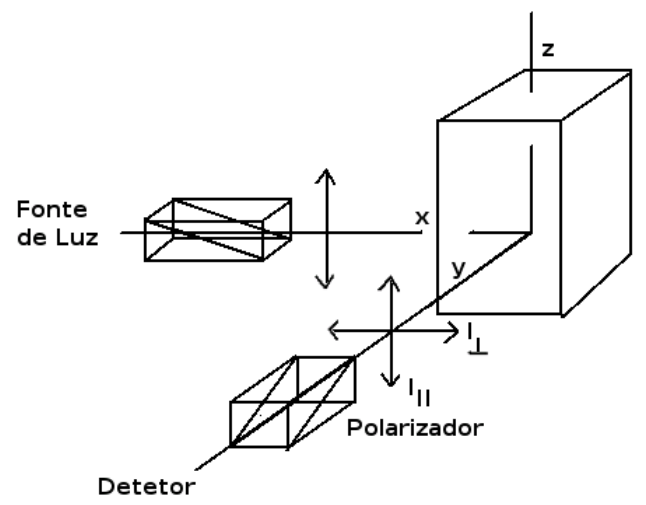

Figura 2.7. Diagrama esquemático para medida de anisotropia de fluorescência.

A figura 2.7 mostra as medidas de anisotropia de fluorescência. A amostra é excitada com luz verticalmente polarizada, onde o vetor elétrico da luz excitada é orientada paralelamente a direção do eixo z. Mede-se então a intensidade de emissão após a passagem desta por um polarizador. Quando o polarizador é 
orientado paralelamente (\|)a direção da excitação polarizada, a intensidade é chamada $I_{\|}$. Por outro lado, quando o polarizador se en contra perpendicular $(\perp)$ à excitação, a intensidade é chamada $I_{\perp}$. Tais valores são utilizados para calcular a anisotropia:

$$
\mathrm{r}=\frac{\mathrm{I}_{\|}-\mathrm{I}_{\perp}}{\mathrm{I}_{\|}+2 \mathrm{I}_{\perp}}
$$

A anisotropia é uma quantidade adimensional que independe da intensidade total da amostra, pois a diferença $I_{\|}-I_{\perp}$ é normalizada pela intensidade total, dada por $I_{\|}+2 I_{\perp}$.

Em algumas publicações é comum encontrarmos ainda, o termo polarização, que é dado por

$$
\mathrm{P}=\frac{\mathrm{I}_{\|}-\mathrm{I}_{\perp}}{\mathrm{I}_{\|}+\mathrm{I}_{\perp}}
$$

Embora não haja nada de errado com a noção de polarização, o seu uso é desencorajado, pois a maioria das expressões matemáticas que descrevem os fenômenos se tornam mais simples quando expressas em termos da anisotropia. Como exemplo pode-se considerar uma mistura de fluoróforos, cada um com polarização $\mathrm{P}_{\mathrm{i}}$ e intensidade de fluorescência fracional $f_{i}$. A polarização desta mistura (P) é dada por

$$
\left(\frac{1}{P}-\frac{1}{3}\right)^{-1}=\sum_{i} \frac{f_{i}}{\left(\frac{1}{P_{i}}-\frac{1}{3}\right)}
$$

enquanto a anisotropia média é dada por

$$
\bar{r}(t)=\sum_{i} f_{i} r_{i}
$$

onde $r_{i}$ indica as anisotropias de cada espécie individual.

Após um pulso de excitação, o decaimento da anisotropia de fluorescência [r(t)] de uma esfera é dada por 


$$
r(t)=r_{0} e^{-t / \theta}
$$

onde $r_{0}$ é a anisotropia em $\mathrm{t}=0$, e $\theta$ é o tempo de correlação rotacional de uma molécula esférica.

Suponhamos que a luz observada através de um polarizador de emissão seja completamente polarizada. Então, $\mathrm{I}_{\|}=0$ e $\mathrm{P}=\mathrm{r}=1.0$. Este valor pode ser observado para luz espalhada para um meio opticamente espalhador e diluído. Emissão completamente polarizada nunca é observada para fluorescência a partir de amostras homogêneas não orientadas. Os valores medidos de P ou r são menores do que a dependência angular de fotoseleção. No caso de emissão completamente despolarizada, temos $\mathrm{I}_{\|}=\mathrm{I}_{\perp}$ e $\mathrm{P}=\mathrm{r}=0$. No entanto, é importante notar que $\mathrm{P}$ e r não são iguais para valores intermediários.

\section{Equação de Perrin}

A difusão rotacional de fluoróforos é a causa dominante de despolarização de fluorescência. Este modo de despolarização é descrito no caso mais simples para rotores esféricos pela equação de Perrin,

$$
\frac{r_{0}}{r}=1+\frac{\tau}{\theta}=1+D \tau
$$

onde $\tau$ é o tempo de vida fluorescente, $\theta$ é tempo de correlação rotacional e D é o coeficiente de difusão rotacional. Se o tempo de correlação rotacional for muito maior do que o tempo de vida $(\theta>>$ t), então a anisotropia medida é igual à anisotropia fundamental $\left(r_{0}\right)$. Se o tempo de correlação rotacional for menor do que o tempo de vida $(\theta<<\tau)$, então a anisotropia é nula. Para uma molécula esférica o decaimento resolvido no tempo da anisotropia $\mathrm{r}(\mathrm{t})$, após um pulso $\delta$ de excitação é uma exponencial simples,

$$
r(t)=r_{0} e^{-t / \theta}=r_{0} e^{-6 D \theta}
$$


Nesta equação, o tempo de correlação rotacional do fluoróforo $(\theta)$ é dado por

$$
\theta=\frac{\eta V}{R T}
$$

onde $\eta$ é a viscosidade, T é a temperatura em kelvins, $\mathrm{R}$ é a constante dos gases, e V é o volume do rotor molecular. O tempo de correlação rotacional é relacionado com o coeficiente de difusão rotacional por $\theta=(6 D)^{-1}$, e somente moléculas esféricas apresentam um decaimento de anisotropia monoexponencial.

A anisotropia de estado estacionário pode ser calculada a partir da média do decaimento da anisotropia $\mathrm{r}(\mathrm{t})$ sobre o decaimento de intensidade $\mathrm{I}(\mathrm{t})$.

$$
r=\frac{\int_{0}^{\infty} I(t) r(t) d t}{\int_{0}^{\infty} I(t) d t}
$$

Para um decaimento de intensidade monoexponencial, a substituição na expressão anterior leva a

$$
r=\frac{r_{0}}{1+(\tau / \theta)}
$$

que é a forma transposta da equação de Perrin.

\subsubsection{Modelo de solvatação: Önsager e equação de Lippert-Mataga}

Os efeitos gerais são decorrentes das interações entre os momentos dipolares tanto do soluto quanto do solvente e baseiam-se no modelo de solvente contínuo apresentado por Önsager, onde a molécula do soluto fica envolvida por uma casca esférica de moléculas do solvente. Importante ressaltar que embora se faça referência às moléculas de solvente, o mesmo deve ser tratado aqui como um meio contínuo. Dependendo do grau de polaridade das moléculas do solvente e do soluto, o momento de dipolo deste último tende a reorientar os momentos de dipolo das moléculas do solvente, de forma que se observa um 
rearranjo da distribuição eletrônica em torno da casca de solvatação, e uma conseqüente formação de um campo reação.

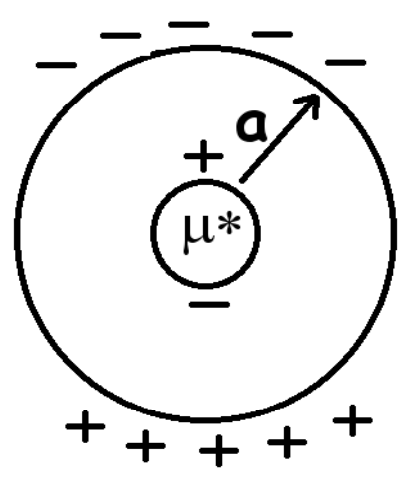

Figura 2.8. Cavidade de Önsager, onde $a$ é o raio da cavidade e $\mu$ é o momento de dipolo da molécula de soluto no estado excitado.

Este mesmo campo reativo é percebido pelo momento dipolar do soluto e temos então uma energia associada a este dipolo sob um campo elétrico. Na figura 2.8, temos uma ilustração simplificada do modelo, onde $a$ é o raio da cavidade de Önsager e $\mu^{*}$ é o momento de dipolo da molécula do soluto no seu estado excitado. Com base neste modelo, Lippert e Mataga, cada qual trabalhando independentemente, chegaram a uma equação onde se quantifica a o deslocamento de Stokes na fluroescência em relação à variação da polaridade do meio caracterizada pela constante dielétrica e índice de refração do solvente.

\section{Equação de Lippert-Mataga}

As interações entre as moléculas do solvente e o fluoróforo afetam a diferença de energia entre o estado fundamental e o excitado. Em uma primeira aproximação esta diferença de energia $\left(\mathrm{em}^{-1}\right)$ depende do índice de refração (n) e da constante dielétrica do solvente $\varepsilon$, o que é descrito pela equação de Lippert-Mataga (ou apenas equação de Lippert, como citam algumas referências), 
cuja dedução será mostrada adiante:

$$
\bar{\nu}_{a}-\overline{\nu_{f}} \simeq \frac{2}{h c}\left(\frac{\varepsilon-1}{2 \varepsilon+1}-\frac{n^{2}-1}{2 n^{2}+1}\right) \frac{\left(\mu^{*}-\mu\right)^{2}}{a^{3}}+\text { const }
$$

Nesta equação, $h$ é a constante de Planck, $c$ é a velocidade da luz, e $a$ é o raio da "cavidade" onde se encontra o fluoróforo no solvente. $\nu_{a}$ e $\nu_{f}$ são respectivamente os números de onda da absorção e da emissão fluorescente. Embora esta equação seja apenas uma aproximação, existe uma razoável correlação entre as perdas de energia calculada e a observada para solventes não-próticos. Por solventes não-próticos devemos entender aqueles que não possuem grupos hidroxilas, ou outros grupos capazes de "doar" de hidrogênio. Termos de ordem maior são desprezados nesta equação. É instrutivo examinar os efeitos opostos de $\varepsilon$ e $n$ sobre o deslocamento de Stokes. Um incremento em $n$ diminui esta perda, enquanto um incremento em $\varepsilon$ resulta em um acréscimo em $\nu_{a}-\nu_{f}$. Esta diferença é explicada pelo princípio de Franck-Condon, e será discutida na dedução da Equação de Lippert-Mataga [24]. Um incremento no índice de refração permite tanto o estado fundamental quanto o excitado a se estabilizarem instantaneamente pelo movimento dos elétrons nas moléculas do solvente. Esta redistribuição eletrônica resulta em um decréscimo na diferença de energia entre os estados fundamental e excitado. Da mesma forma, após um incremento na constante dielétrica, ocorre também a estabilização dos estados fundamental e excitado. No entanto, o decréscimo de energia do estado excitado ocorre somente após a reorientação dos dipolos do solvente. Tal processo requer a movimentação de toda a molécula do solvente, não apenas dos elétrons. Logo, a estabilização dos estados fundamental e excitado do fluoróforo que dependem da constante dielétrica $\varepsilon$ é temporalmente dependente, e a taxa da estabilização depende da temperatura e da viscosidade do solvente. Portanto, os estados excitados se deslocam para energias mais baixas em uma escala de 
tempo comparável ao tempo de reorientação do solvente. Na derivação da equação de Lippert que será feita mais adiante, assumiremos a relaxação do solvente como sendo um efeito anterior à emissão fluorescente. Na expressão 2.33, o termo entre parênteses é chamado de orientação de polarizabilidade $(\Delta f)$. O primeiro termo $(\varepsilon-1) /(2 \varepsilon+1)$ leva em conta os deslocamentos espectrais devidos tanto à reorientação dos dipolos do solvente como da redistribuição dos elétrons nas moléculas do solvente. O segundo termo $\left(n^{2}-1\right) /\left(2 n^{2}+1\right)$ considera somente a redistribuição eletrônica. A diferença destes dois termos é responsável pelos deslocamentos espectrais oriundos da reorientação das moléculas do solvente. Conforme esta simples teoria, somente a orientação do solvente é substancialmente responsável pelo deslocamento de Stokes. A redistribuição eletrônica ocorre instantaneamente, e ambos os estados excitado e fundamental são aproximadamente estabilizados por este processo. Conseqüentemente, a redistribuição eletrônica possui um efeito comparativamente menor sobre o deslocamento de Stokes.

As interações físicas e químicas entre fluoróforo e as moléculas do solvente, responsáveis pelos efeitos gerais de solventes, são observadas na dedução da equação de Lippert:

$$
h c \Delta \bar{\nu}=\frac{2 \Delta f}{a^{3}}\left(\mu^{*}-\mu\right)^{2}
$$

onde $\Delta \bar{\nu}$ é diferença (em $\mathrm{cm}^{-1}$ ) entre os números de onda da absorção e da emissão, $\Delta f$ é a polarizabilidade de orientação, e $\mu^{*}$ e $\mu$ são os momentos de dipolos da molécula nos estados excitado e fundamental, respectivamente. De acordo com o princípio de Franck-Condon, o núcleo não se move durante o decorrer de uma transição eletrônica, e por outro lado os elétrons das moléculas do solvente se redistribuem durante este tempo. Além do mais, devido ao relativo tempo longo do estado excitado $\left(\sim 10^{-8} s\right)$, as moléculas do solvente podem se reorien- 
tar para a sua posição de equilíbrio em torno do estado excitado do fluoróforo anterior à emissão.

A derivação parte da consideração de um dipolo puntual em um meio dielétrico contínuo (fig.2.8). A energia deste dipolo é dada por

$$
E_{\text {dipolo }}=-\mu \mathbf{R}
$$

onde $\mathbf{R}$ é o campo reativo gerado pela redistribuição de cargas na casca de solvatação causada pelo momento dipolar do soluto. O campo reativo é paralelo e oposto à direção do dipolo, e é proporcional à magnitude do momento de dipolo e atua como se estivesse em meio dielétrico contínuo:

$$
R=\frac{2 \mu}{a^{3}} f
$$

Nesta equação $f$ é polarizabilidade do solvente e $a$ é o raio da "cavidade". A polarizabilidade do solvente é um resultado tanto da mobilidade dos elétrons no solvente como dos momentos de dipolos das moléculas do solvente. Cada um destes componentes possuem diferentes dependências temporais. A reorientação dos elétrons em solventes é essencialmente instantânea. Esta polarizabilidade de alta freqüência de $f(n)$ é uma função do índice de refração,

$$
f(n)=\frac{n^{2}-1}{2 n^{2}+1}
$$

A constante dielétrica determina a polarizabilidade do solvente, que inclui o efeito da reorientação molecular das moléculas do solvente. Devido ao tempo longo da orientação molecular, esta componente é chamada de polarizabilidade de baixa freqüência do solvente, sendo dada por

$$
f(\varepsilon)=\frac{\varepsilon-1}{2 \varepsilon+1}
$$


A diferença destes dois termos é

$$
\Delta f=\frac{\varepsilon-1}{2 \varepsilon+1}-\frac{n^{2}-1}{2 n^{2}+1}
$$

Tal diferença é denominada polarizabilidade de orientação. Se o solvente não possui momento de dipolo permanente, $\varepsilon \sim n^{2}$ e $\Delta f \sim 0$.

As interações de um fluoróforo com um solvente podem ser descritas em termos dos seus momentos de dipolos nos estados excitado e fundamental, e os campos reativos em torno destes dipolos. Tais campos podem ser divididos entre aqueles devidos aos fatores eletrônicos $\left(R_{e}\right.$ e $\left.R_{e}^{*}\right)$ e aqueles outros devidos à reorientação do solvente $\left(R_{r}\right.$ e $\left.R_{r}^{*}\right)$. Estes campos são

$$
\begin{array}{ll}
R_{e}=\frac{2 \mu}{a^{3}} f(n) & R_{e}^{*}=\frac{2 \mu^{*}}{a^{3}} f(n) \\
R_{r}=\frac{2 \mu}{a^{3}} \Delta f & R_{r}^{*}=\frac{\mu^{*}}{a^{3}} \Delta f
\end{array}
$$

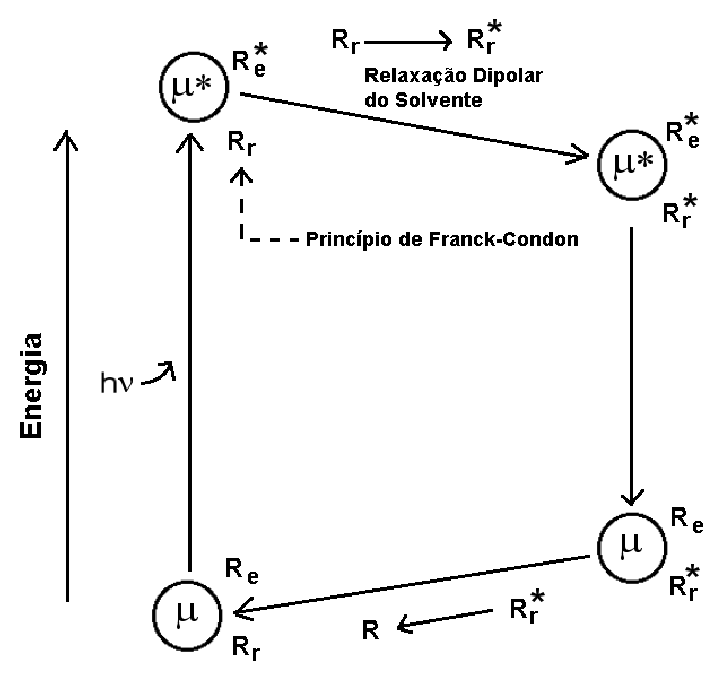

Figura 2.9. Efeitos de campos de reação orientacional e eletrônica na energia de um dipolo em um meio dielétrico. 
A figura 2.9 descreve tais campos durante o processo de excitação e emissão. Para a absorção de luz as energias dos estados fundamental e excitado são:

$$
\begin{gathered}
E^{*}(a b s)=E_{v}^{*}-\mu^{*} R_{r}-\mu^{*} R_{e}^{*} \\
E(a b s)=E_{v}-\mu R_{r}-\mu R_{e}
\end{gathered}
$$

onde $E_{v}$ representa os níveis de energia do fluoróforo no estado de vapor, não perturbado pelos solventes. A energia da luz absorvida é diminuída pelo campo de reação eletrônica induzido pelo estado de dipolo exictado $R_{e}^{*}$. Isto ocorre porque os elétrons no solvente podem seguir a rápida mudança na distribuição eletrônica no fluoróforo. Por outro lado, a orientação das moléculas do solvente não se modifica durante a absorção de luz. Portanto, o efeito da polarizabilidade de orientação é dada por $\mu R-\mu^{*} R_{r}$, e contém somente os campos de reação de orientação do estado fundamental. Esta separação de efeitos é devida ao princípio de Franck-Condon. Lembrando que a energia é relacionada ao número de onda por $\bar{\nu}=\Delta E / h c$, a subtração de 2.41 em 2.40 leva à energia de absorção

$$
h c \bar{\nu}_{a}=h c\left(\bar{\nu}_{a}\right)_{v}-\left(\mu^{*}-\mu\right) R_{r}-\mu^{*} R_{e}^{*}+\mu R_{e}
$$

onde $h c\left(\bar{\nu}_{a}\right)_{v}$ é a diferença de energia para a amostra na fase de vapor onde os efeitos do solvente não estão presentes. Por uma consideração similar se pode obter a energia dos dois níveis eletrônicos para a emissão. Estes são

$$
\begin{gathered}
E^{*}(\text { emis })=E_{v}^{*}-\mu R_{r}^{*}-\mu R_{e}^{*} \\
E(\text { emis })=E_{v}-\mu R_{r}-\mu R_{e}
\end{gathered}
$$

Para derivar tais expressões nós assumimos que o solvente relaxa rapida- 
mente em comparação ao tempo de vida do estado excitado, de forma que o campo de orientação inicial $\left(R_{r}\right)$ se modifica para $R_{r}^{*}$ antes da emissão. Mais uma vez se usa o princípio de Franck-Condon. A freqüência de emissão é obtida de

$$
h c \bar{\nu}_{f}=h c\left(\bar{\nu}_{f}\right)_{v}-\left(\mu^{*}-\mu\right) R_{r}^{*}-\mu^{*} R_{e}^{*}+\mu R_{e}
$$

Na ausência de efeitos ambientes se pode esperar que $\nu_{a}=\nu_{f}$ para átomos na fase de vapor, e $\nu_{a}-\nu_{f}$ como sendo uma constante para moléculas complexas que sofrem relaxação vibracional. Portanto, subtraindo a equação 2.43 de 2.44 obtemos:

$$
\bar{\nu}_{a}-\bar{\nu}_{f}=\frac{1}{h c}\left(\mu^{*}-\mu\right)\left(R_{r}-R_{r}^{*}\right)+\text { const }
$$

Substituição da equação (2.39) leva a equação de Lippert

$$
\begin{gathered}
\bar{\nu}_{a}-\bar{\nu}_{f}=-\frac{2}{h c a^{3}}\left(\mu^{*}-\mu\right)\left(\mu \Delta f-\mu^{*} \Delta f\right) \\
\bar{\nu}_{a}-\bar{\nu}_{f}=\frac{2 \Delta f}{h c a^{3}}\left(\mu^{*}-\mu\right)^{2}
\end{gathered}
$$

\subsection{Descrição experimental}

\subsubsection{Espectrofotômetro de Absorção Óptica}

As medidas de absorção óptica foram obtidas em um espectrofotômetro HP 8452A. Uma lâmpada de deutério é reponsável pela emissão de um feixe de luz, que após atravessar a amostra, incide sobre uma rede de difração, sendo posteriormente detectado por uma rede de diodos. A lâmpada de deutério possui um espectro de emissão que permite cobrir a região entre $190 \mathrm{~nm}$ e $820 \mathrm{~nm}$. Após atravessar a amostra, a luz é decomposta nos seus vários comprimentos 
de onda e em cada um destes a intensidade da luz é medida pela rede de diodos. Ao dar início a uma medida, mede-se antes o espectro de absorção do solvente, e depois procede-se à medição do espectro do absorvedor diluído no mesmo solvente. O espectro do solvente, também chamado espectro "branco" passa a ser descontado dos espectros medidos das amostras absorvedoras. Embora não possua uma alta resolução instrumental $(2 \mathrm{~nm})$, o equipamento permite aquisições de dados rápidas e apresenta boa estabilidade.

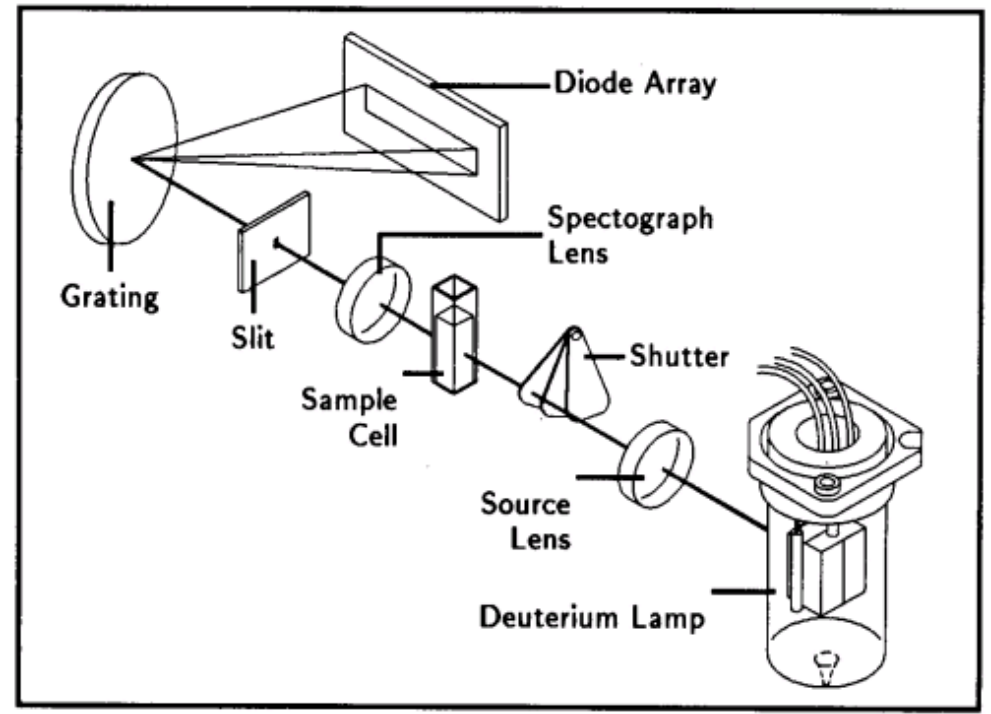

Figura 2.10. Arranjo experimental do espectrofotômetro HP8452A.

As medidas foram sempre realizadas em cubetas de quartzo com caminho ótico de $1,0 \mathrm{~cm}$, e concentrações de $\mathrm{Abz}$ e derivados variando de $10^{-5} \mathrm{M}$ a $10^{-4}$ M. A absorbância em tais concentrações variou de $\sim 0,01$ até valores próximos de 0,2. Nestas últimas circunstâncias tornava-se necessária aplicação de uma correção devido ao efeito de filtro interno.

\subsubsection{Espectrofluorimetro Estático}

Os espectros de fluorescência estática foram obtidos no espectrofluorímetro Fluorolog 3 - Jobin Yvon-Spex. Uma lâmpada de xenônio é responsável pelo 
feixe de luz que excita a amostra. A luz inicialmente emitida possui um espectro com uma larga banda que se estende de $\sim 240 \mathrm{~nm}$ até $\sim 700 \mathrm{~nm}$, e com máximo em $467 \mathrm{~nm}$. Esta mesma luz tem o seu comprimento de onda selecionado por um monocromador de excitação e a sua intensidade é controlada através da regulagem da abertura de uma fenda. Uma vez selecionado o comprimento de onda do feixe de luz, o mesmo incide agora sobre a amostra fluorescente em estudo, excitando-a. Após a desexcitação, é observada a emissão de luz , que por sua vez terá também o seu comprimento de onda selecionado por um monocromador e a sua intensidade ajustada por uma fenda. Após passar por essas etapas, a luz emitida atinge uma fotomultiplicadora, cujos sinais são tratados por um conversor analógico-digital e enviados a um microcomputador, onde serão processados pelo software responsável pela operação do equipamento.

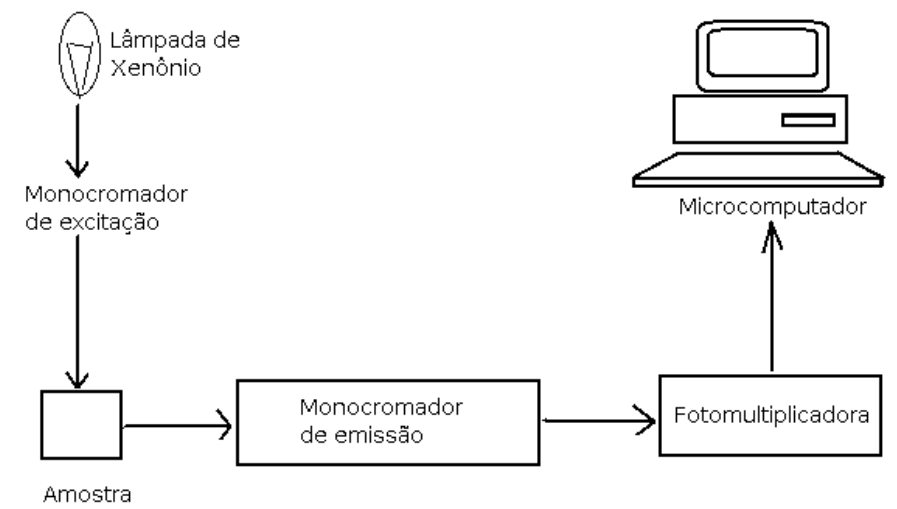

Figura 2.11. Arranjo experimental do espectrofluorímetro estático.

As séries de medidas dos espectros de fluorescência estática eram sempre realizadas em conjunto com as da absorção ótica. Da observação dos máximos nos espectros de absorção é que se determinavam os comprimentos de onda para a excitação da amostra. 


\subsubsection{Espectrofluorimetro de resolução temporal}

A técnica utilizada para a obtenção do decaimento da intensidade de fluorescência baseia-se no método de contagem de fóton único (time correlated single photon couting, TCSPC). Neste método a amostra é excitada por um pulso de luz e os fótons de excitação são correlacionados temporalmente com os fótons emitidos pela amostra, obtendo-se o perfil de decaimento. A figura 2.12 apresenta um esquema genérico de um espectrofluorímetro com resolução temporal. O esquema está dividido em duas partes: sistema de detecção e aquisição de dados e sistema de excitação.

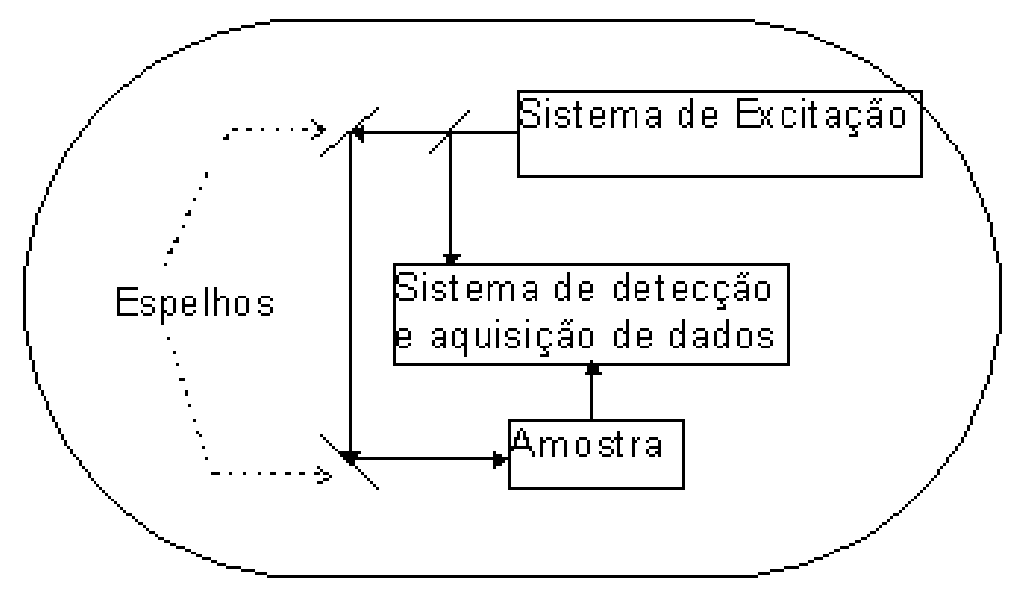

Figura 2.12. Diagrama do fluorimetro com resolução temporal.

\section{Sistema de excitação}

A fonte de excitação usada é um sistema que tem como ponto de partida um laser de estado sólido (MilleniaXs, Spectra Physics), onde um cristal de neodímio ítrio vanadato $\left(\mathrm{Nd}: \mathrm{YVO}_{4}\right)$ é bombeado por dois bancos de diodos por meio de um cabo de fibras ópticas. A luz de saída deste laser, com comprimento de onda em $532 \mathrm{~nm}$ e potência integrada na faixa entre 6.0 e $10.0 \mathrm{~W}$, bombeia um laser de Titânio-safira (Tsunami 3950, Spectra Physics). No cristal de Ti:Safira a banda de absorção se situa entre 400 e 600 nm e a emissão fluorescente ocorre em uma extensa banda que se inicia em 600 nm e vai até $1100 \mathrm{~nm}$. Assim, um 
laser de cristal de Ti:Safira permite gerar pulsos de laser na faixa de comprimentos de onda entre 690 e 1080nm. Para assegurar a boa performance do laser, o fabricante optou por oferecer três configurações de arranjo óptico cobrindo regiões diferentes desta faixa de comprimentos de ondas, de 720 - 850nm, de 840 - 1000nm e de 970 - 1080. No presente arranjo, a configuração adotada é a de 840 - 1000nm, e os pulsos são gerados a uma freqüência de repetição de $82 \mathrm{MHz}$. Estes pulsos, com duração da ordem de 10 ps, são colhidos por um selecionador de pulsos (3980-25, Spectra Physics) que permite a operação em freqüências, na faixa de $800 \mathrm{Khz}$ a $8 \mathrm{MHz}$, mais adequadas ao método de contagem de fótons. Finalmente, da saida do selecionador de pulsos, o feixe é direcionado a um gerador de segundo e terceiro harmônicos (GWN-23PL, Spectra Physics), de modo que o feixe emergente tenha comprimentos de onda sintonizados na região entre 345 e 540 nm (segundo harmônico) ou entre 230 e 360 nm (terceiro harmônico). Neste módulo, a geração do segundo harmônico é obtida através de um cristal de LBO (lítio triborato); já o terceiro harmônico é obtido pela sobreposição das freqüências do segundo harmônico com a fundamental em um cristal de BBO (beta bário borato). Assim, do gerador de segundo e terceiro harmônicos emergem simultaneamente dois feixes, sendo o segundo harmônico mesclado à freqüencia fundamental e o terceiro harmônico isoladamente. O sistema de excitação no método TCSPC, por envolver vários equipamentos com conjuntos óticos de precisão, constitui a parte mais sensível dentro do arranjo experimental. Os cuidados experimentais quanto ao manuseio de tal equipamento envolvem desde o controle permanente de umidade e temperatura do laboratório até o uso de fluxo de gás nitrogênio ultra puro sobre o cristal de Ti:Safira. Esta última providência s e dá pelo fato de que a presença de oxigênio e o vapor de água interferem na transmitância do feixe para regiões entre 900 e 980nm. 


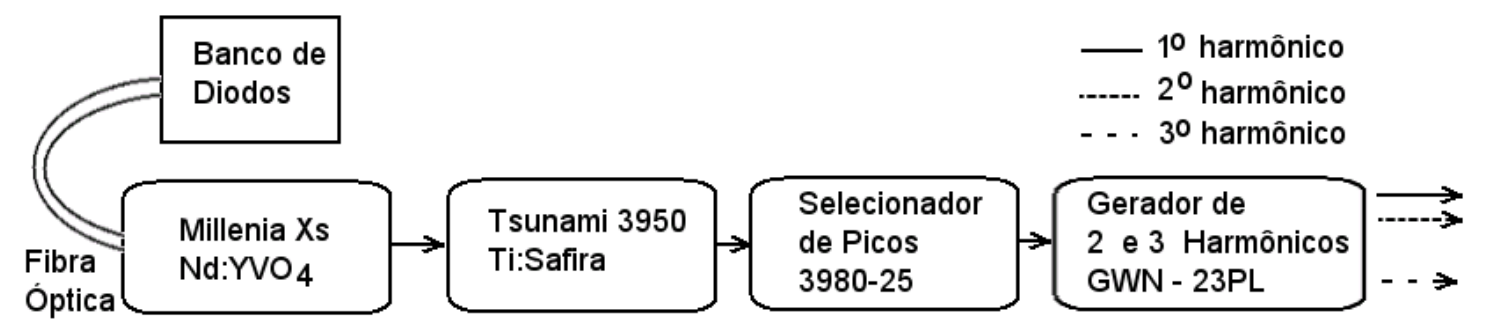

Figura 2.13. Sistema de excitação.

\section{Sistema de detecção e aquisição de dados}

O espectrofotômetro utilizado é o FL-900 Edinburgh, ao qual é acoplado a fotomultiplicadora (R3809U, Hamamatsu) com sistema de refrigeração líqüida (C4878, Hamamatsu). O coração desta técnica situa-se no que é conhecido como Conversor Tempo-Amplitude (TAC); quando ocorre um pulso de excitação, simultaneamente um outro pulso de sincronização de "disparo" (start) dá início ao carregamento de um capacitor no TAC, i.e. ocorre a subida de uma rampa linear de tensão. No arranjo utilizado, o papel do pulso de "disparo" cabe ao feixe não utilizado na excitação; a escolha entre os feixes do segundo ou terceiro harmônico depende do espectro de excitação da amostra. Assim, decorrido algum tempo após a excitação, ocorre a fluorescência, onde um fóton é emitido pela amostra e após passar pelo monocromador do espectrômetro é detectado pela fotomultiplicadora de parada (R3809U), que envia um sinal de "parada" (stop) para o TAC interrompendo a subida da rampa de tensão. O valor da tensão é proporcional ao tempo transcorrido entre a excitação e a emissão e um analisador multicanal (MCA) armazena a ocorrência desse evento no canal relativo à amplitude correspondente. O processo repete-se a cada pulso de excitação e ao final de um número estatisticamente significativo de eventos ( $10^{5}$ contagens) obtém se um histograma descrevendo o decaimento temporal da fluorescência. Toda a aquisição dos dados é feita de forma automatizada pelo computador através de softwares que controlam os parâmetros do espectrofotômetro, como 
monocromadores, largura de fenda e polarizadores. Obtido o histograma, os parâmetros de decaimento são extraídos a partir do ajuste de uma função de decaimento mono ou multi-exponencial conforme descrito na seção 2.1 .2 , através do software do espectrômetro.

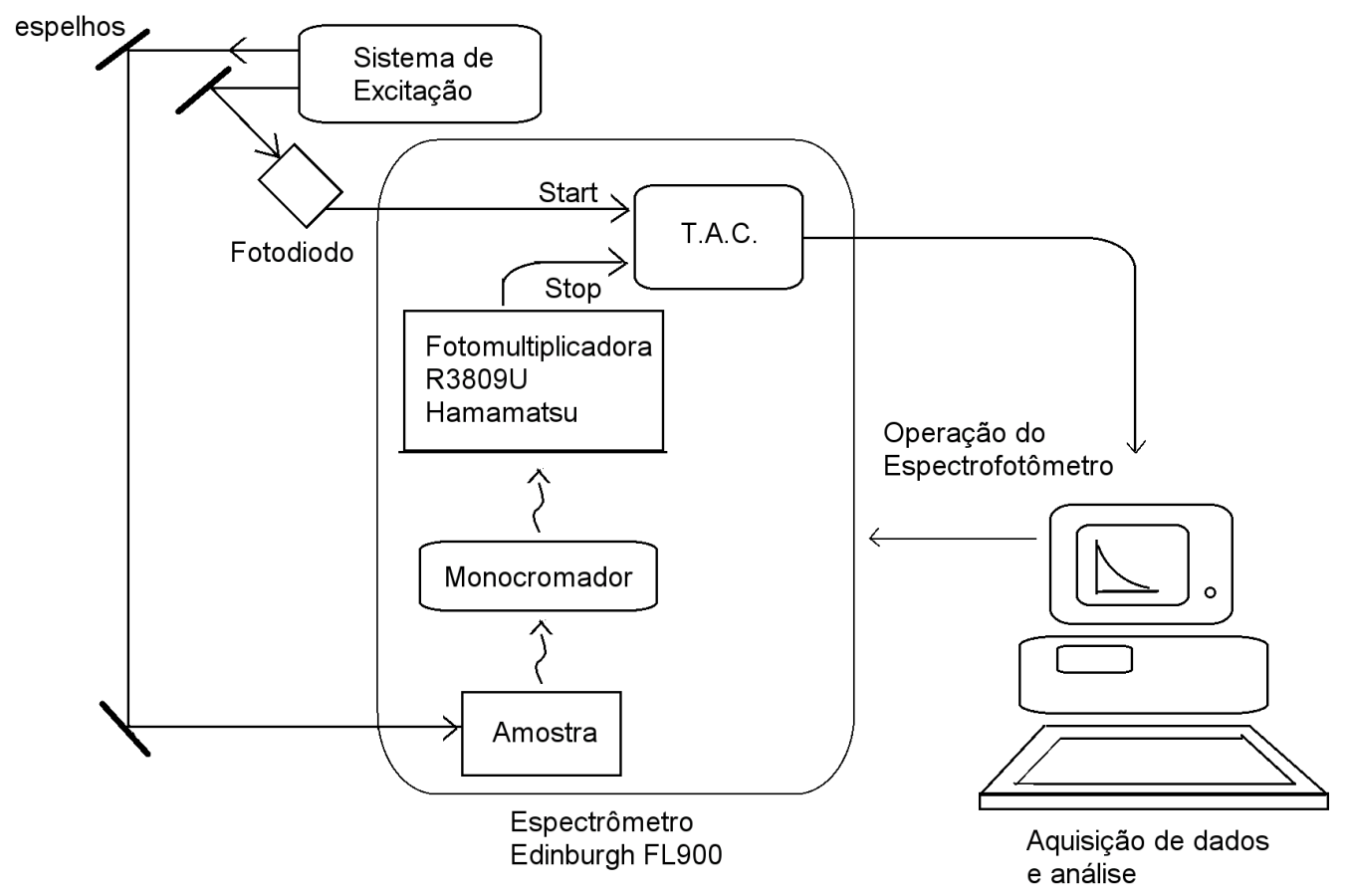

Figura 2.14. Sistema de detecção e aquisição de dados.

Um cuidado experimental que deve ser observado diz respeito ao número de excitações que não pode ser muito alto em relação à taxa de repetição dos pulsos. Os fótons do pulso de excitação são absorvidos não apenas por um único fluoróforo, mas por vários deles simultaneamente; como os tempos de vida são determinados pelo instante da detecção do primeiro fóton feita pela fotomultiplicadora após o pulso de disparo, se excitássemos exatamente todas as moléculas presentes na amostra, observaríamos somente os decaimentos de tempos mais curtos, em detrimento daqueles de tempos longos. Tal problema é 
facilmente contornado através do uso de atenuadores óticos posicionados sobre os pulsos de excitação. 


\section{Capítulo 3}

\section{Fundamentos e Métodos Computacionais}

\subsection{Funções de Ondas para vários elétrons}

O principal interesse no estudo da física molecular e atômica é encontrar soluções aproximadas para a equação de Schrödinger não relativística independente do tempo:

$$
\mathcal{H}|\phi\rangle=\varepsilon|\phi\rangle
$$

onde $\mathcal{H}$ é o operador hamiltoniano para um sistema composto por núcleos e elétrons, cujas posições são descritas pelos vetores de posições $\mathbf{R}_{A}$ e $\mathbf{r}_{i}$, respectivamente. As coordenadas moleculares são apresentadas na figura 3.1.

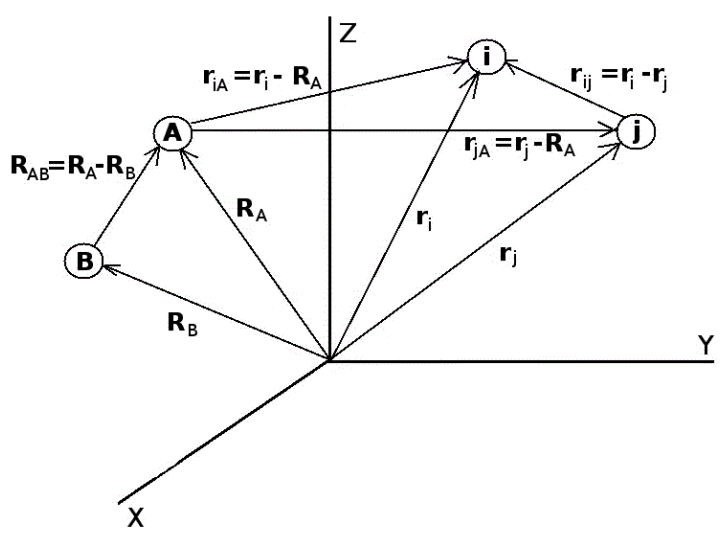

Figura 3.1. Sistema de coordenadas moleculares: $i, j=$ elétrons; $A, B=$ núcleos. 
A distância entre o $i$-ésimo elétron e o $A$-ésimo núcleo é $r_{i A}=\left|\mathbf{r}_{i A}\right|=\left|\mathbf{r}_{i}-\mathbf{R}_{A}\right|$; a distância entre o $i$-ésimo elétron e o $j$-ésimo elétron é $r_{i j}=\left|\mathbf{r}_{i}-\mathbf{r}_{j}\right|$, e a distância entre o A-ésimo núcleo e o B-ésimo núcleo é $R_{A B}=\left|\mathbf{R}_{A}-\mathbf{R}_{B}\right|$. Em unidades atômicas, a Hamiltoniana para $N$ elétrons e $M$ núcleos é

$$
\mathcal{H}=-\sum_{i=1}^{N} \frac{1}{2} \nabla_{i}^{2}-\sum_{A=1}^{M} \frac{1}{2 M_{A}} \nabla_{A}^{2}-\sum_{i=1}^{N} \sum_{A=1}^{M} \frac{Z_{A}}{r_{i A}}+\sum_{i=1}^{N} \sum_{j>i}^{N} \frac{1}{r_{i j}}+\sum_{A=1}^{M} \sum_{A>B}^{M} \frac{Z_{A} Z_{B}}{R_{A B}}
$$

$\mathrm{Na}$ equação (3.2), $M_{A}$ é a razão da massa do núcleo $A$ em relação à massa do elétron, e $Z_{A}$ é o número atômico do núcleo $A$. Os operadores Laplacianos $\nabla_{i}^{2}$ e $\nabla_{A}^{2}$ envolvem a diferenciação com relação às coordenadas do i-ésimo elétron e A-ésimo núcleo. O primeiro termo é o operador para a energia cinética dos elétrons; o segundo termo é o operador para a energia cinética dos núcleos; o terceiro termo representa a atração coulombiana entre os elétrons e os núcleos; o quarto e quinto termos representam as repulsões entre os elétrons e entre os núcleos, respectivamente.

\subsubsection{Aproximação de Born-Oppenheimer}

Como os núcleos são mais pesados do que os elétrons, se movem muito lentamente em relação a estes. Logo, em uma boa aproximação, pode se considerar os elétrons em uma molécula como se movessem em um campo de núcleos fixos. Nesta aproximação, o segundo termo da equação (3.2), a energia cinética dos núcleos, pode ser desprezada, e o último termo, a repulsão entre os núcleos, pode ser considerada constante [26]. Qualquer constante adicionada a um operador apenas se soma ao autovalor do operador, não possuindo efeito sobre sua autofunção. Os termos restantes constituem o assim chamado Hamiltoniano eletrônico, que descreve o movimento dos $N$ elétrons no campo de $M$ cargas puntuais, 


$$
\mathcal{H}_{e l}=-\sum_{i=1}^{N} \frac{1}{2} \nabla_{i}^{2}-\sum_{i=1}^{N} \sum_{A=1}^{M} \frac{Z_{A}}{r_{i A}}+\sum_{i=1}^{N} \sum_{j>i}^{N} \frac{1}{r_{i j}}
$$

A solução para a equação de Schrödinger envolvendo a Hamiltoniana eletrônica,

$$
\mathcal{H}_{e l} \Phi_{e l}=\varepsilon_{e l} \Phi_{e l}
$$

é a função de onda eletrônica

$$
\Phi_{e l}=\Phi_{e l}\left(\left\{\mathbf{r}_{i}\right\} ;\left\{\mathbf{R}_{A}\right\}\right)
$$

que descreve o movimento dos elétrons e depende explicitamente das coordenadas eletrônicas, mas depende parametricamente das coordenadas nucleares, assim como a energia eletrônica,

$$
\varepsilon_{e l}=\varepsilon_{e l}\left(\left\{\mathbf{R}_{A}\right\}\right)
$$

Por dependência paramétrica, queremos dizer que para os diferentes arranjos dos núcleos, $\Phi_{e l}$ é uma função de coordenadas eletrônicas diferente e as coordenadas dos núcleos não aparecem explicitamente.

teoria

\subsubsection{Anti-simetria ou Principio de Exclusão de Pauli}

A Hamiltoniana eletrônica apresentada anteriormente depende somente das coordenadas espaciais dos elétrons. Para descrevermos completamente o elétron é necessário no entanto, especificar seu spin. Nós o fazemos dentro do contexto não relativístico através da introdução das funções de spin, $\alpha(\omega)$ e $\beta(\omega)$, correspondentes a spin para cima $(\uparrow)$ e spin para baixo $(\downarrow)$, respectivamente, onde a 
variável $\omega$ é inespecífica; do ponto de vista operacional, tudo o que precisamos saber é que as duas funções de spin são completas e ortogonais,

$$
\begin{gathered}
\int d \omega \alpha^{*}(\omega) \alpha(\omega)=\int d \omega \beta^{*}(\omega) \beta(\omega)=1 \\
\langle\alpha \mid \alpha\rangle=\langle\beta \mid \beta\rangle=1
\end{gathered}
$$

e

$$
\begin{gathered}
\int d \omega \alpha^{*}(\omega) \beta(\omega)=\int d \omega \beta^{*}(\omega) \alpha(\omega)=0 \\
\langle\alpha \mid \beta\rangle=\langle\beta \mid \alpha\rangle=0
\end{gathered}
$$

Neste formalismo, um elétron é descrito não somente pelas três coordenadas espaciais r, mas também por uma coordenada de spin $\omega$. Denotaremos estas quatro coordenadas por $\mathbf{x}$,

$$
\mathbf{x}=\{\mathbf{r}, \omega\}
$$

Uma função de onda de $\mathrm{N}$ elétrons passa a ser então uma função das coordenadas $\mathbf{x}_{1}, \mathbf{x}_{2}, \ldots, \mathbf{x}_{N}$, e logo, podemos escrever $\Phi\left(\mathbf{x}_{1}, \mathbf{x}_{2}, \ldots, \mathbf{x}_{N}\right)$.

Como o operador Hamiltoniano não faz nenhuma referência ao spin, simplesmente tornar a função de onda dependente de spin não leva a lugar algum. Entretanto, uma teoria satisfatória pode ser obtida, se fizermos a seguinte exigência à função de onda: Uma função de onda de vários elétrons deve ser 
anti-simétrica em relação à troca das coordenadas $\boldsymbol{x}$ (tanto espaciais quanto de spin) de quaisquer dois elétrons.

$$
\Phi\left(\mathbf{x}_{1}, \ldots, \mathbf{x}_{i}, \ldots, \mathbf{x}_{j}, \ldots, \mathbf{x}_{N}\right)=-\Phi\left(\mathbf{x}_{1}, \ldots, \mathbf{x}_{j}, \ldots, \mathbf{x}_{i}, \ldots, \mathbf{x}_{N}\right)
$$

Esta exigência, também chamado de princípio da antisimetria, é um estabelecimento geral do familiar Princípio de Exclusão de Pauli, e é um postulado independente da mecânica quântica. A função de onda exata não somente deve satisfazer à equação de Schrödinger, como também deve ser anti-simétrica conforme a equação (3.12). Como será visto adiante, a exigência da anti-simetria será facilmente atendida através do uso do determinante de Slater.

\subsubsection{Orbitais espaciais, orbitais de spin e Determinante de Slater}

Definimos o orbital como sendo uma função de onda para uma única partícula, o elétron. Como estamos interessados em estrutura eletrônica molecular, utilizaremos orbitais moleculares para as funções de onda dos elétrons em uma molécula. Um orbital espacial $\Psi_{i}(\mathbf{r})$ é uma função do vetor posição $\mathrm{r}$ e descreve a distribuição espacial de um elétron, tal que $|\Psi(\mathbf{r})|^{2} d \mathbf{r}$ é a probabilidade de encontrar o elétron em um pequeno elemento de volume $d \mathbf{r}$, cercando r. Usualmente assume-se que os orbitais moleculares espaciais formam um conjunto ortonormal

$$
\int d r \Psi_{i}^{*}(\mathbf{r}) \Psi_{j}(\mathbf{r})=\delta_{i j}
$$

Se o conjunto de orbitais moleculares $\left\{\Psi_{i}\right\}$ for completo, então qualquer função arbitrária $f(\boldsymbol{r})$ pode ser expandido exatamente como

$$
f(\mathbf{r})=\sum_{i=1}^{\infty} a_{i} \Psi_{i}(\mathbf{r})
$$

onde os $a_{i}^{\prime} s$ são coeficientes constantes. Em geral, o conjunto deveria ser 
infinito para ser completo; na prática, nunca teremos um conjunto completo, mas somente um conjunto finito $\left\{\Psi_{i} \mid i=1,2, \ldots, K\right\}$ de $K$ orbitais. Este conjunto apenas expande uma certa região do espaço completo; contudo podemos descrever os resultados como sendo "exatos", dentro do subespaço expandido pelo mesmo conjunto finito de orbitais. Para descrever completamente um elétron, é necessário especificar seu spin. Para cada orbital espacial $\Psi(\mathbf{r})$, pode-se formar dois diferentes orbitais, um correspondendo ao spin "para cima" e outro ao spin “para baixo”, pela multiplicação com as funções de spin $\alpha$ ou $\beta$, respectivamente,

$$
\chi(\mathbf{x})=\left\{\begin{array}{c}
\Psi(\mathbf{r}) \alpha(\omega) \\
\text { оu } \\
\Psi(\mathbf{r}) \beta(\omega)
\end{array}\right.
$$

Dado um conjunto de $K$ orbitais espaciais $\left\{\Psi_{i} \mid i=1,2, \ldots, K\right\}$, pode se então formar um conjunto de $2 K$ orbitais $\left\{\chi_{i} \mid i=1,2, \ldots, 2 K\right\}$ como

$$
\left.\begin{array}{c}
\chi_{2 i-1}(\mathbf{x})=\Psi_{i}(\mathbf{r}) \alpha(\omega) \\
\chi_{2 i}(\mathbf{x})=\Psi_{i}(\mathbf{r}) \beta(\omega)
\end{array}\right\} i=1,2, \ldots, K
$$

Se os orbitais espaciais são ortonormais, assim também são os orbitais de spin,

$$
\int d \mathbf{x} \chi_{i}^{*}(\mathbf{x}) \chi_{j}(\mathbf{x})=\left\langle\chi_{i} \mid \chi_{j}\right\rangle=\delta_{i j}
$$

Temos visto até então que a função de um único elétron é um spin orbital; agora vamos considerar funções de onda para um conjunto de elétrons, i.e, uma função de ondas para N-elétrons. Antes de considerarmos a forma exata de uma função de onda exata de um sistema totalmente interagente, vamos primeiro considerar um sistema simples não interagente, com Hamiltoniana da forma 


$$
\mathcal{H}=\sum_{i=1}^{N} h(i)
$$

onde $h(i)$ é o operador que descreve a energia cinética e energia potencial do elétron $i$. Se desprezarmos a repulsão elétron - elétron, então a Hamiltoniana contendo todos os elétrons possui esta forma. Alternativamente, $h(i)$ pode vir a ser uma Hamiltoniana efetiva de um elétron que inclue os efeitos de repulsão elétron - elétron na forma de média.

Vemos agora, que o operador $h(i)$ terá um conjunto de autofunções que podemos tomar como sendo um conjunto de orbitais de spin $\left\{\chi_{i}\right\}$,

$$
h(i) \chi_{j}\left(\mathbf{x}_{i}\right)=\varepsilon_{j} \chi_{j}\left(\mathbf{x}_{i}\right)
$$

Como a Hamiltoniana $\mathcal{H}$ é a soma das Hamiltonianas de um elétron, o produto simples das funções de onda dos orbitais de spin para cada elétron é uma autofunção de $\mathcal{H}$, com autovalor $E$,

$$
\begin{gathered}
\Psi^{H P}\left(\mathbf{x}_{1}, \mathbf{x}_{2}, \ldots, \mathbf{x}_{N}\right)=\chi_{i}\left(\mathbf{x}_{1}\right) \chi_{j}\left(\mathbf{x}_{2}\right) \ldots \chi_{k}\left(\mathbf{x}_{N}\right) \\
\mathcal{H} \Psi^{H P}=E \Psi^{H P}
\end{gathered}
$$

onde o E é a soma das energias de cada spin orbital,

$$
E=\varepsilon_{i}+\varepsilon_{j}+\ldots+\varepsilon_{k}
$$

Tal função de onda para vários elétrons é denominada produto Hartree, com o elétron um sendo descrito pelo spin orbital $\chi_{i}$, o elétron dois por $\chi_{j}$, etc.

O produto Hartree é uma função de onda descorrelacionada ou de elétrons independentes, pois o quadrado da função de onda total 


$$
\left|\Psi^{H P}\left(\mathbf{x}_{1}, \ldots, \mathbf{x}_{N}\right)\right|^{2} d \mathbf{x}_{1} \ldots d \mathbf{x}_{N}
$$

é a probabilidade simultânea de encontrar o elétron um no elemento de volume $d \mathbf{x}_{1}$, centrado em $\mathbf{x}_{1}$, elétron dois em $d \mathbf{x}_{2}$, etc., e é igual ao produto das probabilidades individuais

$$
\left|\chi_{i}\left(\mathbf{x}_{1}\right)\right|^{2} d \mathbf{x}_{1}\left|\chi_{j}\left(\mathbf{x}_{2}\right)\right|^{2} d \mathbf{x}_{2} \ldots\left|\chi_{k}\left(\mathbf{x}_{N}\right)\right|^{2} d \mathbf{x}_{N}
$$

Assumindo a independência dos elétrons e um Hamiltoniano na forma da equação (3.18), ainda há uma deficiência básica no produto de Hartree, que não leva em conta a indistingüibilidade dos elétrons, mas especificamente distingüe o elétron um ocupando o spin orbital $\chi_{i}$, o elétron dois ocupando $\chi_{j}$, etc. $\mathrm{O}$ princípio da anti-simetria não faz distinção entre elétrons idênticos e exige que as funções de onda dos elétrons sejam anti-simétricas (troca de sinal) em relação à troca das coordenadas de espaço e spin de quaisquer dois elétrons. No entanto, podemos obter as funções de onda anti-simétricas da forma como se segue. Tomamos como exemplo o caso de dois elétrons, onde os spin orbitais $\chi_{i}$ e $\chi_{j}$ são ocupados pelo elétron um e elétron dois, respectivamente.

$$
\Psi_{12}^{H P}\left(\mathbf{x}_{1}, \mathbf{x}_{2}\right)=\chi_{i}\left(\mathbf{x}_{1}\right) \chi_{j}\left(\mathbf{x}_{2}\right)
$$

Por outro lado, se pusermos o elétron um em $\chi_{j}$ e o elétron dois em $\chi_{i}$, teremos

$$
\Psi_{21}^{H P}\left(\mathbf{x}_{1}, \mathbf{x}_{2}\right)=\chi_{i}\left(\mathbf{x}_{2}\right) \chi_{j}\left(\mathbf{x}_{1}\right)
$$

Cada um destes produtos de Hartree faz distinção entre os elétrons; no entanto, podemos obter um função de onda que não faz, e que satisfaz a exigência 
do princípio da anti-simetria, fazendo uma combinação linear apropriada destes dois produtos

$$
\Psi\left(\mathbf{x}_{1}, \mathbf{x}_{2}\right)=2^{-1 / 2}\left[\chi_{i}\left(\mathbf{x}_{1}\right) \chi_{j}\left(\mathbf{x}_{2}\right)-\chi_{j}\left(\mathbf{x}_{1}\right) \chi_{i}\left(\mathbf{x}_{2}\right)\right]
$$

O fator $2^{-1 / 2}$ é um fator de normalização. O sinal negativo assegura que $\Psi\left(\mathbf{x}_{1}, \mathbf{x}_{2}\right)$ seja anti-simétrica com relação à troca de coordenadas dos dois elétrons.

Claramente,

$$
\Psi\left(\mathbf{x}_{1}, \mathbf{x}_{2}\right)=-\Psi\left(\mathbf{x}_{2}, \mathbf{x}_{1}\right)
$$

Da equação (3.27) fica evidente que a função de onda se anula, caso ambos os elétrons ocupem o mesmo spin orbital (i.e., se $i=j$ ). Isso nos leva imediatamente ao Princípio de Exclusão de Pauli, onde se estabelece que dois elétrons não podem ocupar o mesmo orbital. A função de onda anti-simétrica (3.27) pode ser reescrita como um determinante

$$
\Psi\left(\mathbf{x}_{1}, \mathbf{x}_{2}\right)=2^{-1 / 2}\left|\begin{array}{cc}
\chi_{i}\left(\mathbf{x}_{1}\right) & \chi_{j}\left(\mathbf{x}_{1}\right) \\
\chi_{i}\left(\mathbf{x}_{2}\right) & \chi_{j}\left(\mathbf{x}_{2}\right)
\end{array}\right|
$$

e é denominado Determinante de Slater. Para um sistema de $N$-elétrons, a generalização da equação (3.29) nos leva a

$$
\Psi\left(\mathbf{x}_{1}, \mathbf{x}_{2}\right)=(N !)^{-1 / 2}\left|\begin{array}{cccc}
\chi_{i}\left(\mathbf{x}_{1}\right) & \chi_{j}\left(\mathbf{x}_{1}\right) & \ldots & \chi_{k}\left(\mathbf{x}_{1}\right) \\
\chi_{i}\left(\mathbf{x}_{2}\right) & \chi_{j}\left(\mathbf{x}_{2}\right) & \ldots & \chi_{k}\left(\mathbf{x}_{2}\right) \\
\vdots & \vdots & \ddots & \vdots \\
\chi_{i}\left(\mathbf{x}_{N}\right) & \chi_{j}\left(\mathbf{x}_{N}\right) & \ldots & \chi_{k}\left(\mathbf{x}_{N}\right)
\end{array}\right|
$$

O fator $(\mathrm{N} !)^{-1 / 2}$ é um fator de normalização. Este determinante de Slater 
possui $N$ elétrons ocupando $\mathrm{N}$ spins orbitais, sem especificar que elétron ocupa qual orbital. Notemos que as linhas de um determinante são designadas pelos elétrons: primeira linha $\left(\mathrm{x}_{1}\right)$, segunda linha $\left(\mathrm{x}_{2}\right)$, etc., e as colunas pelos orbitais: primeira coluna $\left(\chi_{i}\right)$, segunda coluna $\left(\chi_{j}\right)$, etc. Intercambiar as coordenadas de dois elétrons corresponde a intercambiar duas linhas da matriz, o que muda o sinal do determinante e portanto, atende-se ao princípio da anti-simetria. Por outro lado, fazer com que dois elétrons ocupem o mesmo spin orbital corresponde a fazer duas colunas iguais, e isso leva a um determinante nulo. Logo, não mais do que um elétron pode ocupar o mesmo spin orbital e satisfaz-se assim, o Princípio de Exclusão de Pauli.

Como vimos anteriormente, o produto Hartree é uma função de onda de elétrons independentes, uma vez que a probabilidade de encontrar um determinado elétron um em $\mathrm{dx}_{1}$, elétron dois em $\mathrm{dx}_{2} \mathrm{dx} 2$, etc. é simplesmente igual ao produto das probabilidades individuais. Mas ao introduzirmos o caráter anti-simétrico através do determinante de Slater, observamos a correlação de troca, assim chamada porque surge da exigência de que $|\Psi|^{2}$ seja invariante à troca das coordenadas espaciais e de spin de quaisquer dois elétrons. Em particular, o determinante de Slater incorpora a correlação de troca, o que significa que o movimento de dois elétrons de spins paralelos é correlacionado.

\subsection{Hartree-Fock, CI e DFT}

\subsubsection{Método Hartree-Fock e as equações de Roothan}

Agora que conhecemos a forma funcional da função de onda na teoria de Hartree - Fock [27], vamos reexaminar a Hamiltoniana. Definimos o operador de um elétron $h$ como se segue

$$
h(i)=-\frac{1}{2} \nabla_{i}^{2}-\sum_{A} \frac{Z_{A}}{r_{i A}}
$$


e um operador de dois elétrons $v(i, j)$ como

$$
v(i, j)=\frac{1}{r_{i j}}
$$

Agora, podemos escrever a Hamiltoniana eletrônica simplesmente como

$$
\hat{H}_{e l}=\sum_{i} h(i)+\sum_{i<j} v(i, j)+V_{N N}
$$

Como $V_{N N}$ é meramente uma constante para o conjunto fixo de coordenadas nucleares $\{R\}$, iremos ignorá-las por enquanto (não modificam as autofuncões e apenas deslocam os autovalores). Agora que temos uma forma para a função de onda e uma notação simplificada para o Hamiltoniano, temos um bom ponto de partida para a solução do problema.

Estabelecemos que a função de onda de Hartree-Fock terá a forma do determinante de Slater, e que a energia será dada pela expressão usual da mecânica quântica (assumindo que a função de onda é normalizada):

$$
E_{e l}=\left\langle\Psi\left|\hat{H}_{e l}\right| \Psi\right\rangle
$$

Empregamos agora o teorema variacional, que estabelece que a energia obtida é sempre maior do que o valor verdadeiro da energia. Assim, obteremos a melhor aproximação da função de onda $\Psi$, variando os seus parâmetros até que tenhamos minimizado a energia $E_{e l}$. Os orbitais moleculares podem ser numericamente obtidos usando-se a integração sobre um dado intervalo, ou mais comumente através de uma dada base de funções (bases de funções "orbitais atômicos”, usualmente gaussianas centradas nos átomos). Podemos agora reescrever a energia de Hartree-Fock $E_{e l}$ em termos de integrais de operadores para um e dois elétrons: 


$$
E_{H F}=\sum_{i}\langle i|h| i\rangle+\frac{1}{2} \sum_{i j}[i i \mid j j]-[i j \mid j i]
$$

onde a integral de um elétron é

$$
\langle i|h| j\rangle=\int d \mathbf{x}_{1} \chi_{i}^{*}\left(\mathbf{x}_{1}\right) h\left(\mathbf{r}_{1}\right) \chi_{j}\left(\mathbf{x}_{1}\right)
$$

e a integral de dois elétrons (notação de químicos) como

$$
[i j \mid k l]=\int d \mathbf{x}_{1} d \mathbf{x}_{2} \chi_{i}^{*}\left(\mathbf{x}_{1}\right) \chi_{j}\left(\mathbf{x}_{1}\right) \frac{1}{r_{12}} \chi_{k}^{*}\left(\mathbf{x}_{2}\right) \chi_{l}\left(\mathbf{x}_{2}\right)
$$

Novamente, o método de Hartree-Fock busca resolver aproximadamente a equação eletrônica de Schrödinger, e assume que a função de onda pode ser aproximada por um único determinante de Slater composto pelos spin orbitais de cada elétron. Como a expressão da energia é simétrica, o teorema variacional é assegurado, e então sabemos que o determinante de Slater obtido pela mais baixa energia é o mais próximo que podemos obter para a função de onda verdadeira para a forma funcional que assumimos para o determinante de Slater simples.

Assim, precisamos minimizar a expressão da energia de Hartree-Fock com relação às mudanças nos orbitais $\chi_{i} \rightarrow \chi_{i}+\delta \chi_{i}$. Assumimos também que os orbitais $\chi$ são ortonormais, e queremos assegurar que o nosso procedimento variacional conserve a ortonormalidade. Podemos fazê-lo através do método dos multiplicadores de Lagrange, onde empregamos um funcional $\mathcal{L}$, definido como

$$
\mathcal{L}\left[\left\{\chi_{i}\right\}\right]=E_{H F}\left[\left\{\chi_{i}\right\}\right]-\sum_{i j} \epsilon_{i j}\left(\langle i \mid j\rangle-\delta_{i j}\right)
$$

onde $\epsilon_{i j}$ são os multiplicadores de Lagrange e , $\langle i \mid j\rangle$ é a sobreposição entre os spin orbitais $i$ e $j$, i.e., 


$$
\langle i \mid j\rangle=\int \chi_{i}^{*}(\mathbf{x}) \chi_{j}(\mathbf{x}) d \mathbf{x}
$$

Ajustando a primeira variação $\delta \mathcal{L}=0$, e trabalhando a álgebra, chegaremos às equações de Hartree_Fock definindo os orbitais:

$h\left(\mathbf{x}_{1}\right) \chi_{i}\left(\mathbf{x}_{1}\right)+\sum_{j \neq i}\left[\int d \mathbf{x}_{2}\left|\chi_{j}\left(\mathbf{x}_{2}\right)\right|^{2} r_{12}^{-1}\right] \chi_{i}\left(\mathbf{x}_{1}\right)-\sum_{j \neq i}\left[\int d \mathbf{x}_{2} \chi_{j}^{*}\left(\mathbf{x}_{2}\right) \chi_{i}\left(\mathbf{x}_{2}\right) r_{12}^{-1}\right] \chi_{j}\left(\mathbf{x}_{1}\right)=\epsilon_{i} \chi_{i}\left(\mathbf{x}_{1}\right)$,

onde $\epsilon_{i}$ é o autovalor energia associado com o orbital $\chi_{i}$.

As equações de Hartree-Fock podem ser resolvidas numericamente (Hartree-Fock exato), ou podem ser resolvidas no espaço expandido por um base de funções (equações Hartree-Fock-Roothan)[28, 27, 29]. Em qualquer caso, notemos que a solução depende dos orbitais. Portanto, precisamos fazer um palpite para os orbitais iniciais e então refinar a nossa escolha iterativamente. Por essa razão, o método Hartree-Fock é chamado de aproximação do campo auto-consistente (SCF).

O primeiro termo entre os colchetes,

$$
\sum_{j \neq i}\left[\int d \mathbf{x}_{2}\left|\chi_{j}\left(\mathbf{x}_{2}\right)\right|^{2} r_{12}^{-1}\right] \chi_{i}\left(\mathbf{x}_{1}\right)
$$

fornece a interação de Coulomb de um elétron em spin orbital $\chi_{i}$ com a distribuição média de cargas dos outros elétrons. Este é chamado de termo de Coulomb, e é conveniente definir um operador de Coulomb como

$$
\jmath_{j}\left(\mathbf{x}_{1}\right)=\int d \mathbf{x}_{2}\left|\chi_{j}\left(\mathbf{x}_{2}\right)\right|^{2} r_{12}^{-1}
$$

que fornece o potencial médio local em um ponto $\mathrm{x}_{1}$ devido à distribuição de cargas do elétron no orbital $\chi_{j}$.

O outro termo entre os colchetes na equação 3.40, não possui um análogo 
clássico e surge da exigência da antisimetria da função de onda, como foi mostrado na seção anterior. Se parece com o termo de Coulomb, exceto pela troca dos spin orbitais $\chi_{i}$ e $\chi_{j}$. É o termo de correlação de troca (exchange):

$$
\sum_{j \neq i}\left[\int d \mathbf{x}_{2} \chi_{j}^{*}\left(\mathbf{x}_{2}\right) \chi_{i}\left(\mathbf{x}_{2}\right) r_{12}^{-1}\right] \chi_{i}\left(\mathbf{x}_{1}\right),
$$

Podemos definir então operador de troca em termos de sua ação em um spin orbital arbitrário $\chi_{i}$ :

$$
\kappa_{j}\left(\mathbf{x}_{1}\right) \chi_{i}\left(\mathbf{x}_{1}\right)=\left[\int d \mathbf{x}_{2} \chi_{j}^{*}\left(\mathbf{x}_{2}\right) r_{12}^{-1} \chi_{i}\left(\mathbf{x}_{2}\right)\right] \chi_{i}\left(\mathbf{x}_{1}\right)
$$

Em termos destes operadores de Coulomb e de troca, as equações de Hartree-Fock se tornam mais compactas:

$$
\left[h\left(\mathbf{x}_{1}\right)+\sum_{j \neq i} \jmath_{j}\left(\mathbf{x}_{1}\right)-\sum_{j \neq i} \kappa_{j}\left(\mathbf{x}_{1}\right)\right] \chi_{i}\left(\mathbf{x}_{1}\right)=\epsilon_{i} \chi_{i}\left(\mathbf{x}_{1}\right)
$$

Agora é mais perceptível o fato de que as equações de Hartree-Fock são equações de autovalores:

$$
\left[\jmath_{j}\left(\mathbf{x}_{1}\right)-\kappa_{j}\left(\mathbf{x}_{1}\right)\right] \chi_{i}\left(\mathbf{x}_{1}\right)=0
$$

e então se torna claro que podemos remover a restrição $j \neq i$ na soma e podemos introduzir um novo operador, o operador de Fock, como

$$
f\left(\mathbf{x}_{1}\right)=h\left(\mathbf{x}_{1}\right)+\sum_{j} \jmath_{j}\left(\mathbf{x}_{1}\right)-\kappa_{j}\left(\mathbf{x}_{1}\right)
$$

E agora as equações de Hartree-Fock são apenas

$$
f\left(\mathbf{x}_{1}\right) \chi_{i}\left(\mathbf{x}_{1}\right)=\epsilon_{i} \chi_{i}\left(\mathbf{x}_{1}\right)
$$

Introduzindo uma base de funções transforma as equações de Hartree-Fock 
nas equações de Roothan. Denotando a base de funções orbitais atômicos como $\tilde{\chi}$, temos a expansão

$$
\chi_{i}=\sum_{\mu=1}^{K} C_{\mu i} \tilde{\chi}_{\mu}
$$

para cada spin orbital $i$. Isto leva a

$$
f\left(\mathbf{x}_{1}\right) \sum_{\nu} C_{v i} \tilde{\chi}_{v}\left(\mathbf{x}_{1}\right)=\epsilon_{i} \sum_{\nu} C_{v i} \tilde{\chi}_{v}\left(\mathbf{x}_{1}\right)
$$

Multiplicando a esquerda por $\tilde{\chi}_{\mu}\left(\mathbf{x}_{1}\right)$ e integrando leva à equação matricial:

$$
\sum_{\nu} C_{v i} \int d \mathbf{x}_{1} \tilde{\chi}_{\mu}^{*}\left(\mathbf{x}_{1}\right) f\left(\mathbf{x}_{1}\right) \tilde{\chi_{\nu}}\left(\mathbf{x}_{1}\right)=\epsilon_{i} \sum_{\nu} C_{v i} \int d \mathbf{x}_{1} \tilde{\chi}_{\mu}^{*}\left(\mathbf{x}_{1}\right) \tilde{\chi}_{v}\left(\mathbf{x}_{1}\right)
$$

Esta pode ser simplificada pela introdução da notação de elemento matricial

$$
\begin{aligned}
S_{\mu \nu} & =\int d \mathbf{x}_{1} \tilde{\chi_{\mu}^{*}}\left(\mathbf{x}_{1}\right) \tilde{\chi_{\nu}}\left(\mathbf{x}_{1}\right) \\
F_{\mu \nu} & =\int d \mathbf{x}_{1} \tilde{\chi_{\mu}^{*}}\left(\mathbf{x}_{1}\right) f\left(\mathbf{x}_{1}\right) \tilde{\chi_{\nu}}\left(\mathbf{x}_{1}\right) .
\end{aligned}
$$

Agora, as equações de Hartree-Fock-Roothan podem ser escritas na forma matricial como

$$
\sum_{\nu} F_{\mu \nu} C_{\nu i}=\epsilon_{i} \sum_{\nu} S_{\mu \nu} C_{\nu i}
$$

ou simplesmente como matrizes

$$
\mathbf{F C}=\mathbf{S C} \epsilon
$$

onde $\epsilon$ é a matriz diagonal das energias orbitais $\epsilon_{i}$. Esta é como uma equação de autovalor, exceto pela matriz de sobreposição S. Se realiza uma transformação de base de forma a se chegar a uma base ortogonal que faça $\mathbf{S}$ desaparecer. Então é apenas uma questão de resolver uma equação de autovalores, diagona- 
lizando F. Desde que F depende de sua própria solução (através dos orbitais), o processo precisa ser feito iterativamente. Por isto a resolução das equações de Hartree-Fock-Roothan são freqüentemente chamadas de procedimento do campo auto-consistente (SCF).

\subsubsection{Interação de Configurações e Energia de Correlação Eletrônica}

Cálculos de alta precisão mostram que a função de onda aproximada por um único determinante de Slater, embora inclua fenômenos de troca, ainda tende a ser uma solução um tanto grosseira da Equação de Schrödinger e além disso, tal função de onda na maioria dos casos não é confiável nem na obtenção de resultados qualitativos. Tão importante quanto os fenômenos de troca são também aqueles dependentes dos movimentos individuais das diferentes partículas. Assim, concluiu-se que uma teoria mais precisa para descrever sistemas de muitas partículas somente poderia ser obtida se a correlação entre o movimento individual fosse levada em conta [30]. Além de suprir as deficiências da teoria do campo médio, é interessante também que se possa calcular algumas propriedades que a teoria anterior não permite obter de forma apropriada, como a geometria do primeiro estado excitado. O método Hartree-Fock permite apenas prever a geometria e as propriedades do estado fundamental. Para que se possa obter algo a respeito dos estados excitados, é preciso ter na função de onda a possibilidade de se criar excitações representando tais estados.

Em Hartree-Fock, apesar das interações entre os elétrons serem consideradas através do campo médio, não se levam em conta as interações instantâneas entre eles. Se em um átomo multieletrônico, e.g. um dos elétrons está mais próximo do núcleo, energeticamente é mais favorável que os outros elétrons permaneçam longe do núcleo naquele instante. Os movimentos dos elétrons são correlacionados uns com os outros, e a isso denominamos correlação eletrônica. 
Define-se energia de correlação como sendo a diferença entre a energia exata não-relativística $\left(\varepsilon_{0}\right)$ e a energia de Hartree-Fock $\left(E_{0}\right)$ :

$$
E_{\text {corr }}=\varepsilon_{0}-E_{0}
$$

Como a energia de Hartree-Fock é maior do que a energia exata, a energia de correlação é sempre negativa. Uma das maneiras de se fazer correções sobre a função de onda Hartree-Fock é adicionando contribuições associadas aos estados excitados do sistema, dando origem ao método chamado interação de configurações (CI). Não iremos em maiores detalhes, mas basicamente a função de onda exata é representada como uma combinação linear de funções de N-elétrons e é usado o método variacional linear. Tomando-se como exemplo o átomo de He, a partir do seu estado fundamental $1 s^{2}$ podemos formar configurações como $1 s^{1} 2 s^{1}, 1 s^{1} 2 p^{1}, 2 s^{2}, 2 s^{1} 2 p^{1}$ e assim por diante. Cada uma destas configurações $\phi_{i}$ é um determinante de Slater ou uma combinação linear de alguns determinantes de Slater. O que se faz então é escrever a função de onda como uma combinação linear das configurações descritas acima:

$$
\Phi=\sum_{i} C_{i} \phi_{i}
$$

Parte-se então para o tratamento da função $\Phi$ como uma função variacional linear. Faz-se a minimização da somatória variacional através da variação dos coeficientes $C_{i}$, levando a uma equação secular análoga à obtida por Hartree-Fock:

$$
\left|\mathcal{H}_{i j}-E S_{i j}\right|=0
$$


onde as configurações com mesmo autovalor do momento angular que o de $\phi_{i}$ contribuem na expansão.

\subsubsection{Teoria do Funcional Densidade}

A teoria do funcional densidade surgiu como uma alternativa aos tradicionais métodos ab initio e semi-empíricos no estudo de propriedades do estado fundamental de sistemas moleculares. A característica principal da DFT é substituir as funções de onda de vários elétrons com $3 \mathrm{~N}$ variáveis por uma densidade eletrônica dependente de apenas 3 variáveis. A grande vantagem sobre os métodos ab-initio padrões está no ganho em velocidade computacional e espaço em memória. Para se ter uma idéia, o esforço computacional para DFT é da ordem de $n^{3}$, enquanto que para Hartree-Fock aumenta em $n^{4}$ ou $n^{5}$, onde $\mathrm{n}$ é o número de funções de base.

Um predecessor da DFT foi o modelo de Thomas-Fermi, desenvolvido em 1927, onde a energia de um átomo foi calculada representando-se a sua energia cinética como uma função da densidade eletrônica e combinando-a com suas expressões clássicas para as interações elétron-núcleo e elétron-elétron. Apesar do importante passo, o modelo era limitado por não incluir a energia de Exchange predita pela Teoria de Hartree-Fock. Um termo de energia de Exchange fora adicionado por Dirac em 1928, mas o modelo de Thomas-Fermi-Dirac ainda permaneceu inacurado para a maioria das aplicações e ainda não contabilizava a correlação eletrônica. A solução exata foi dada por Hohenberg e Kohn em 1964, tendo rendido o Nobel de Química em 1998 à Walter Kohn. Um importante avanço na aplicabilidade da DFT foi feito em 1965 por Kohn e Sham, e desde então o seu uso em estudos de átomos, moléculas e sólidos vem crescendo bastante e desde a última década tem se mostrado o método mais eficiente para o cálculo de propriedades eletrônicas e estruturais do estado fundamental.

Como nos cálculos de estrutura de vários corpos, os núcleos são mantidos 
fixos (aproximação Born-Oppenheimmer), gerando um potencial externo V no qual os elétrons se movem. Um estado eletrônico estacionário é então descrito pela função de onda $\Psi\left(r_{1}, \ldots, r_{N}\right)$, satisfazendo a equação de Schrödinger para vários elétrons.

$$
H \Psi=[T+V+U] \Psi=\left[\sum_{i}^{N}-\frac{\hbar^{2}}{2 m} \nabla_{i}^{2}+\sum_{i}^{N} V\left(\overrightarrow{r_{i}}\right)+\sum_{i<i}^{N} U\left(\overrightarrow{r_{i}}, \overrightarrow{r_{j}}\right)\right] \Psi=E \Psi
$$

onde os operadores T e U são chamados operadores universais, por serem os mesmo para qualquer sistema, enquanto V(r) é não universal, por depender do sistema em particular. Em DFT, entra em cena a densidade $\rho(\vec{r})$, que é dada por

$$
\rho(\vec{r})=N \int d^{3} r_{2} \int d^{3} r_{3} \ldots \int d^{3} r_{N} \Psi^{*}\left(\vec{r}, \overrightarrow{r_{2}}, \ldots, \overrightarrow{r_{N}}\right) \Psi\left(\vec{r}, \overrightarrow{r_{2}}, \ldots, \overrightarrow{r_{N}}\right)
$$

Hohenberg e Kohn provaram em 1964, que a relação anterior pode ser revertida, i.e. para uma dada densidade $\rho(\vec{r})$, em princípio é possível calcular a corrrespondente função de onda $\Psi_{0}\left(\overrightarrow{r_{1}}, \ldots, \overrightarrow{r_{N}}\right)$. Em outras palavras, $\Psi_{0}$ é uma funcional única de $\rho(\vec{r})$, i.e.:

$$
\Psi_{0}=\Psi_{0}\left[\rho_{0}\right]
$$

e conseqüentemente, todos os outros observáveis do estado fundamental $\mathcal{O}$ são também funcionais de $\rho_{0}$ :

$$
\langle\mathcal{O}\rangle\left[\rho_{0}\right]=\left\langle\Psi_{0}\left[\rho_{0}\right]|\mathcal{O}| \Psi_{0}\left[\rho_{0}\right]\right\rangle
$$

Disto, segue que também a energia do estado fundamental é uma funcional de $\rho_{0}$ 


$$
E_{0}=E\left[\rho_{0}\right]=\left\langle\Psi_{0}\left[\rho_{0}\right]|T+V+U| \Psi_{0}\left[\rho_{0}\right]\right\rangle,
$$

onde a contribuição do potencial externo $\left\langle\Psi_{0}\left[\rho_{0}\right]|\mathrm{V}| \Psi_{0}\left[\rho_{0}\right]\right\rangle$, pode ser escrito explicitamente em termos da densidade

$$
V[\rho]=\int V(\vec{r}) \rho(\vec{r}) d^{3} r
$$

Os funcionais $T[\rho]$ e $U[\rho]$ são denominados funcionais universais, enquanto $V[\rho]$ é obviamente não universal, uma vez que depende do sistema em estudo. Especificado o sistema, i.e. sendo conhecido V, busca-se minimizar a funcional

$$
E[\rho]=T[\rho]+U[\rho]+\int V(\vec{r}) \rho(\vec{r}) d^{3} r
$$

com relação à $\rho(\vec{r})$, uma vez que se conheçam expressões confiáveis para $T[\rho]$ e $U[\rho]$. Uma minimização da funcional da energia leva então à densidade $\rho_{0}$ para o estado fundamental e nos permite obter então outros observáveis para tal estado.

O problema variacional de minimização da funcional energia $E[\rho]$ pode ser resolvido aplicando-se o método dos multiplicadores de Lagrange, o que foi feito por Kohn e Sham em 1965. Assim, usamos o fato de que o funcional na equação anterior pode ser escrita como uma funcional de densidade fictícia de um sistema não interagente:

$$
E_{s}[\rho]=\left\langle\Psi_{s}[\rho]\left|T_{s}+V_{s}\right| \Psi_{s}[\rho]\right\rangle
$$

onde $T_{s}$ denota a energia cinética não interagente e $V_{s}$ é um potencial efetivo 
externo no qual as partículas estão se movendo. Obviamente, $\rho_{s}(\vec{r})=\rho(\vec{r})$, desde que $V_{s}$ seja escolhido de forma que

$$
V_{s}=V+U+\left(T-T_{s}\right)
$$

Logo, podemos resolver a assim chamada equção de Kohn-Sham deste sistema não interagente "auxiliar"

$$
\left[-\frac{\hbar^{2}}{2 m} \nabla^{2}+V_{s}(\vec{r})\right] \phi_{i}(\vec{r})=\epsilon_{i} \phi_{i}(\vec{r})
$$

que leva aos orbitais $\phi_{i}$, que reproduzem a densidade $\rho(\vec{r})$ do sistema original de vários corpos

$$
\rho(\vec{r}) \equiv \rho_{s}(\vec{r})=\sum_{i}^{N}\left|\phi_{i}(\vec{r})\right|^{2} .
$$

O potencial efetivo de uma única partícula $V_{s}$ pode ser escrita em maiores detalhes como

$$
V_{s}=V+\int \frac{e^{2} \rho_{s}\left(\vec{r}^{\prime}\right)}{\left|\vec{r}-\vec{r}^{\prime}\right|} d^{3} r^{\prime}+V_{e c}\left[\rho_{s}(\vec{r})\right]
$$

onde o segundo termo denota o assim chamado termo de Hartree que descreve a repulsão Coloumbiana elétron-elétron, enquanto o último termo $V_{e c}$ é o chamado potencial correlação de exchange. Aqui, $V_{e c}$ inclui todas as interações de várias partículas. Desde que o termo de Hartree e $V_{e c}$ dependem de $\rho(\vec{r})$, que depende de $\phi_{i}$, que por sua vez depende de $V_{s}$, o problema de resolver a equação de Kohn-Sham é solucionado de modo auto-consistente, i.e. de forma iterativa. Geralmente partimos de uma aposta inicial para $\rho(\vec{r})$, e então calculamos o correspondente $V_{s}$, e resolvemos as equações de Kohn-Sham para os $\phi_{i}$. 
Destes últimos, calculamos a nova densidade e recomeçamos o processo. Este procedimento é repetido até que se atinja a convergência.

\subsection{Dinâmica Molecular e método de Monte Carlo}

Ao se fazer a simulação de um sistema complexo envolvendo várias moléculas, sobressaem-se dois métodos distintos, que permitem bons resultados: a Dinâmica Molecular e o Método de Monte Carlo. No presente caso, o sistema a ser simulado é de uma molécula de soluto, solvatado por várias outras moléculas de um mesmo solvente. Ambas as metodologias permitem observar formações de agregados, ligações de hidrogênio entre moléculas de soluto e de solvente, efeitos solvatocrômicos, etc. A dinâmica molecular se caracteriza pelo determinismo e permite obter a evolução temporal das configurações, mas esbarra na limitação computacional. Já o método de Monte Carlo é estocástico e exige poucoa demanda por processamento, mas não permite observar a evolução temporal das configurações geradas. Porém, o desevolvimento teórico de ambos os métodos baseia-se na hipótese ergódica, onde nas simulações infinitamente longas, os dois métodos permitem a visitação de todo o espaço de configurações, de modo que se tornam equivalentes [31].

As seções que se seguem buscam esclarecer as diferenças acerca dos dois métodos. Uma vez que este trabalho em particular faz uso do método de Monte Carlo, abordaremos de forma superficial, porém elucidativa os principais conceitos envolvidos na Dinâmica Molecular e procuraremos dar maior ênfase à descrição do método de Monte Carlo.

\subsubsection{O Potencial de Interação}

Antes de abordar os dois métodos de simulação, é importante fazer uma explanação acerca do Potencial de Interação $U$, comum nas duas metodologias. As forças moleculares são essencialmente de origem eletrostática e são descri- 
tas pelas interações entre núcleos e elétrons. Assim, o problema se resumiria em resolver a equação de Schrödinger para o movimento de elétrons e núcleos. Apesar de não se conhecer a solução exata para um sistema de mais de três corpos, é possível fazer algumas simplificações que viabilizam o estudo das forças moleculares.

A primeira simplificação é a aproximação de Born-Oppenheimer, que se baseia no fato dos núcleos serem muito mais pesados do que os elétrons. Resolvemos assim, o problema eletrônico para uma configuração estática dos núcleos, e deduzimos a função de energia potencial U dependendo somente das coordenadas nucleares, que podem ser usadas para determinar o movimento nuclear.

A segunda simplificação se baseia no fato das forças intermoleculares serem geralmente bem mais fracas do que as forças intramoleculares. Assim, freqüentemente se pode ignorar algum acoplamento entre os movimentos intramoleculares e os movimentos da molécula como um todo. Tal é o modelo adotado pelas moléculas rígidas, que ignoram todo o acoplamento, pois o potencial de interação molecular depende apenas da posição do centro de massa e da orientação da molécula. Esta aproximação não se aplica nos casos onde a molécula é flexível e nem ao estudo de certas propriedades como o espectro vibracional.

A terceira simplificação, que advém do fato da massa nuclear ser relativamente grande, descreve o comportamento molecular através da mecânica clássica e da mecânica estatística, complementado onde necessário por correções quânticas. Tal aproximação, no entanto, não é adequada para sistemas leves como hélio ou hidrogênio, porém o é para para a maioria dos líquidos.

O líquido é um sistema denso, onde as moléculas estão próximas e em constante movimento de translação e rotação, difundindo por todo o volume disponível e interagindo com toda vizinhança. O potencial de interações moleculares pode ser descrito como: 


$$
U(\mathbf{r})=\sum_{i} u_{1}\left(\overrightarrow{r_{i}}\right)+\sum_{i} \sum_{j>i} u_{2}\left(\overrightarrow{r_{i}}, \overrightarrow{r_{j}}\right)+\sum_{i} \sum_{j>i} \sum_{k>j} u_{3}\left(\overrightarrow{r_{i}}, \overrightarrow{r_{j}}, \overrightarrow{r_{k}}\right)+\cdots
$$

onde o primeiro termo, $u_{1}$ é o potencial que atua em um corpo e representa o efeito das forças externas no sistema; $u_{2}$ é o potencial de pares que representa a interações entre dois corpos; $u_{3}$ é o potencial que representa a interação de três corpos e assim sucessivamente. Como a contribuição do potencial de quatro corpos é esperada como sendo pequena quando comparada a $u_{2}$ e $u_{3}$, os potenciais de interações são truncados em $u_{3}$. Na prática os termos envolvendo três átomos consomem muito tempo, e o que se faz então é incluir parte destes efeitos médios num potencial efetivo de dois corpos $v_{2}^{e f f}\left(r_{i j}\right)$. Assim, as simulações acabam utilizando o seguinte potencial:

$$
U \cong \sum_{i} v_{1}\left(\mathbf{r}_{i}\right)+\sum_{i} \sum_{j>i} v_{2}^{e f f}\left(\mathbf{r}_{i j}\right)
$$

É conveniente dividir o potencial de pares em duas partes: intramolecular e intermolecular. O potencial intramolecular descreve as mudanças geométricas, ou distorções moleculares. Um modelo clássico bastante usado para este potencial é:

$$
U^{i n t r a}(r)=\sum_{\text {lig }} E_{r}\left(r_{i j}-r_{e q}\right)^{2}+\sum_{a n g} E_{\theta}\left(\theta_{i j}-\theta_{e q}\right)^{2}+\sum_{\text {diedro }} \frac{E_{n}}{2}\left[1+\cos \left(n \psi_{i j}-\gamma\right)\right]
$$

onde o primeiro termo descreve a variação de distância entre dois átomos ligados, o segundo termo descreve a distorção no ângulo entre os dois átomos ligados e o terceiro termo descreve os possíveis mínimos de energia em relação ao ângulo diédrico entre quatro átomos.

A figura 3.57 ilustra os três termos do potencial intramolecular. O primeiro 


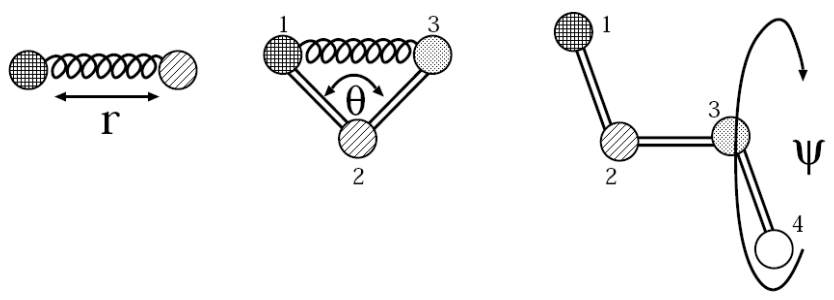

Figura 3.2. Distorções moleculares descritos pela equação 3.57.

desenho representa o primeiro termo da equação, dois átomos ligados por uma mola de constante elástica $E_{r}$ e comprimento natural $r_{e q}$. O desenho central representa o segundo termo, onde os átomos 1 e 3 se ligam ao átomo 2 por um distância fixa, porém se ligam entre si por uma mola de constante elástica $E_{\theta} \mathrm{e}$ comprimento natural tal que o ângulo entre 1,2 e 3 seja $\theta_{e q}$. O terceiro desenho representa o terceiro termo da equação, onde os átomos 1, 2 e 3 estão ligados e fixos no plano do papel, enquanto o átomo 4 é livre para girar em torno do eixo definido pelos átomos 2 e 3, sendo $\psi_{i j}$ o ângulo que o átomo 4 faz em relação ao plano.

Com a conseqüente organização interna dos átomos em cada molécula, o potencial intermolecular apresenta dependências radial e angular. Mas devido à complexidade dos termos angulares, em geral o potencial intermolecular é descrito através do somatório dos potenciais atômicos, ou potenciais de sítios que descrevem a molécula. Neste caso, a interação que descreve duas moléculas $a$ e $b$ é descrita por:

$$
U_{a b}^{i n t e r}=\sum_{i}^{e m a} \sum_{j}^{e m b} U\left(r_{i j}\right),
$$

onde $i$ são os sítios da molécula $a, j$ são os sítios da molécula $b$ e $r_{i j}$ é a distância entre os sítios $i$ e $j$. Na figura 3.3 ilustramos a interação entre duas moléculas com dois sítios cada. O potencial de interação entre as moléculas $a$ e $b$ é a soma de quatro termos: $U\left(r_{i_{1} j_{1}}\right), U\left(r_{i_{1} j_{2}}\right), U\left(r_{i_{2} j_{1}}\right)$ e $U\left(r_{i_{2} j_{2}}\right)$. 


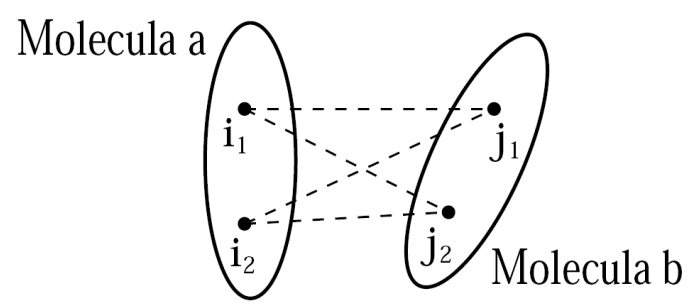

Figura 3.3. Interação entre duas moléculas com dois sítios cada.

Existem várias formas de descrever o potencial de van der Waals. O potencial intermolecular $U\left(r_{i j}\right)$ mais usado na descrição de sistemas em fase líquida é o potencial de Lennard-Jones, com o potencial de Coulomb:

$$
U\left(r_{i j}\right)=4 \epsilon_{i j}\left[\left(\frac{\sigma_{i j}}{r_{i j}}\right)^{12}-\left(\frac{\sigma_{i j}}{r_{i j}}\right)^{6}\right]+\frac{q_{i} q_{j}}{r_{i j}} .
$$

onde $\epsilon_{i j}=\sqrt{\epsilon_{i} \epsilon_{j}} ; \sigma_{i j}=\sqrt{\sigma_{i} \sigma_{j}}$ ou $\sigma_{i j}=\left(\sigma_{i}+\sigma_{j}\right) / 2 ; \epsilon_{i}$ e $\sigma_{i}$ são os parâmetros LJ e $q_{i}$ é a carga do sítio $i$.

O potencial de Lennard-Jones é formado por dois termos: um atrativo de longa distância, causado essencialmente pela correlação entre as nuvens eletrônicas que rodeiam os átomos e outro repulsivo de curto alcance, devido à repulsão eletrostática entre os átomos. Já o potencial de Coulomb descreve as interações eletrostáticas dos momentos de multipolos permanentes de duas moléculas.

\subsubsection{Dinâmica Molecular}

Nessa simulação, o sistema é uma representação tridimensional de uma molécula de soluto rodeada de $\mathrm{N}$ moléculas de solvente. O interesse da simulação é gerar configurações $\Gamma_{i}(r)$, onde $r$ é o conjunto das posições atômicas $r=\left(\overrightarrow{r_{1}}, \overrightarrow{r_{2}}, \overrightarrow{r_{3}}, \ldots, \overrightarrow{r_{N}}\right)$ de átomos que ficam confinados em uma caixa. Os átomos de cada uma das moléculas interagem segundo um potencial U. Ou seja, partindo de uma configuração inicial $\Gamma_{i}(r)$, desejamos obter uma configuração 
posterior $\Gamma_{i+1}(r)$, e a partir desta $\Gamma_{i+2}(r)$, e assim sucessivamente. A Dinâmica Molecular, caracterizada pelo determinismo, resolve as equações de movimento para a molécula do soluto e as $\mathrm{N}$ moléculas do solvente, interagindo sob o efeito de um potencial $\mathrm{U}$.

No formalismo lagrangeano [32, 33], a equação principal é dada por

$$
\frac{d}{d t}\left(\frac{\partial L}{\partial \dot{q}_{k}}\right)-\left(\frac{\partial L}{\partial q_{k}}\right)=0
$$

onde

$$
L=K-U,
$$

sendo $K$ a energia cinética. Podemos escrever os momentos conjugados $p_{k}$ como:

$$
p_{k}=\frac{\partial L}{\partial \dot{p}_{k}}
$$

Estes momentos podem ser escritos através do uso das equações de Hamilton do movimento como:

$$
\begin{gathered}
\dot{q_{k}}=\frac{\partial \mathcal{H}}{\partial \dot{p_{k}}} \\
\dot{p_{k}}=\frac{\partial \mathcal{H}}{\partial q_{k}}
\end{gathered}
$$

onde $\mathcal{H}$, a hamiltoniana do sistema é definida pela equação:

$$
\mathcal{H}\left(p_{k}, q_{k}\right)=\sum_{k} \dot{q}_{k} p_{k}-L\left(p_{k} \dot{q}_{k}\right)
$$

As equações de Hamilton podem ser escritas como: 


$$
\begin{gathered}
\dot{q}_{i}=\frac{p_{i}}{m_{i}}, \quad i=1,2,3 \\
\dot{p}_{i}=-\nabla_{i} U=F_{i}, \quad i=1,2,3 .
\end{gathered}
$$

Para calcular o movimento de um sistema de $\mathrm{N}+1$ moléculas ( $\mathrm{N}$ solvente + 1 soluto), precisamos resolver $3(\mathrm{~N}+1)$ equações de segunda ordem (equação 3.62)no formalismo lagrangeano, ou um conjunto equivalente de $6(\mathrm{~N}+1)$ equações de primeira ordem (equações 3.66 e 3.67). Assim, sendo conhecidas as posições e as velocidades de um dado conjunto de moléculas no instante $t$, através de um algoritmo de dinâmica molecular podemos determinar quais serão as novas posições e velocidades num instante subseqüente $t+\delta t$. Como se pode observar, o sistema envolve interações clássicas entre as moléculas. Num tempo infinito, a Dinâmica Molecular é capaz de visitar todas as configurações de espaços de fase acessíveis às moléculas tal qual o Método de Monte Carlo, porém só a Dinâmica permite fazê-lo incluindo a dependência temporal. A desvantagem, como foi mencionado na introdução deste capítulo, reside na elevada demanda computacional necessária para resolver as equações de movimento.

\subsubsection{Método de Monte Carlo}

A descrição geral do Método Monte Carlo que se segue corresponde ao que foi implementado no código computacional DICE, desenvolvido em FORTRAN/77 pela Prof.a Kaline Coutinho[34, 35] e pelo Prof. Sylvio Canuto, ambos pertencentes ao Instituto de Física da USP - São Paulo.

A simulação de Monte Carlo é iniciada com uma configuração qualquer, com $\mathrm{N}$ moléculas confinadas em uma caixa de volume $V$ a uma temperatura $T$. A evolução da simulação se dá através da sucessão de passos, conhecidos como passos MC. Em nossas simulações, um passo MC é definido quando as $\mathrm{N}$ mo- 
léculas do sistema são visitadas aleatoriamente. A cada visita, cinco números aleatórios são gerados: $\delta x, \delta y$ e $\delta z$, num intervalo de $\pm \delta r=(\delta x, \delta y, \delta z)$ e uma rotação de $\delta \theta$ num eixo sorteado. Nem todos os movimentos moleculares são aceitos. É a técnica de amostragem que estabelece as regras de aceitação, ou rejeição dos movimentos. Existem várias técnicas de amostragem e todas elas têm como objetivo gerar configurações de acordo com a distribuição de equilíbrio de um ensemble. No caso do ensemble NVT, onde o número de partículas, volume e temperatura são mantidos constantes, a distribuição de equilíbrio é a distribuição de probabilidades de Gibbs proporcional a $\rho_{N V T}\left(\Gamma_{i}\right)=e^{-\left(U_{i} / k T\right)}$. Neste trabalho usamos a técnica de amostragem de Metropolis[36], que usa a variação de energia entre as configurações como termo decisivo na regra de aceitação de uma nova configuração. Para uma boa descrição de um sistema molecular é importante que se tenha um bom modelo para o potencial de interação $U$. Tal questão foi discutida em subseção anterior. Os efeitos de superfície, provocados pela interação com as paredes da caixa são evitados através da utilização do método das réplicas, ou das imagens, acoplado com o uso de condições de contorno periódicas. O método consiste em replicar a caixa em todas as direções (fig. 3.4), fazendo com que as moléculas da caixa original não interajam mais com as paredes, mas sim com outras moléculas que são réplicas das moléculas da caixa original. A desvantagem do método é a introdução de periodicidade, onde cada molécula pode vir a interagir com uma molécula original e sua réplica. Este problema pode ser contornado, através da utilização de um raio de corte $r_{c}$, onde cada molécula poderá interagir somente com moléculas separadas por uma distância menor do que o raio de corte. É importante ressaltar que independentemente do uso das réplicas, somente as coordenadas das moléculas da caixa original são consideradas na configuração $\Gamma$ do sistema.

Resumindo, a simulação é iniciada com uma configuração qualquer, selecionamos uma molécula i qualquer, fazemos um movimento aleatório nesta mo- 


\begin{tabular}{|c|c|c|}
\hline $0_{0}^{0} 0_{0}^{0} 0_{0}^{0}$ & $\mid \begin{array}{ccc}0 & & 0 \\
0 & 0 & 0 \\
0 & 0 & 0 \\
0 & 0 & 0\end{array}$ & 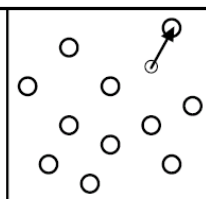 \\
\hline $0_{0}^{0} 0_{0}^{0} 0_{0}^{0}$ & $\left(0^{\circ}\right.$ & $\mid \begin{array}{ccc}0 & & 0 \\
0 & 0 & 0 \\
0 & 0 & 0 \\
0 & 0 & 0 \\
& 0 & 0\end{array}$ \\
\hline $0_{0}^{0} 0_{0}^{0} 0_{0}^{0}$ & $\begin{array}{ccc}0 & 0 \\
0 & 0 & 0 \\
0 & 0 & 0 \\
0 & 0 & 0\end{array}$ & $\mid \begin{array}{ccc}0 & 0 & 0 \\
0 & 0 & 0 \\
0 & 0 & 0 \\
0 & 0 & 0\end{array}$ \\
\hline
\end{tabular}

Figura 3.4. Método das réplicas num sistema bidimensional com caixa quadrada.

lécula; aplicamos o teste de aceitação; caso o movimento seja aprovado, a nova posição é aceita; caso contrário, ela é rejeitada; selecionamos outra molécula e repetimos o mesmo procedimento adotado com a molécula $i$ até completar um ciclo com as $N$ moléculas. Ao final do ciclo, temos um passo MC; salvamos a configuração e começamos um novo ciclo.

A evolução da simulação se divide em dois estágios. O primeiro estágio é não estacionário, conhecido como termalização, e o segundo é estacionário, conhecido como equilíbrio ou estágio de médias. Os dois estágios são observados no comportamento da energia do sistema durante a simulação, pois o sistema sai da energia inicial $U_{0}$ e gradualmente atinge o valor de energia $\langle U\rangle$, no qual fica flutuando. Este comportamento é ilustrado na figura 3.5.

Em nossas simulações, a configuração inicial gerada aleatoriamente possui energia muito maior do que a energia média do equilíbrio, $U_{0} \gg\langle U\rangle$. Levando em conta que o sistema leva muitos passos MC para chegar ao equilíbrio, optamos por usar um procedimento inicial diferente, que é o de não usar Metropolis nos primeiros passos, e sim, usar um processo onde só são aceitas as configurações que diminuem a energia do sistema. Assim, o sistema sai rapidamente da energia $U_{0}$ para energias mais próximas a $\langle U\rangle$. 


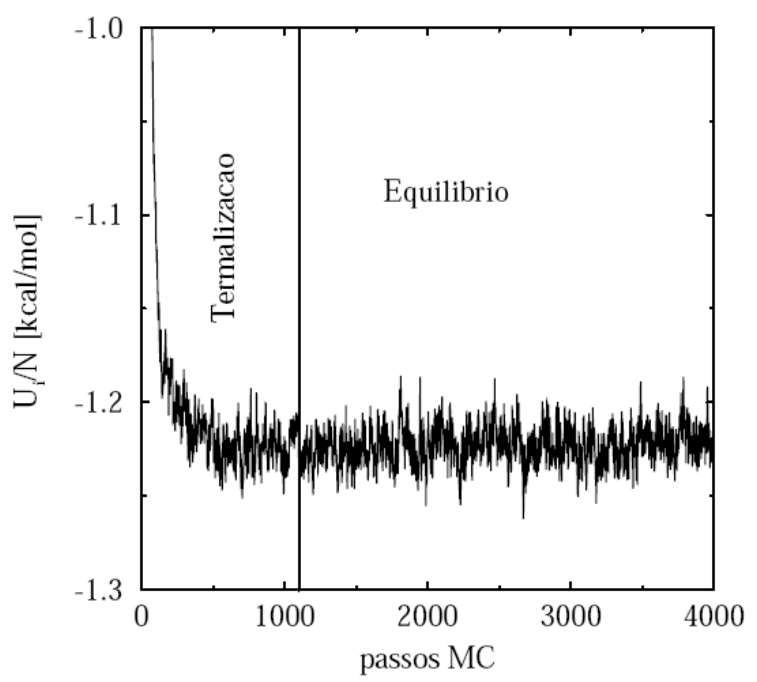

Figura 3.5. Evolução da energia por átomo durante simulação de argônio líquido no ensemble NVT.

\section{Técnica de Amostragem de Metropolis}

Tendo sido escolhido um ensemble, as propriedades macroscópicas do sistema, como energia interna, calor específico etc. são determinadas através de cálculos de médias sobre o ensemble. O valor médio de uma grandeza mensurável sobre um ensemble $f$ é

$$
\langle f\rangle_{\text {ens }}=\frac{1}{Z} \int_{\{\Gamma\}} f(\Gamma) \rho_{\text {ens }} d \Gamma
$$

onde $\Gamma$ representa um espaço configuracional genérico, $\rho_{\text {ens }} / Z$ é a distribuição de probabilidade de um ensemble qualquer (NVT, NPT, etc) e Z, conhecida como função de partição, é o fator de normalização da distribuição

$$
Z=\int_{\{\Gamma\}} \rho_{e n s}(\Gamma) d \Gamma
$$

A equação 3.68 é analiticamente intratável para a maior parte dos modelos usados para descrever o potencial de interação $U$. Assim, cálculos de valor médio 
de propriedades são feitos na simulação usando técnicas de amostragem média. Em 1953, Metropolis sugeriu substituir a equação 3.68 pela seguinte equação:

$$
\langle f\rangle_{\text {ens }}=\langle f\rangle_{l}=\frac{1}{l} \sum_{i=1}^{l} f\left(\Gamma_{i}\right)
$$

onde o problema é gerar uma seqüência de configurações aleatórias $\Gamma_{i}$ pertencentes ao espaço de configurações $\{\Gamma\}$ que ao final da simulação cada configuração tenha ocorrido na proporção devida. Podemos gerar uma cadeia markoviana de configurações [37], com distribuição limite $\rho_{\text {ens }}$, através de uma matriz de transição $\pi$ que satisfaz condições especiais.

$$
\pi_{i j} \geq 0 \quad \text { e } \quad \sum_{i} \pi_{i j}=1 \quad \text { paratodo } j
$$

que satisfaz a reversibilidade microscópica:

$$
\rho_{i} \pi_{i j}=\rho_{j} \pi_{j i}
$$

Metropolis sugeriu a matriz de transição $\pi$ como:

$$
\begin{array}{lll}
\pi_{i j}=1 & \text { se } \rho_{j} \geq \rho_{i} & \text { para } i \neq j \\
\pi_{i j}=\frac{\rho_{j}}{\rho_{i}} & \text { se } \rho_{j} \leq \rho_{i} & \text { para } i \neq j \\
\pi_{i j}=1-\sum_{i \neq j} \pi_{i j} & & \text { para } i=j
\end{array}
$$

No caso prático da simulação no ensemble $N V T$, se uma molécula é movida para uma nova posição e a energia do sistema diminui, $\left(U_{n e w}<U_{\text {old }}\right)$, a posição é imediatamente aceita. Caso a energia aumente $\left(U_{n e w}>U_{\text {old }}\right)$, então um número aleatório $\xi$ entre 0 e 1 é gerado e se este número for menor ou igual a probabilidade de transição $\pi_{\text {new,old }}=\rho_{\text {new }} / \rho_{\text {old }}=e^{-\left(U_{\text {new }}-U_{\text {old }}\right) / k T}=e^{-\Delta U / k T}$, a nova posição 
é aceita, apesar da energia ter aumentado; caso contrário $\left(\xi>e^{-\Delta U / k T}\right)$ a nova posição é rejeitada. A equação 3.71 é reescrita como:

$$
\begin{array}{lll}
\pi_{i j}=1 & \text { se } U_{j} \geq U_{i} & \text { para } i \neq j \\
\pi_{i j}=\frac{e^{-U_{j} / k T}}{e^{-U_{i} / k T}} & \text { se } U_{j} \leq U_{i} & \text { para } i \neq j \\
\pi_{i j}=1-\sum_{i \neq j} e^{-\Delta U / k T} & & \text { para } i=j
\end{array}
$$

assim,

$$
\text { se }\left\{\begin{array}{ll}
\xi \leq \pi_{i j} & \text { aceita } \\
\xi>\pi_{i j} & \text { rejeita }
\end{array} \quad \text { para } 0<\xi<1\right.
$$

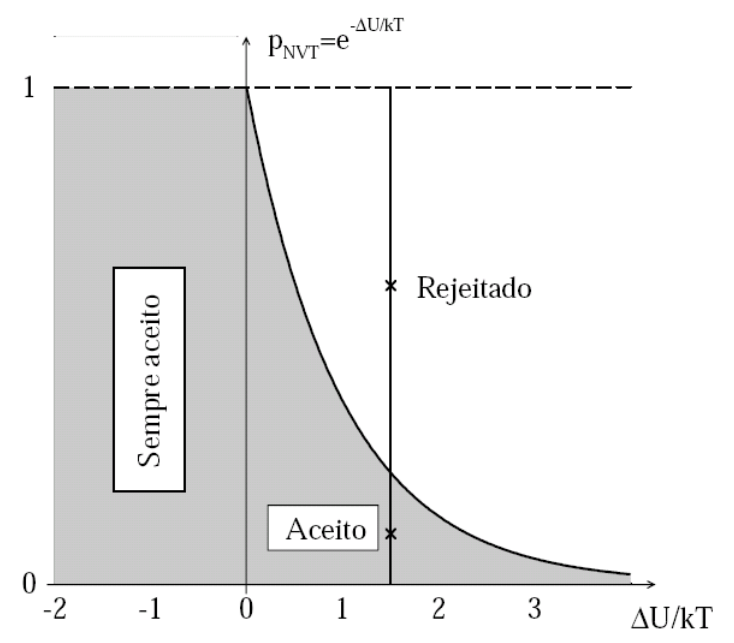

Figura 3.6. Regiões de aceitação e rejeição na técnica de amostragem de Metropolis.

A figura 3.6, ilustra a região de aceitação da técnica de amostragem de Metropolis em função de kT.

No caso da simulação no ensemble $N P T$, o mesmo procedimento é adotado e a diferença só aparece na probabilidade de transição

$$
\pi_{\text {new }, \text { old }}=\rho_{\text {new }} / \rho_{\text {old }}=e^{-(\Delta U+P \Delta V) / k T+\ln \left(V_{\text {new }} / V_{\text {old }}\right)}
$$


onde o último termo decorre do rescalonamento de todas as posições moleculares devido a mudança de volume. Este reescalonamento é implementado na simulação para evitar que as moléculas fiquem fora da caixa quando o volume diminui, ou que existam espaços vazios quando o volume aumenta. 


\section{Capitulo 4}

\section{Resultados e Discussões}

\subsection{Espectros de Absorção e Emissão Fluorescente}

Os resultados que se seguem foram obtidos a partir de espectros de absorção óptica e emissão fluorescente dos seguintes derivados do o-Abz: $\mathrm{Abz}-\mathrm{NH}_{2}$, $\mathrm{Abz}-\mathrm{NH}\left(\mathrm{CH}_{3}\right)$ e $\mathrm{Abz}-\mathrm{N}\left(\mathrm{CH}_{3}\right)_{2}$. Os compostos representam um modelo simplificado para Abz-aminoácidos nos quais o grupo carboxila do Abz formariam uma ligação peptídica com o grupo amina de um aminoácido, e foram sintetizados por Izaura Hirata do grupo de Biofísica da Universidade Federal de São Paulo (Escola Paulista de Medicina).

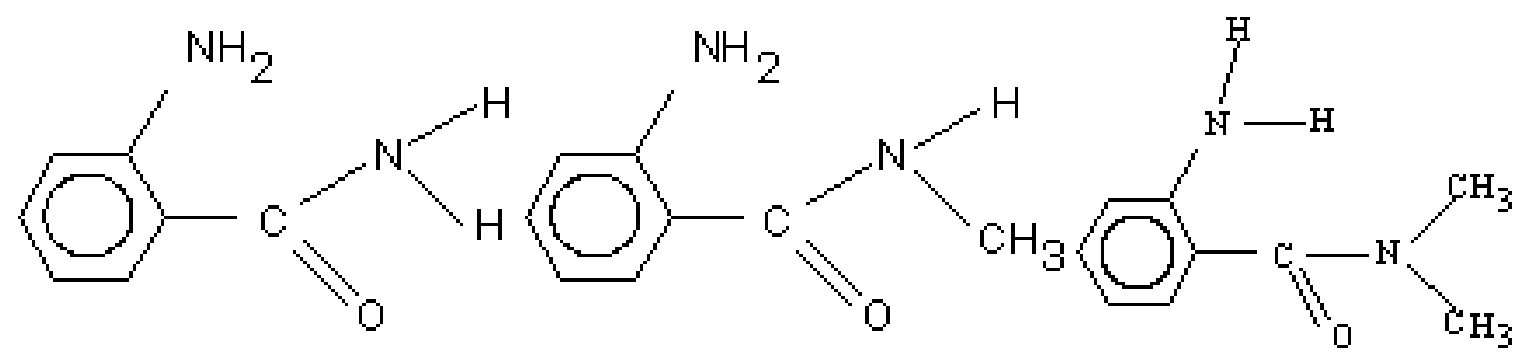

Figura 4.1. Derivados do ácido orto-Aminobenzóico: o-Abz: $\mathrm{Abz}-\mathrm{NH}_{2}, \mathrm{Abz}-\mathrm{NH}\left(\mathrm{CH}_{3}\right) \quad e$ $\mathrm{Abz}-\mathrm{NH}\left(\mathrm{CH}_{3}\right)_{2}$.

As figuras que se seguem ilustram os espectros de absorção óptica e emissão fluorescente das três amostras em solução tampão HEPES $\left(10^{-2} \mathrm{M}\right)$ a pH 7,4 em concentração $\sim 5 \times 10^{-5}$ M. Embora todas as três amostras apresentem absorção óptica com semelhantes intensidades, percebe-se uma grande diminuição da 
emissão fluorescente, quando há a presença de dois grupos metilas. Para que se pudesse observar os espectros (figura 4.3) foi necessário adotar a escala logaritmica no eixo da intensidade da fluorescência. Como há ainda uma considerável absorção mesmo diante da presença das metilas, há também uma população de moléculas no estado excitado, que no entanto retorna ao estado fundamental por vias de desexcitação não radiativas. As metilas de alguma forma são responsáveis por esse meio de desexcitação.

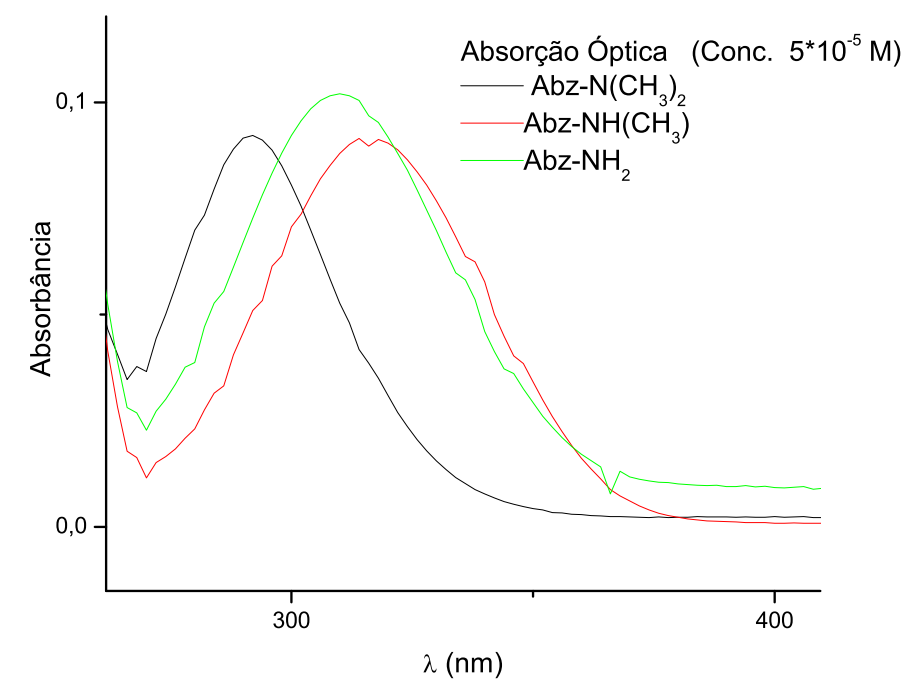

Figura 4.2. Espectros de absorção óptica de derivados do o-Abz em tampão hepes (10mM, pH $7,4)$. 


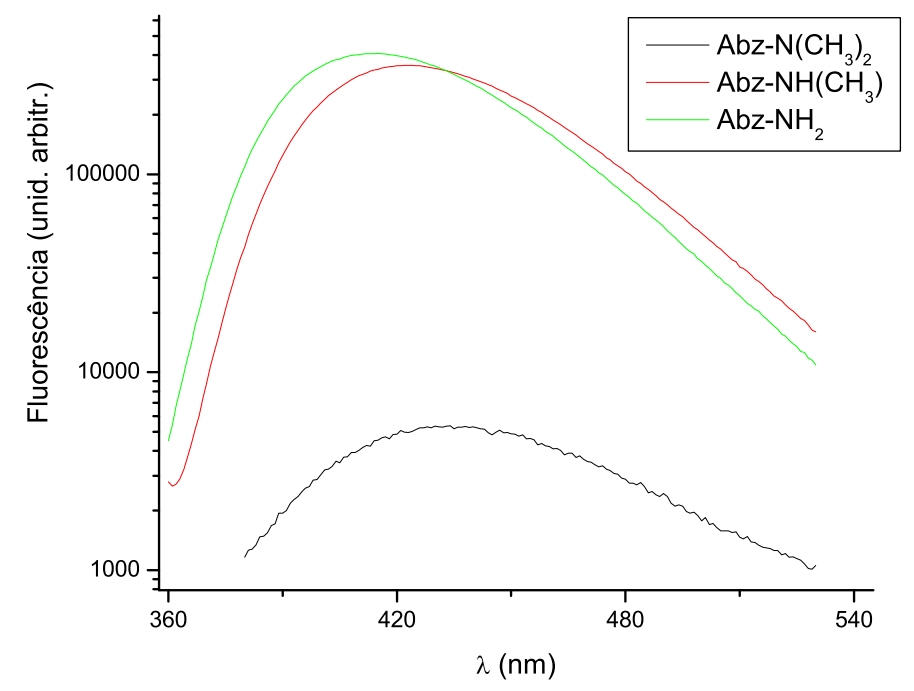

Figura 4.3. Espectros de emissão fluorescente de derivado de o-Abz em tampão hepes (10mM, pH 7,4). A escala logarítmica foi adotada por questão de conveniência, dada a baixa emissão do $\mathrm{Abz}-\mathrm{N}\left(\mathrm{CH}_{3}\right)_{2}$.

Tais medidas foram repetidas para as amostras em vários outros solventes, variando-se também a concentração de 10 a $50 \mu M$, afim de se obter uma média. Em nenhum instante se observou algum deslocamento espectral considerável, provocado pela mudança na concentração da amostra no mesmo meio solvente. Assim, para as três amostras, foram utilizados os seguintes solventes de grau espectroscópico: solução tampão HEPES 10mM, etanol, metanol, benzeno, ciclohexano, dioxano, dimetilsulfóxido (DMSO), trifluoroetanol (TFE), clorofórmio e acetonitrila.

\subsubsection{Efeitos Gerais}

\section{Equação de Lippert-Mataga}

Dos espectros foram extraídos os comprimentos de onda, tanto da absorção como da emissão fluorescente . E a partir da literatura, foram obtidos os valores das constantes dielétricas e índices de refração dos solvente utilizados[61], per- 
mitindo assim o cálculo da polarizabilidade de orientação molecular $\Delta f$, a ser aplicada na equação de Lippert-Mataga (vide equações 2.38 e 2.48).

\begin{tabular}{cccc}
\hline & $\varepsilon$ & $n$ & $\Delta f$ \\
\hline \hline ciclohexano & 2,02 & 1,426 & 0,001 \\
dioxano & 2,21 & 1,422 & 0,021 \\
benzeno & 2,28 & 1,501 & 0,003 \\
etanol & 24,55 & 1,361 & 0,289 \\
TFE & 27,68 & 1,291 & 0,320 \\
metanol & 0,62 & 1,328 & 0,309 \\
acetonitrila & 37,5 & 1,344 & 0,305 \\
DMSO & 47 & 1,479 & 0,263 \\
água & 78,3 & 1,333 & 0,320 \\
\hline
\end{tabular}

Tabela 4.1. Constantes dielétricas e índices de refração de solventes.

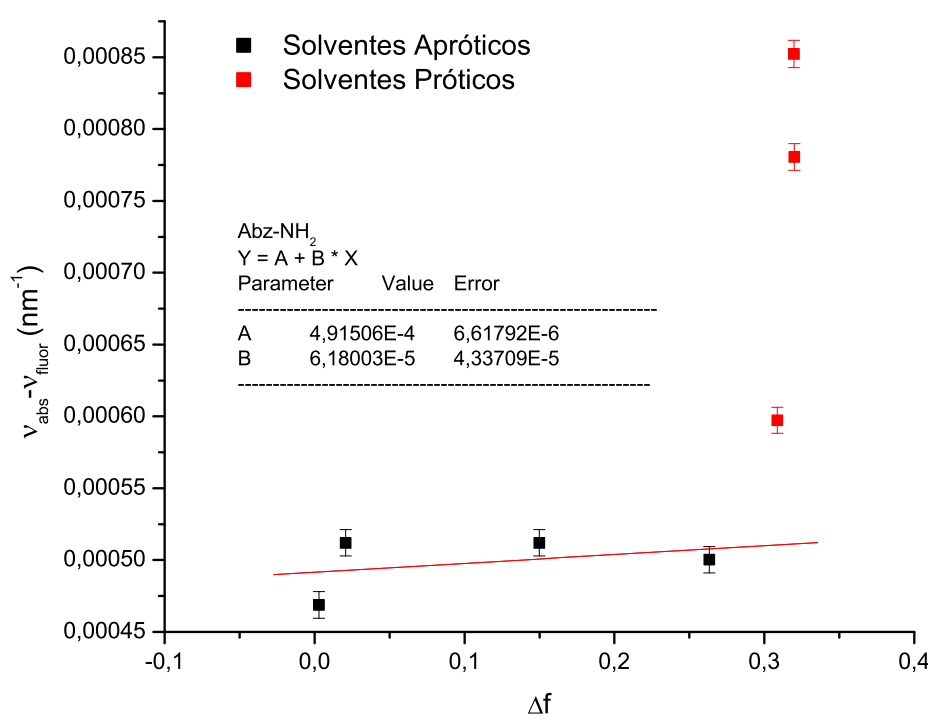

Figura 4.4. Gráfico do deslocamento de Stokes $(\Delta \nu)$ em função da polarizabilidade de orientação $\Delta f$ do Abz-NH2. A linha vermelha representa o ajuste da equação de Lippert-Mataga.

Alguns solventes como a água e os alcoóis tendem a atuar como doadores de $\mathrm{H}+$ ( próton ), e assim, foram classificados como próticos (doador de $\mathrm{H}+$ ) e apróticos (não doador de $\mathrm{H}+$ ), com base na sua capacidade de estabelecer tais 
ligações de hidrogênio [19]. Os critérios para essa classificação são apresentados no próximo capítulo; por ora, a utilizamos apenas para poder separar os efeitos gerais dos específicos.

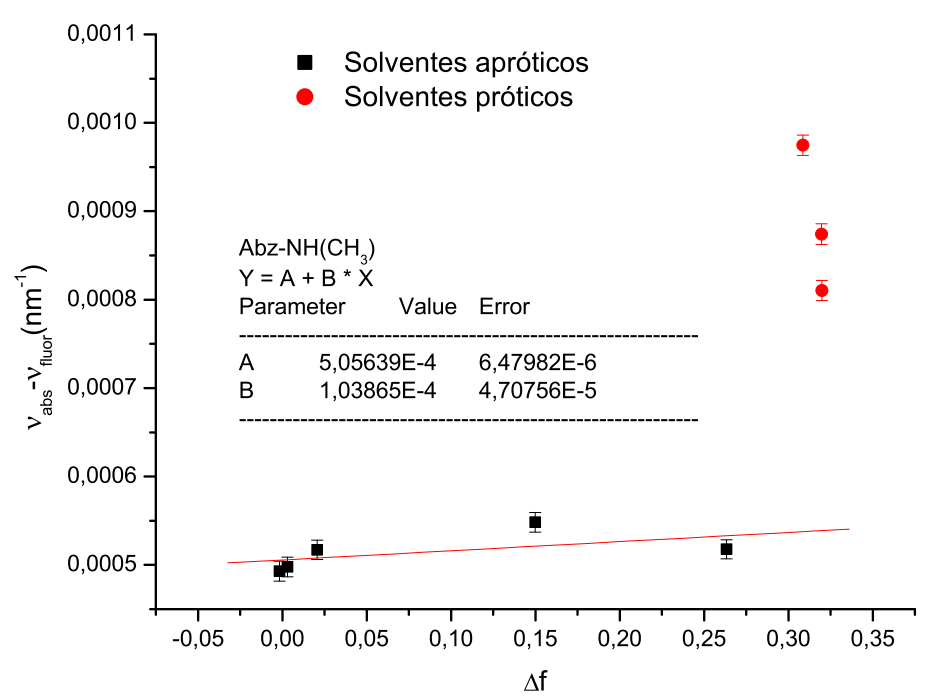

Figura 4.5. Gráfico do deslocamento de Stokes $(\Delta \nu)$ em função da polarizabilidade de orientação $\Delta f$ do Abz-NH(CH3)2. A linha vermelha representa o ajuste da equação de Lippert-Mataga.

Nas figuras 4.4, 4.5 e 4.6, observamos claramente o comportamento destoante dos pontos relativos às medidas feitas com solventes próticos, quanto ao comportamento linear que seria esperado a partir da equação de Lippert. As razões para isso estão relacionadas às ligações de hidrogênio formadas entre soluto e solvente, mais especificamente aquelas onde o solvente atua como doador do hidrogênio, caso dos solventes ditos próticos. Assim, por se relacionarem aos efeitos específicos, os pontos referentes aos solventes próticos são excluídos do ajuste linear, sendo este aplicado somente àqueles dos solventes apróticos. 


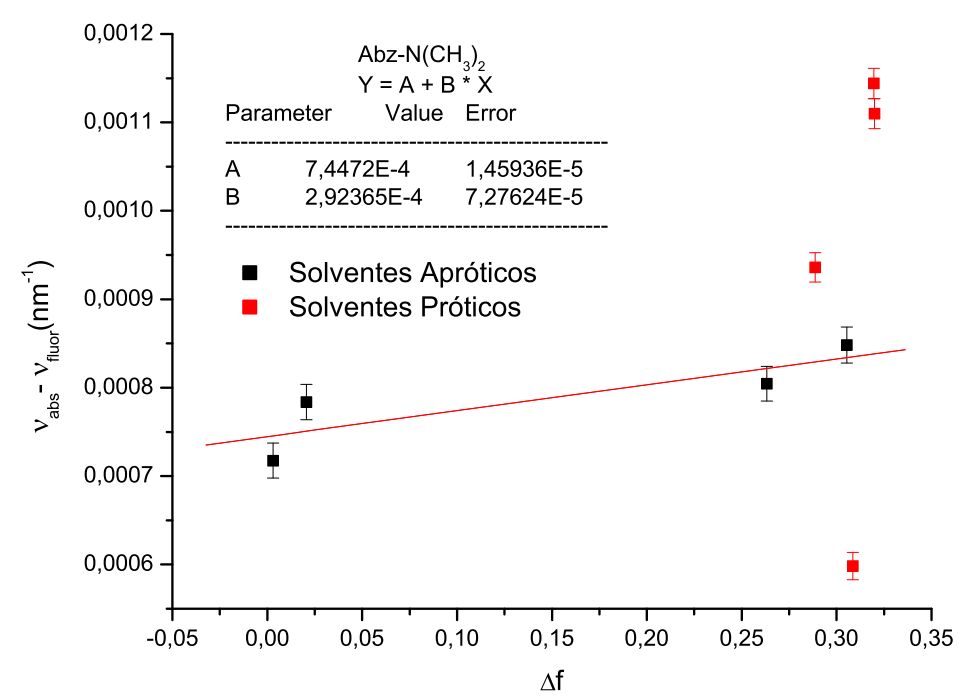

Figura 4.6. Gráfico do deslocamento de Stokes $(\Delta \nu)$ em função da polarizabilidade de orientação $\Delta f$ do Abz-N(CH3)2. A linha vermelha representa o ajuste da equação de Lippert-Mataga.

Com o coeficiente angular obtido do ajuste $\mathrm{Y}=\mathrm{A}+\mathrm{BX}$, calculamos a diferença entre os momentos de dipolos excitado e fundamental $(\mu *-\mu)$ ou $\Delta \mu$, fazendo:

$$
B=\frac{2}{h c a^{3}}\left(\mu^{*}-\mu\right)^{2}
$$

A grandeza $a$, também chamada de raio de Onsager é o raio da cavidade esférica onde a molécula se encontra solvatada, e por aproximação, considerou-se o diâmetro como sendo o comprimento da molécula, obtido através de cálculos de optimização ab initio de estrutura usando o software Gaussian98.

Assim, 


\begin{tabular}{cccc}
\hline Amostra & $a(\AA)$ & $\mathrm{B}\left(\mathrm{nm}^{-1}\right)$ & $(\mu *-\mu)(\mathrm{D})$ \\
\hline \hline $\mathrm{Abz}-\mathrm{NH}_{2}$ & 3,5 & $(6 \pm 4) * 10^{-5}$ & $1,7 \pm 1,2$ \\
$\mathrm{Abz}-\mathrm{NH}\left(\mathrm{CH}_{3}\right)$ & 3,9 & $(10 \pm 5) * 10^{-5}$ & $2,5 \pm 1,1$ \\
$\mathrm{Abz}-\mathrm{N}\left(\mathrm{CH}_{3}\right)_{2}$ & 4,0 & $(29 \pm 7) * 10^{-5}$ & $4,3 \pm 1,1$ \\
$\mathrm{o}-\mathrm{Abz}^{*}$ & 3,0 & $(19 \pm 6) * 10^{-5}$ & $2,3 \pm 0,7$ \\
\hline
\end{tabular}

Tabela 4.2. Resultados do ajuste da equação de Lippert aos derivados de o-Abz, onde a é o raio de Onsager, B é o coeficiente linear ajustado e $\left(\mu^{*}-\mu\right)$ a diferença de dipolos nos estados excitado e fundamental. O valor obtido para o o-Abz isolado foi obtido de trabalhos anteriores[5, 8].

Comparado ao o-Abz isolado, cujo valor para $\Delta \mu$ foi obtido em trabalho anterior $[8,5]$, percebe-se uma proximidade quanto aos valores obtidos para os derivados. Embora se observem grandes desvios nos coeficientes angulares obtidos nos ajustes, verifica-se uma tendência para o aumento na diferença dos momentos de dipolos, com o acréscimo dos grupos metilas. De certa forma, o acréscimo de metilas aumenta a dimensão da molécula, e isso deve favorecer uma maior separação de cargas nos estados excitados, aumentando o momento de dipolo correspondente. Outro fato importante já citado no item anterior diz respeito ao baixo rendimento quântico do $\mathrm{Abz}-\mathrm{N}\left(\mathrm{CH}_{3}\right)_{2}$ observado através da sua baixíssima intensidade de fluorescência, embora mantivesse a absorção óptica comparável a das outras amostras. Percebe-se que a presença das metilas nos terminais carboxílicos do o-Abz, além de acentuar o deslocamento de Stokes , tendem a favorecer a desexcitação por processos não radiativos.

\subsubsection{Efeitos Especificos}

\section{Parâmetros empíricos de polaridade do solvente}

A polaridade de um solvente é um termo comumente utilizado para relacionar a capacidade de um solvente na solvatação de uma carga dissociada ou uma espécie dipolar. Embora seja fácil estudá-lo qualitativamente, torna-se difícil expressá-lo quantitativamente. As tentativas de fazê-lo envolvem principalmente as propriedades físicas como constante dielétrica, índice de refração 
e momento de dipolo. Destas propriedades físicas, a considerada mais relevante é a constante dielétrica, a qual freqüentemente é tomada como um parâmetro inicial das características polares do solvente. No entanto, esta aproximação pode ser inadequada, pois as teorias que o fazem tomam o solvente como um meio contínuo e não estruturado, não sendo composto de moléculas individuais com interações soluto-solvente próprias, e não levam em conta também interações específicas como ligações de hidrogênio e interações EPA/EPD (aceitador de pares de elétrons / doador de pares de elétrons) [38, 39, 40]. Assim, tem sido apresentadas na literatura algumas escalas empíricas de polaridade de solvente que buscam contabilizar os efeitos das ligações de hidrogênio, baseadas em convenientes processos referências bem conhecidos e sensiveis a solventes. Uma destas escalas empíricas, a de Kamlet-Taft, mostrou-se adequada para uma larga classe de outros processos dependentes de solventes, refletindo as possíveis interações soluto/solvente presentes nos processos influenciados por solventes [40].

\section{A escala $\pi^{*}$}

A escala $\pi^{*}$ foi introduzida por Kamlet, Taft et al, e possui tal nome por ser derivada dos efeitos de solventes em uma conhecida transição eletrônica $\pi \rightarrow \pi^{*}$ de uma variedade de nitroaromáticos (4-nitroanisole, N,N-diethyl-3- nitroaniline, 4-methoxy- $\beta$ - nitrostyrene, 1-ethyl-4- nitrobenze- ne, N-methyl-2-nitro-p-toluidine, N,N-diethyl-4-nitroaniline e 4- dimethylamino- benzophenone). Os efeitos de solventes nos valores de $\nu_{\max }$ destes sete indicadores solvatocrômicos foram empregados na construção da escala $\pi^{*}$, que foi então expandida e refinada por múltiplas correlações de mínimos quadrados além da adição de novos indicadores solvatocrômicos. Deste modo, uma escala $\pi^{*}$ média de polaridade de solventes havia sido estabelecida, com a medida da capacidade do solvente de estabilizar uma carga ou um dipolo em virtude de seu efeito dielétrico. Um in- 
tervalo normalizado de 0,00 (para o Ciclohexano) até 1,00 (Dimetilsulfóxido) foi estabelecido para os valores de $\pi^{*}$. Nessa escala, um solvente como a água está classificado como altamente capaz de estabilizar cargas ou dipolos no soluto.

Além disso, definiram-se os parâmetros alpha e beta que caracterizam, respectivamente, a capacidade do solvente de formar ligações de hidrogênio como doador de prótons e como aceitador de prótons [41, 42].

\begin{tabular}{cccc}
\hline Solventes & $\beta$ & $\alpha$ & $\pi^{*}$ \\
\hline \hline Ciclohexano & 0.00 & 0.00 & 0.00 \\
Etanol & 0.77 & 0.83 & 0.54 \\
1,4-dioxano & 0.37 & 0.00 & 0.55 \\
Clorofórmio & 0.10 & 0.20 & 0.58 \\
Benzeno & 0.10 & 0.00 & 0.59 \\
Metanol & 0.62 & 0.93 & 0.60 \\
2,2,2-trifluoroetanol & 0.00 & 1.51 & 0.73 \\
Acetonitrila & 0.31 & 0.19 & 0.75 \\
Dimetil sulfoxido & 0.76 & 0.00 & 1.00 \\
Água & 0.18 & 1.17 & 1.09 \\
\hline
\end{tabular}

Tabela 4.3. Alguns valores da tabela de parâmetros empíricos de Kamlet-Taft. (Reichardt, 1990)

Classificaram-se como solventes próticos aqueles capazes de formar ligações de hidrogênio como doadores de prótons, sendo caracterizados então, dentro da classificação de Kamlet-Taft, conforme o valor de $\alpha$ próximo da unidade. Exemplos de solventes próticos são a água e os alcoóis, cujas hidroxilas acabam atuando como doadoras de prótons. Já os solventes apróticos são todos aqueles desprovidos de tal característica, o que no entanto não significa incapacidade de formar ligaçoes de hidrogênio do outro tipo, como aceitadores de prótons. Certos solventes próticos, como a maioria dos alcoóis, são capazes de formar ligações de hidrogênio de ambos os tipos, enquanto alguns, como o TFE são incapazes de aceitar prótons, apresentando o parâmetro $\beta=0$.

Um caso interessante é o da anilina [59], que apresenta um deslocamento 
espectral para o azul no seu espectro de absorção óptica ao formar ligações de hidrogênio com a água. O que ocorre é uma transição do tipo $l \rightarrow \pi^{*}$, onde $l$ é um orbital do Nitrogênio. O elétron situado no orbital $l$ do Nitrogênio é promovido ao orbital delocalizado $\pi^{*}$, e nisso se verifica uma transferência de carga entre o substituinte $\mathrm{N}$ e o anel aromático da anilina. A formação da ligação de hidrogênio entre o solvente e o grupo amina da anilina estabiliza o estado fundamental, de forma que se torna necessária maior quantidade de energia para que ocorra a transição para o estado excitado.

\section{Efeitos especificos}

Os efeitos específicos podem ter como causas as formações de ligações de hidrogênio e de complexos de transferência de cargas. No presente trabalho, nos detemos nas situações onde podemos identificar a existência das ligações de hidrogênio e o seu tipo. Fazendo uso da escala empírica (tabela 4.3) na caracterização da polaridade do solvente, analisamos os comportamentos dos derivados metilados do o-Abz nos diversos solventes próticos e apróticos. Os solventes próticos, sendo doadores de prótons, tendem a formar ligações de hidrogênio com o soluto do tipo R - H .... ou R - H .... N, onde os átomos $\mathrm{O}$ e $\mathrm{N}$ pertencem à molécula do soluto [41]. Dos solventes apróticos, alguns também são capazes de estabelecer ligações de hidrogênio, porém do tipo R - O ...H ou R - N ... H, onde desta vez, o átomo de Hidrogênio pertence ao fluoróforo [42]. Se consultarmos a tabela contendo os parâmetros empíricos $\alpha$ e $\beta$ [43], veremos que a água possui uma forte capacidade de formação de ligações do primeiro tipo, enquanto os alcoóis em geral (no presente caso metanol e etanol) conseguem formar tanto as do primeiro tipo quanto as do segundo tipo. Os solventes apróticos aqui utilizados foram o ciclohexano, dioxano, benzeno, acetonitrila, clorofórmio e DMSO, com valores de $\alpha$ iguais ou próximos de zero. Os próticos 
foram o etanol, metanol, TFE e água, que apresentam valores de $\alpha$ próximos da unidade.

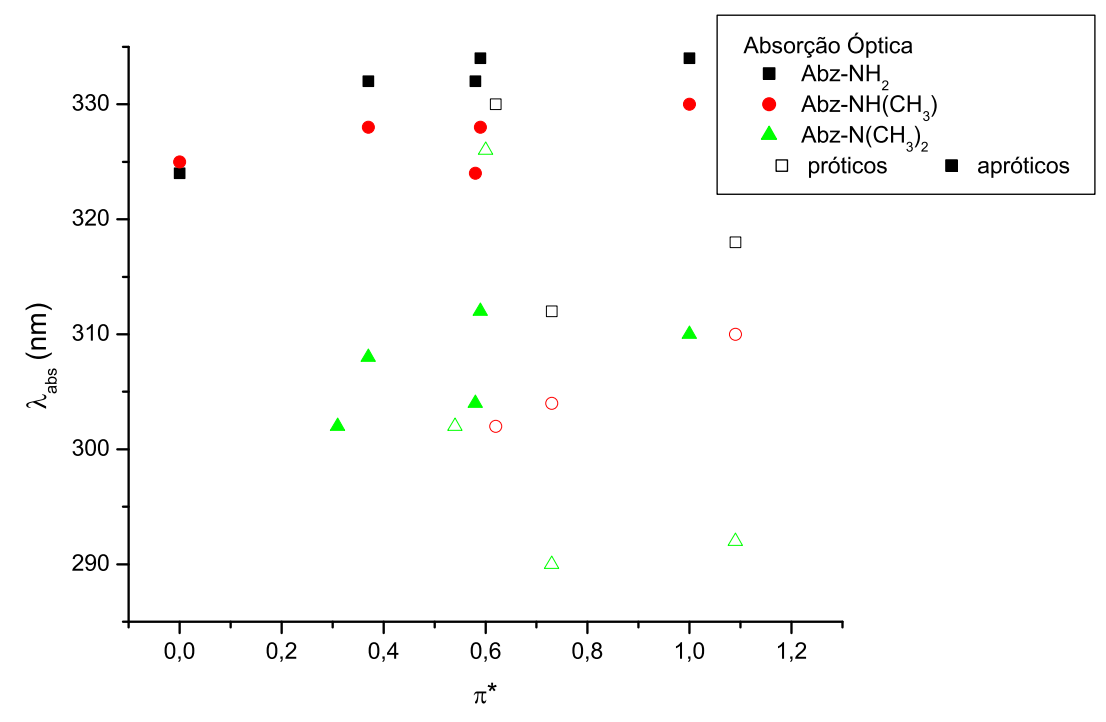

Figura 4.7. Comprimentos de onda nos máximos de absorção óptica versus parâmetro empírico de polaridade $\pi^{*}$.

A presença de meios próticos tende a provocar deslocamentos para o azul nos comprimentos de onda nos máximos de absorção (fig.4.7). Isso pode estar relacionado com as ligações de hidrogênio formadas entre as amostras e os solventes. Tal ligação, onde a amostra recebe o próton $(\mathrm{H}+)$ que irá estabelecê-la, de certa forma deve estabilizar (diminuição de energia) o nível fundamental de energia, gerando possivelmente uma maior rigidez estrutural, que por sua vez, exigiria maior quantidade de energia para fazer a transição para um nível de energia superior.

Já na figura 4.8 percebe-se claramente a tendência de deslocamentos para o vermelho nos máximos da emissão fluorescente quando em solventes próticos. Desta vez, no processo de relaxação do primeiro estado excitado, as ligações de hidrogênio com o solvente provocam uma diminuição mais intensa da energia do estado excitado. 


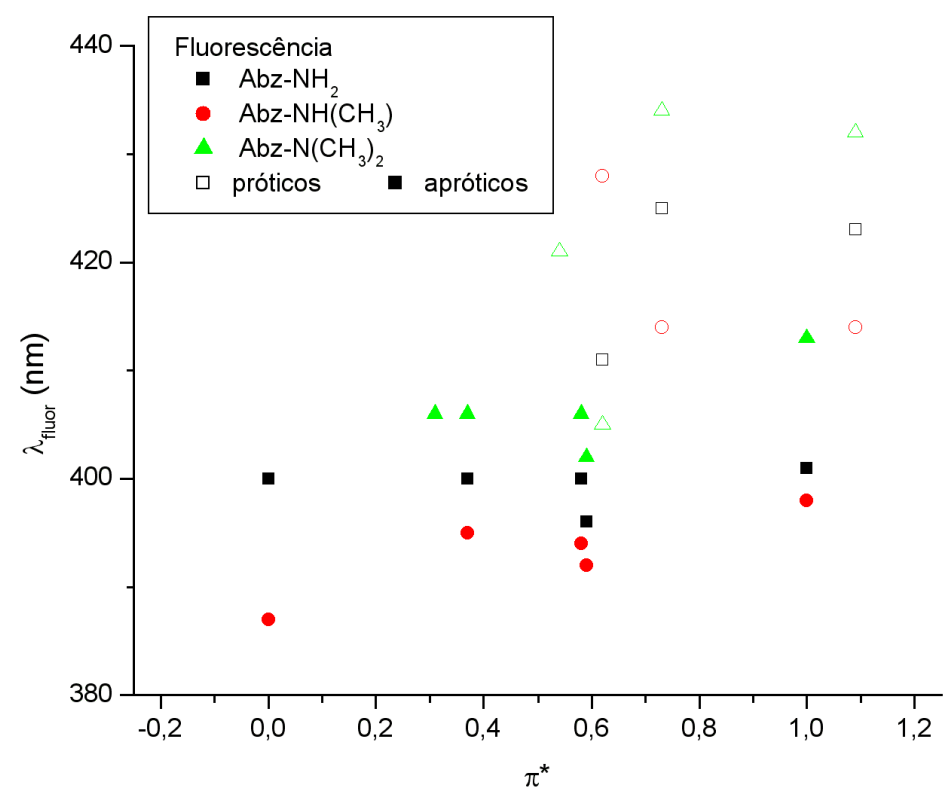

Figura 4.8. Comprimentos de onda nos máximos de emissão fluorescente versus parâmetro empírico de polaridade $\pi^{*}$.

\section{Tempos de Vida}

Para as mesmas amostras, diluídas nos diversos solventes apresentados, foram realizadas também medidas de decaimento temporal da fluorescência. $\mathrm{Na}$ figura que se segue, temos uma ilustração da curva ajustada ao decaimento fluorescente do $\mathrm{Abz}-\mathrm{NH}_{2}$ em tampão HEPES, seguida da sua função de autocorrelação residual, que permite avaliar a qualidade do ajuste da curva juntamente com o valor de $\chi^{2}$ próximo da unidade.

Nas tabelas que se seguem, temos os parâmetros obtidos dos ajustes das curvas de decaimento fluorescente da amostras derivadas do Abz diluídas nos diversos solventes. O ajuste se dá sobre uma curva de decaimento multiexponencial do tipo:

$$
F(t)=A+B_{1} * e^{t / \tau_{1}}+B_{2} * e^{t / \tau_{2}}+B_{3} * e^{t / \tau_{3}}
$$



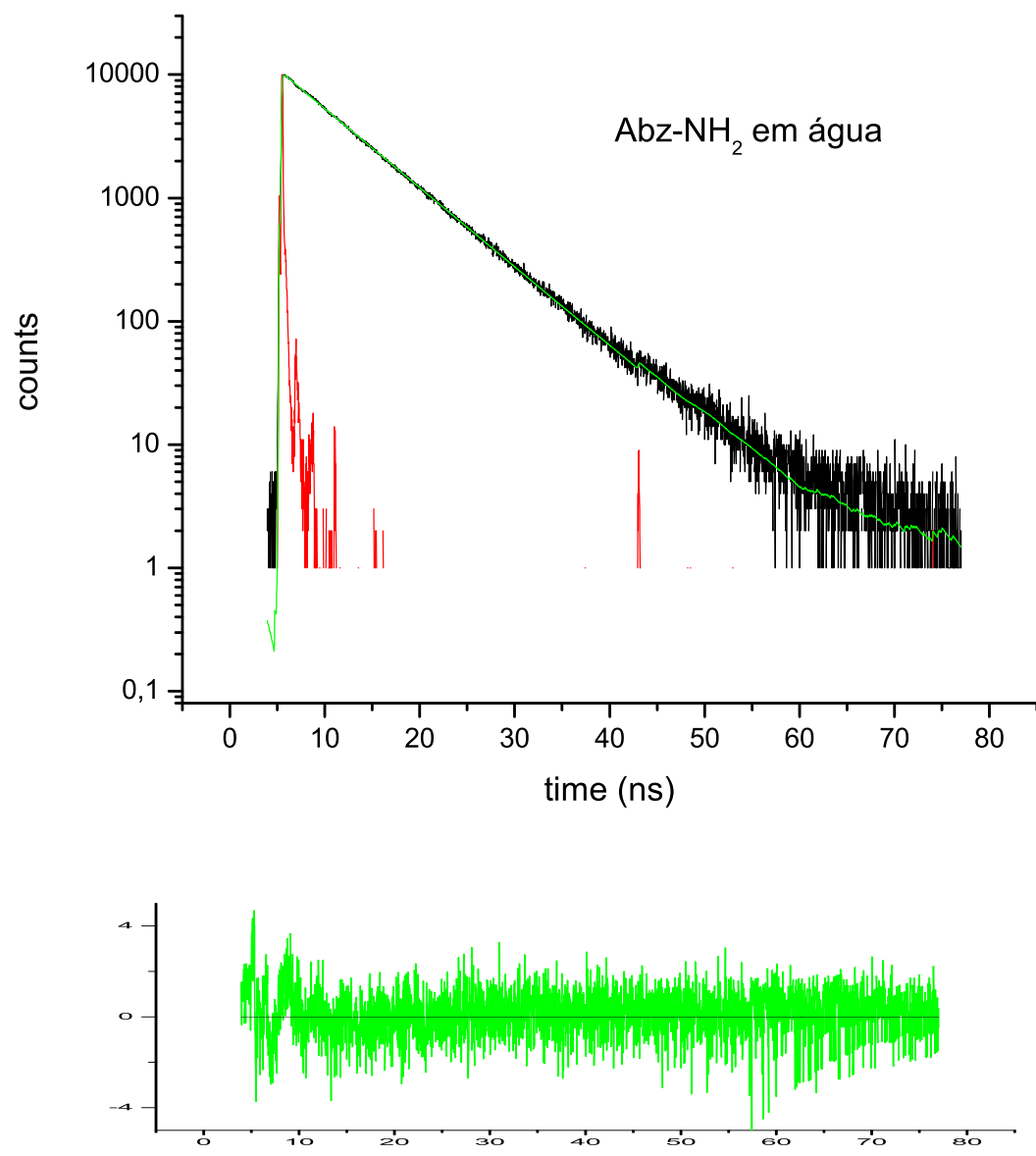

Figura 4.9. Curva ajustada em escala logarítimica para o decaimento temporal do Abz em água ( $p H$ 7,4). Superposto à curva do decaimento vemos também o pulso de excitação. Abaixo, a função de autocorrelação residual da curva ajustada para o Abz.

Em tal tipo de ajuste, cada um dos tempos $\tau_{i}$ é geralmente associado a uma espécie fluorófora presente na amostra, e os coeficientes $B_{i}$, determinam a contribuição desta componente dentro do decaimento total. É importante observar que dependendo da situação, as quantidades $B_{i}$ e $\tau_{i}$ podem não ter tal significado físico. Um exemplo são os decaimentos não-exponenciais, comumente observados em fluoróforos suprimidos por transferência de energia em que sofrem relaxação de solvente. Assim, nem sempre podemos considerar $B_{i}$ e $\tau_{i}$ como componentes isoladas da amostra, a menos que hajam indicações que 
corroborem com tal interpretação. Nos ajustes feitos, algumas medidas apresentaram decaimentos onde o melhor ajuste se deu somente após a inclusão de um terceiro tempo.

\begin{tabular}{cccccccc}
\hline Abz-NH2 Solventes & $\tau_{1}(n s)$ & $\tau_{2}(n s)$ & $\tau_{3}(n s)$ & $B 1$ & $B 2$ & $B 3$ & $\tau_{\text {medio }}(n s)$ \\
\hline \hline TFE & 6.6629 & 0.636 & - & 0.130 & 0.012 & - & 6.610 \\
Dmso & 7.1263 & 0.4979 & - & 0.128 & 0.016 & - & 7.069 \\
Acetonitrila & 4.613 & 3.0174 & - & 0.111 & 0.029 & - & 4.380 \\
Metanol & 7.3702 & 0.4207 & - & 0.129 & 0.012 & - & 7.334 \\
Benzeno & 5.0766 & 2.2017 & 11.6194 & 0.017 & 0.124 & 0.006 & 4.310 \\
Dioxano & 10.7086 & 0.6581 & 4.2439 & 0.093 & 0.030 & 0.015 & 10.144 \\
Etanol & 7.4091 & 2.5608 & - & 0.131 & 0.006 & - & 7.334 \\
Hepes & 6.7501 & 0.5471 & - & 0.122 & 0.018 & - & 6.677 \\
Cloroformio & 6.8063 & 2.330 & - & 0.127 & 0.008 & - & 6.712 \\
\hline
\end{tabular}

Tabela 4.4. Parâmetros ajustados para as curvas de decaimento multi-exponencial do Abz-NH2, em diversos solventes.

\begin{tabular}{cccccccc}
\hline Abz-NH(CH3) Solventes & $\tau_{1}(n s)$ & $\tau_{2}(n s)$ & $\tau_{3}(n s)$ & $B 1$ & $B 2$ & $B 3$ & $\tau_{\text {medio }}(n s)$ \\
\hline \hline TFE & 7.7234 & 0.3162 & 21.9335 & 0.131 & 0.019 & 0.001 & 7.980 \\
DMSO & 7.7932 & 6.0352 & 0.2941 & 0.083 & 0.049 & 0.021 & 7.196 \\
Acetonitrila & 4.3405 & 0.3643 & - & 0.195 & 0.017 & - & 4.298 \\
Metanol & 2.0021 & 7.3328 & - & 0.002 & 0.005 & - & 2.575 \\
Benzeno & 2.4298 & 0.4486 & 8.4507 & 0.132 & 0.025 & 0.003 & 2.767 \\
Dioxano & 9.3975 & 5.0744 & - & 0.017 & 0.013 & - & 9.127 \\
Etanol & 6.8436 & 2.1743 & - & 0.152 & 0.008 & - & 6.753 \\
Hepes & 7.3956 & 0.4027 & - & 0.005 & 0.021 & - & 7.322 \\
Clorofórmio & 2.552 & 0.5989 & - & 0.144 & 0.012 & - & 2.511 \\
\hline
\end{tabular}

Tabela 4.5. Parâmetros ajustados para as curvas de decaimento multi-exponencial do $\mathrm{Abz}-\mathrm{N}(\mathrm{CH} 3)_{2}$, em diversos solventes.

Os tempos médios foram calculados utilizando-se a seguinte expressão:

$$
\tau_{\text {medio }}=\frac{\sum_{i} B_{i} \tau_{i}^{2}}{\sum_{i} B_{i} \tau_{i}}
$$




\begin{tabular}{cccccccc}
\hline Abz-N(CH3)2 & $\tau_{1}(n s)$ & $\tau_{2}(n s)$ & $\tau_{3}(n s)$ & $B 1$ & $B 2$ & $B 3$ & $\tau_{\text {medio }}(n s)$ \\
\hline \hline TFE & 1.647 & 6.7231 & - & 0.155 & 0.002 & - & 1.901 \\
Dmso & 0.6352 & 7.5139 & - & 0.001 & 0.002 & - & 1.380 \\
Acetonitrila & 0.1211 & 4.083 & - & 0.276 & 0.003 & - & 1.184 \\
Metanol & 1.9991 & 7.4327 & - & 0.152 & 0.004 & - & 2.483 \\
Benzeno & 0.0586 & 1.6856 & 8.2778 & 0.584 & 0.017 & 0.001 & 1.670 \\
Dioxano & 0.0577 & 2.1185 & 8.228 & 2.005 & 0.006 & 0.002 & 1.167 \\
Etanol & 2.1889 & 0.2391 & 6.0787 & 0.131 & 0.030 & 0.001 & 2.221 \\
Hepes & 0.2681 & 7.3611 & - & 0.197 & 0.004 & - & 2.807 \\
Clorofórmio & 0.0995 & 0.9272 & 3.0434 & 0.658 & 0.011 & 0.002 & 0.422 \\
\hline
\end{tabular}

Tabela 4.6. Parâmetros ajustados para as curvas de decaimento multi-exponencial do Abz-NH(CH3), em diversos solventes.

Embora não seja possível verificar uma relação funcional entre os tempos de vida médio e a polaridade dos solventes, percebe-se a clara tendência a tempos menores, próximos a 2 ns, na espécie com duas metilas $\mathrm{Abz}-\mathrm{N}\left(\mathrm{CH}_{3}\right)_{2}$. A esse fato se relaciona diretamente a forte supressão observada nos espectros de fluorescência estática. Já oAbz- $\mathrm{NH}_{2}$ e o $\mathrm{Abz}-\mathrm{NH}\left(\mathrm{CH}_{3}\right)$ na maioria dos solventes apresentaram tempos próximos a 7 ns, à exceção do dioxano, onde os tempos se mostraram mais longos e em acetonitrila e benzeno estiveram mais curtos.

Todos os resultados apresentados nesta seção mostram claramente uma grande alteração no comportamento fluorescente do o-Abz quando ligado a dois grupos metilas. Nos efeitos gerais, provocados apenas pela variação de polaridade do solvente estudado pela equação de Lippert Mataga, observaram-se sempre aumentos nos deslocamentos de Stokes diante de solventes mais polares. Tal fato sugere que o momento de dipolo no estado excitado é maior do que no estado fundamental [59], o que é condizente com o comportamento do o-Abz estudado isoladamente (cf. [8]). No entanto, foi observada uma acentuada queda na intensidade da fluorescência do composto $\mathrm{Abz}-\mathrm{N}\left(\mathrm{CH}_{3}\right)_{2}$, que possui dois grupos metila ligados no terminal carboxílico. A diminuição do tempo de vida $\tau$ (tabela 4.10), consistente com o baixo rendimento quântico, mostra que 


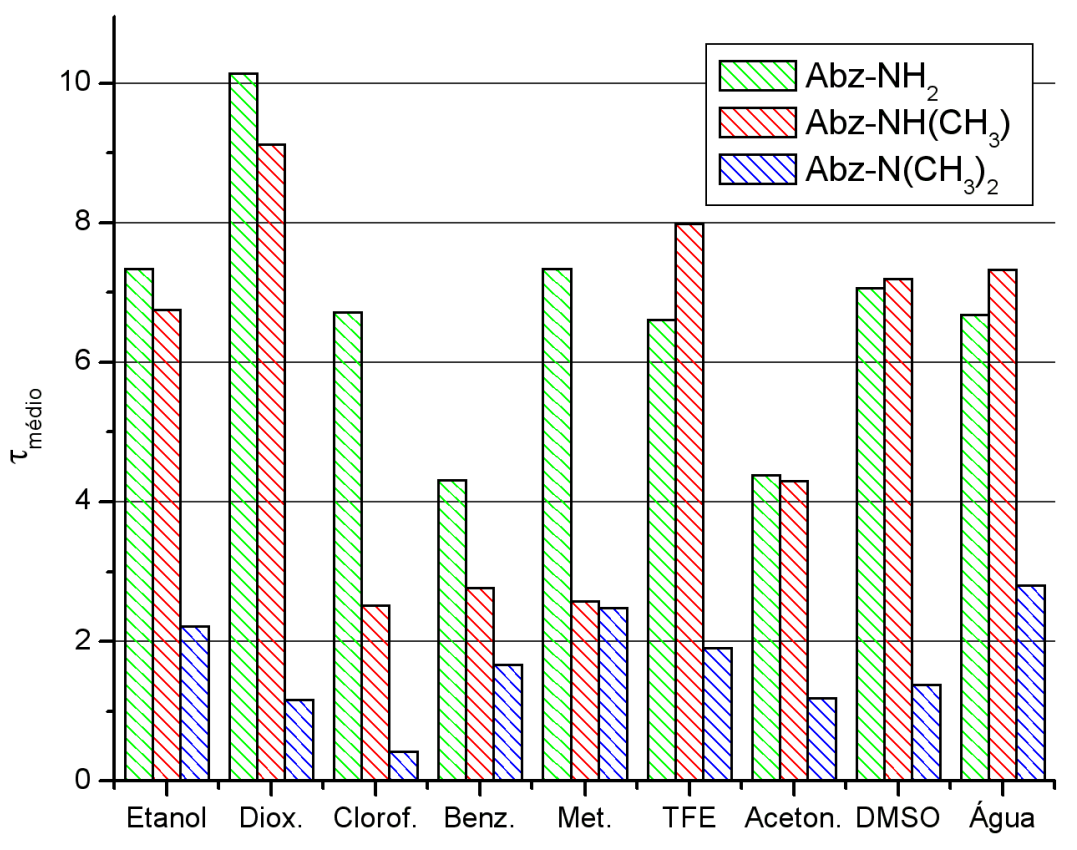

Figura 4.10. Tempos de vida médio dos Derivados do o-Abz.

a presença dos grupos metila, de alguma forma pode estar favorecendo a desexcitação da molécula por vias não radiativas. Esta possibilidade é reforçada pelo fato de terem sido verificados valores menores nos cálculos das forças de oscilador do $\mathrm{Abz}-\mathrm{N}\left(\mathrm{CH}_{3}\right)_{2}$, conforme veremos mais adiante na seção 4.4 e uma vez que as forças são proporcionais às taxas de excitação (eq. 2.7), de acordo com a equação 2.9 estas forças deveria apresentar valores maiores quando comparado a dos outros derivados. Assim, o tempo de vida curto do estado excitado deve ser atribuído a outros fatores que não o próprio decaimento radiativo, conforme nos indica a equação 2.11 .

Percebeu-se também que a presença das metilas tendem a aumentar a diferença entre os momentos de dipolos do estado excitado para o fundamental. Já em relação aos efeitos específicos, as possíveis ligações de hidrogênio formadas 
entre solventes e amostras ocasionaram deslocamentos para o azul nos comprimentos de onda nos máximos de absorção e para o vermelho nos da emissão fluorescente. As ligações de hidrogênio devem de alguma forma alterar a rigidez estrutural da molécula fluorescente, estabilizando os estados fundamentais e assim, deslocar os niveis de energia.

É necessário observar que no modelo de Lippert-Mataga, tal qual foi utilizado, não se levou em consideração o fato de que os momentos de dipolo nos estados fundamental e excitado nem sempre são na mesma direção. O modelo de Lippert prevê uma correção [24], onde é necessário conhecer o ângulo formado entre os momentos de dipolos nos estados fundamental e excitado. No presente trabalho optou-se por fazer a aproximação, ainda que grosseira, de igualar esse ângulo a zero, pois o objetivo da análise é mais qualitativo do que quantitativo.

\section{Efeitos de pH nos espectros de absorção óptica e emissão fluorescente}

Uma verificação clara da ocorrência de efeitos específicos de interação com o solvente vem de experimentos envolvendo a variação de $\mathrm{pH}$ do meio. O o-Abz, quando isolado tende a apresentar protonações nos seus grupos amina e ácido carboxílico por volta dos pH's 4,5 e 1,9, respectivamente [8]. Entretanto, nos derivados a ligação das metilas se dá através do grupo ácido carboxílico e logo não deve ser observada a protonação neste mesmo grupo, mas somente no grupo amina. Medidas de absorção ótica e fluorescência estática envolvendo os derivados do o- $\mathrm{Abz}, \mathrm{Abz}-\mathrm{NH}\left(\mathrm{CH}_{3}\right)$ e $\mathrm{Abz}-\mathrm{N}\left(\mathrm{CH}_{3}\right)_{2}$ foram realizadas sob diversos $\mathrm{pH}$ 's e assim foi feita a titulação do grupo amina.

As amostras foram diluídas sob a concentração aproximada de $\sim 5 \times 10^{-5} \mathrm{M}$ em $2 \mathrm{ml}$ de solução tampão Hepes $\left(10^{-2} M\right)$ e a variação de $\mathrm{pH}$ se deu através do acréscimo de pequenos volumes $(\sim 10 \mu l)$ de $\mathrm{HCl}(20 \mathrm{M})$ e $\mathrm{NaOH}(12 \mathrm{M})$. Sob a temperatura ambiente de $23^{\circ} \mathrm{C}$, o $\mathrm{pH}$ foi monitorado através de um $\mathrm{pH}$-meter 
Mettler Toledom 340, com um intervalo de cinco minutos para estabilização da amostra, entre uma mudança do pH até a obtenção das medidas.

Em pH neutro os comprimentos de onda nos máximos de absorção do $\mathrm{Abz}-\mathrm{NH}_{2}$, $\mathrm{Abz}-\mathrm{NH}\left(\mathrm{CH}_{3}\right)$ e do $\mathrm{Abz}-\mathrm{N}\left(\mathrm{CH}_{3}\right)_{2}$ ficaram em 318, 310 e $290 \mathrm{~nm}$, respectivamente (vide tabela 4.7 e figura4.11). Já na emissão fluorescente, os correspondentes máximos ficaram em 419, 414 e $430 \mathrm{~nm}$, levando ao aumento do deslocamento de Stokes com a presença das metilas nos derivados, como descrito anteriormente. Em resultados anteriores obtidos acerca de outros derivados do o-Abz, até então não haviam sido observados comprimentos de onda no máximo de absorção menores do que aquele verificado para o o-Abz isolado em $\mathrm{pH} \mathrm{7,4,}$ em $310 \mathrm{~nm}$.

\begin{tabular}{|c|c|c|}
\hline amostra & $\lambda_{\text {abs }}(\mathrm{nm})$ & $\lambda_{\text {fluor }}(\mathrm{nm})$ \\
\hline $\mathrm{o}-\mathrm{Abz}$ & 310 & 398 \\
\hline $\mathrm{Abz}-\mathrm{NH}_{2}$ & 318 & 419 \\
\hline $\mathrm{Abz}-\mathrm{NH}\left(\mathrm{CH}_{3}\right)$ & 310 & 414 \\
\hline $\mathrm{Abz}-\mathrm{N}\left(\mathrm{CH}_{3}\right)_{2}$ & 290 & 430 \\
\hline
\end{tabular}

Tabela 4.7. Comprimentos de onda nos máximos de absorção e emissão fluorescente medidos em pH 7,4. Nos demais valores de pH não foram observadas variações significativas.

Quando forma ligação com outros compostos através do terminal carboxílico sob as mesmas condições, o o-Abz tende a apresentar um deslocamento para o vermelho no seu máximo de absorção, ficando por volta de $318 \mathrm{~nm}$ ou mais, como no caso dos compostos com aminoácidos [4]. Dos três derivados, o $\mathrm{Abz}-\mathrm{NH}_{2}$, que não possue metilas, foi o que apresentou um comportamento próximo a este. 


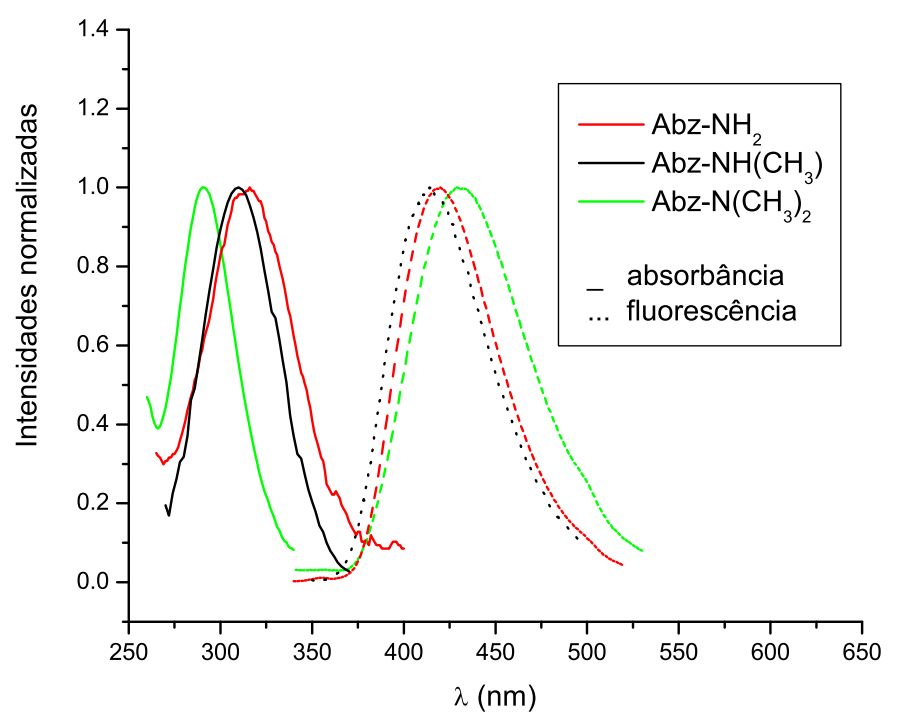

Figura 4.11. Espectros normalizados de absorção óptica e emissão fluorescente dos compostos $\mathrm{Abz}-\mathrm{NH}_{2}, \mathrm{Abz}-\mathrm{NH}\left(\mathrm{CH}_{3}\right)$ e $\mathrm{Abz}-\mathrm{N}\left(\mathrm{CH}_{3}\right)_{2}$.

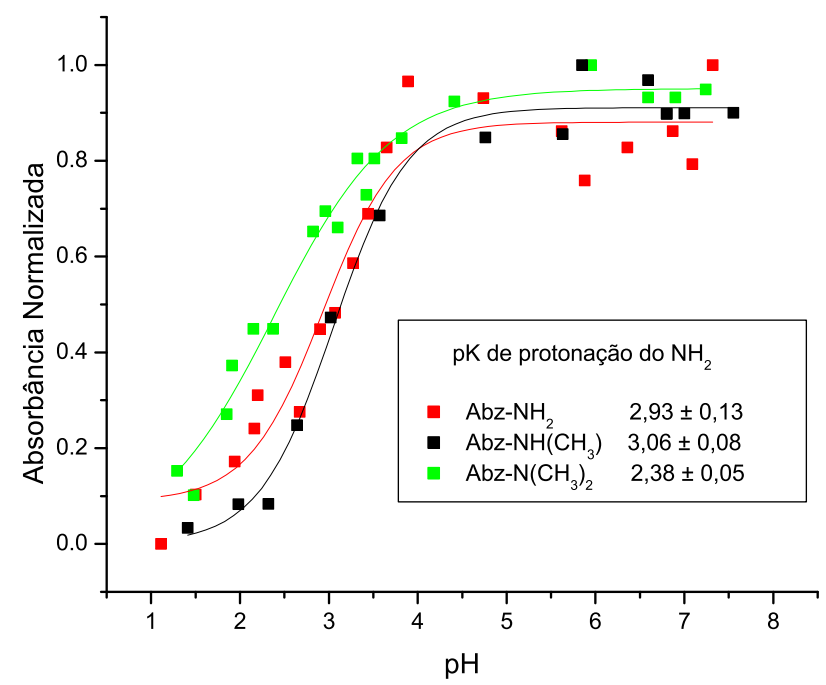

Figura 4.12. Absorbâncias do $\mathrm{Abz}-\mathrm{NH}_{2}, \mathrm{Abz}-\mathrm{NH}\left(\mathrm{CH}_{3}\right)$ e $\mathrm{Abz}-\mathrm{N}\left(\mathrm{CH}_{3}\right)_{2}$ versus $\mathrm{pH}$.

As principais mudanças se deram nos parâmetros relacionados às taxas de excitação e decaimento, tais como as intensidades, tanto as de absorção como 
as de emissão fluorescente. As figuras 4.12 a 4.13 nos mostram as intensidades medidas nos máximos de absorção e de emissão fluorescente, ante a variação do pH das soluções. Não se observaram mudanças significativas nos comprimentos de onda. Porém, quando em pH’s baixos, verifica-se em ambos os derivados a diminuição nas intensidades de absorção ótica e emissão fluorescente.

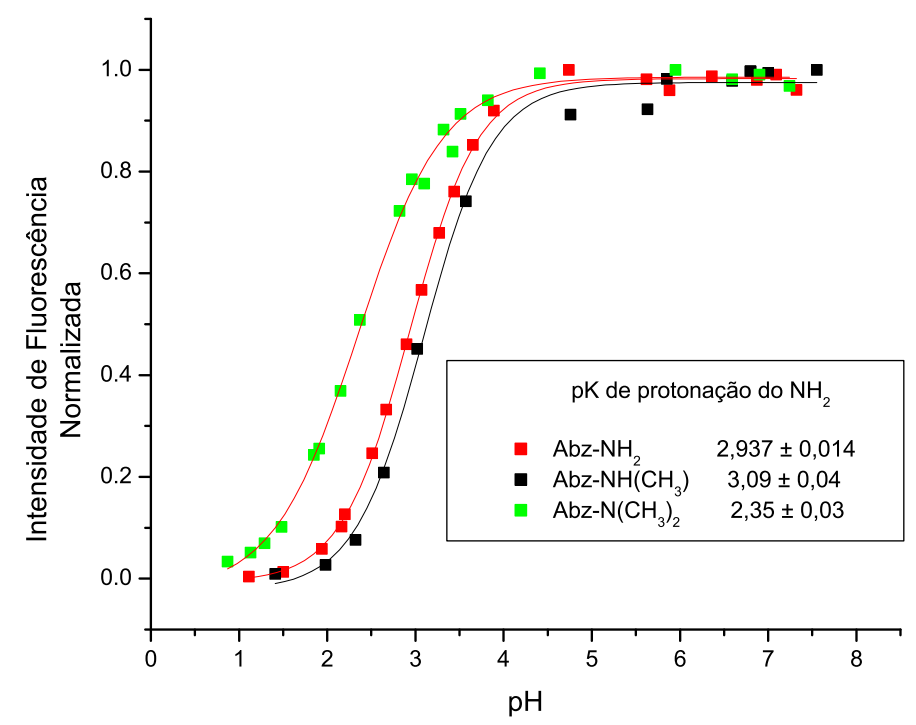

Figura 4.13. Intensidades de fluorescência do $\mathrm{Abz}-\mathrm{NH}_{2}, \mathrm{Abz}-\mathrm{NH}\left(\mathrm{CH}_{3}\right)$ e $\mathrm{Abz}-\mathrm{N}\left(\mathrm{CH}_{3}\right)_{2}$ versus pH.

\begin{tabular}{ccccc} 
& $\mathrm{o}-\mathrm{Abz}$ & $\mathrm{Abz}-\mathrm{NH}_{2}$ & $\mathrm{Abz}-\mathrm{NH}\left(\mathrm{CH}_{3}\right)$ & $\mathrm{Abz}-\mathrm{N}\left(\mathrm{CH}_{3}\right)_{2}$ \\
\hline \hline $\mathrm{pK}$ & $4,5^{*}$ & $2,93 \pm 0,07$ & $3,07 \pm 0,04$ & $2,37 \pm 0,03$ \\
& $1,9 * *$ & & & \\
\hline
\end{tabular}

Tabela 4.8. Valores de $p K$ de protonação do $\mathrm{NH}_{2}$. Somente o-Abz: *NH2 , ${ }^{* * C O O}$.

Na tabela 4.8 verifica-se um valor das constantes de protonação dos agrupamentos amina próximo de 3 para os derivados $\mathrm{Abz}-\mathrm{NH}_{2}$ e $\mathrm{Abz}-\mathrm{NH}\left(\mathrm{CH}_{3}\right)$, o que nos mostra uma maior afinidade por prótons do composto aminado destes em relação ao $\mathrm{Abz}-\mathrm{N}\left(\mathrm{CH}_{3}\right)_{2}$, que apresentou pK por volta de 2,4. Para efeitos de comparação, acrescentamos também os pK's de protonação dos grupos amina 
ácido carboxílico do o-Abz isolado. Como o o-Abz tem caráter ácido, o oxigênio da carboxila está na forma desprotonada em pH's maiores que 1,9. A carga negativa na carboxila tende a criar uma afinidade local por prótons, fazendo com que o grupo amina permaneça protonado em valores de $\mathrm{pH}$ abaixo de 4,5. Já nos derivados, por não haver a presença de uma carga negativa, essa afinidade pelos prótons é menor, e torna-se necessária uma concentração maior de prótons para que o grupo $\mathrm{NH}_{2}$ seja protonado, diminuindo o valor de pK. Essa sensibilidade da atividade fluorescente do o-Abz, mesmo quando ligado às outras moléculas faz dela uma interessante sonda no monitoramento de variações de pH local. Quando ligado a uma molécula anfifilica por exemplo [7], o o-Abz se mostra uma boa sonda fluorescente na medição de $\mathrm{pH}$ local na superfície de uma membrana de uma célula.

\subsection{Polarização da fluorescência do o-Abz: determinação de volume molecular}

Nesta seção, examinamos propriedades de anisotropia de fluorescência do o-Abz. Através da equação de Perrin é possível obter informações acerca da molécula em estudo, como o seu volume. Podemos variar a viscosidade de um meio aquoso através do acréscimo de glicerina à água. Foram preparadas amostras de abz isolada e ligada à bradicinina, em concentrações por volta de $10^{-5} \mathrm{M}$, aos quais foram sendo acrescentados diferentes volumes de glicerina. O decaimento da anisotropia, é obtido a partir da equação 2.23 , onde consideramos as intensidades I como dependentes do tempo, i.e. I=I(t). Assim,

$$
r(t)=\frac{I_{\|}(t)-I_{\perp}(t)}{I_{\|}(t)+2 I_{\perp}(t)}
$$

onde as curvas de decaimentos são medidas para cada uma das quatro combinações de ajustes dos polarizadores. Na polarização do feixe de fluorescência 
foi usado um polarizador de filtro polaróide, enquanto na entrada do feixe de excitação foi utilizado um compensador de polarização "Soleil Babinet", que permite polarizar o feixe do laser, sem que haja o processo de "filtragem", com perdas menores por atenuação.

\subsubsection{Abz em mistura água + glicerina}

O gráfico que se segue nos mostra o comportamento do decaimento temporal de anisotropia do o-Abz diluído em mistura de água e glicerina. As medidas de fluorescência temporal foram feitas excitando-se no comprimento de onda de 310 nm e tomando-se a emissão em 398 nm.

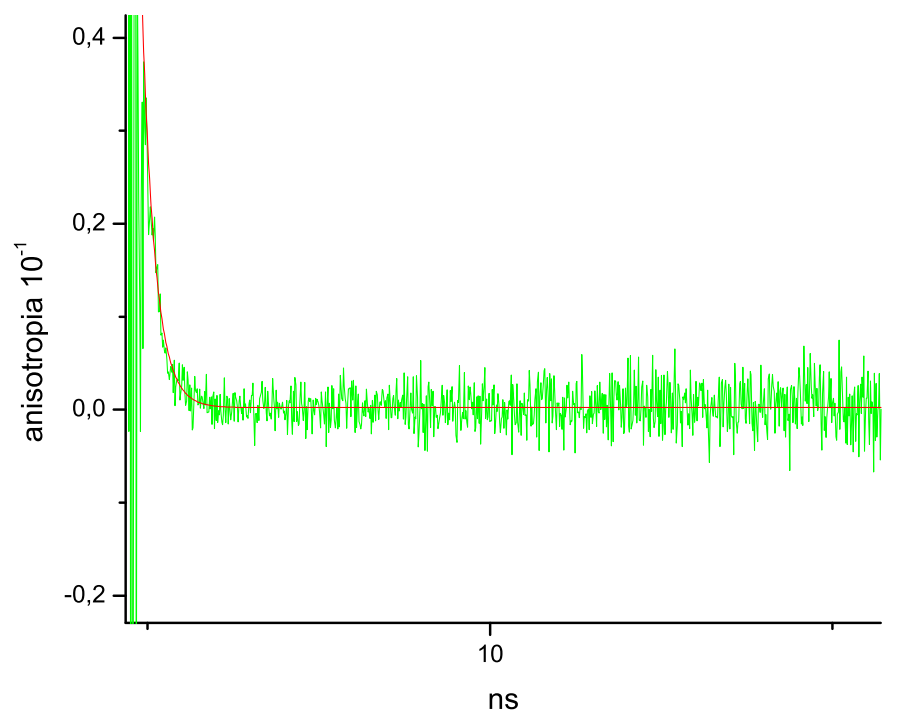

Figura 4.14. Decaimento resolvido no tempo da anisotropia do o-Abz em água e glicerina (20\%).

Através do próprio software de aquisição de dados do espectrofluorímetro é possível fazer o ajuste de uma função aos valores experimentais obtidos para o decaimento da anisotropia. São ajustados então os parâmetros da função que se segue, 


$$
r(t)=A+B_{1} e^{-t / \tau 1}+B_{2} e^{-t / \tau 2}+B_{3} e^{-t / \tau 3}+B_{4} e^{-t / \tau 4} \cdots
$$

Tendo se um valor de A próximo de zero, e observando-se um único tempo de decaimento, podemos associar os parâmetros ajustados $B_{1}$ e $\tau_{1}$ a $r_{0}$ e $\theta$, respectivamente, na equação de Perrin,

$$
r(t)=r_{0} e^{-t / \theta}
$$

onde $r_{0}$ corresponde a anisotropia fundamental e $\theta$ ao tempo de correlação rotacional. $\mathrm{O}$ valor de $\theta$ permite que se obtenha o volume $\mathrm{V}$ da molécula em estudo, neste caso o Abz, a partir do ajuste de uma reta $\theta$ versus $\eta$ ( vide figura 4.15 ) , sendo este último a viscosidade do solvente.

O mesmo tipo de medida foi obtido ainda para outras diferentes proporções de água e glicerina. A partir de dados obtidos na literatura [46], foi elaborada uma curva de calibração da qual foram extraídos os valores da viscosidade correspondente a cada diferente proporção de água e glicerina, considerando-se a temperatura ambiente de $293 \mathrm{~K}$. 


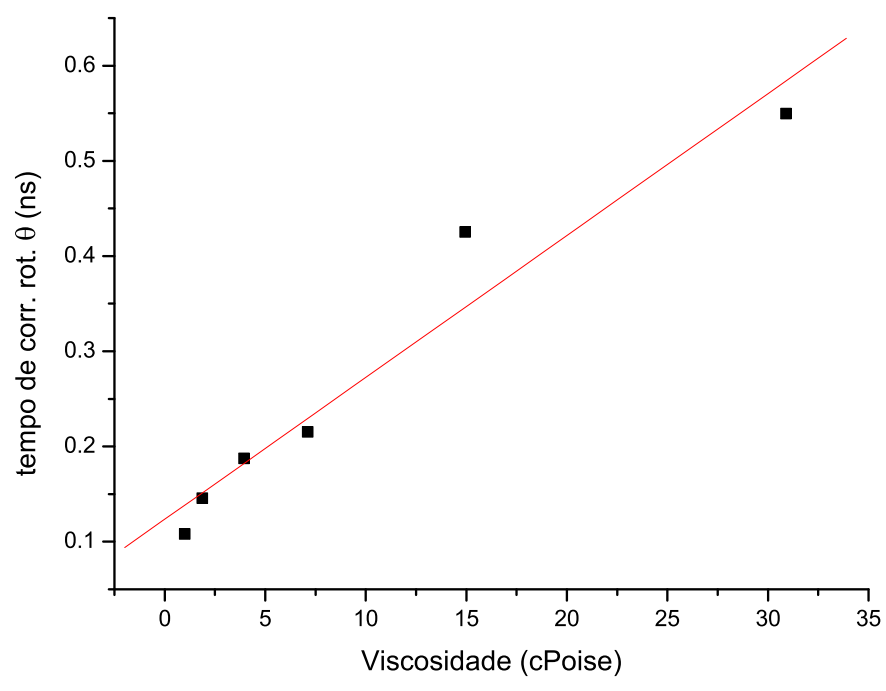

Figura 4.15. Tempo de correlação rotacional $\theta$ versus viscosidade $\eta$ do Abz.

Do ajuste de reta $y=$ ax a tais pontos, obtemos o seguinte coeficiente angular:

$$
a=\frac{V}{R T}=0,00149 \text { ns } / \text { mPoise }
$$

Sendo conhecidos R (8,31x107 erg/(K*mol)) e T (295 K), podemos então calcular o volume molar do Abz, e dividindo pelo número de Avogadro, o volume de uma molécula:

$$
\mathrm{V}=60,7 \AA^{3}
$$

Como tal volume leva em consideração a aproximação do volume por um esfera, podemos obter o raio aproximado da molécula:

$$
\mathrm{r}=2,4 \AA
$$

Tal valor nos mostra a validade do modelo, pois permite observar boa concordância dos valores de raio obtidos pela equação de Perrin, em relação aos valores previstos (Mataga, 1963) já apresentados na literatura: 


\subsubsection{Abz-Bradicinina em mistura água + glicerina}

A bradicinina é um hormônio com seqüência Arg-Pro-Pro-Gly-Phe-Ser-Pro-Phe-Arg. Presente em fluídos do corpo humano, envolve-se em vários processos fisiológicos, como vasodilatação, inflamação e dor [47, 49, 50].

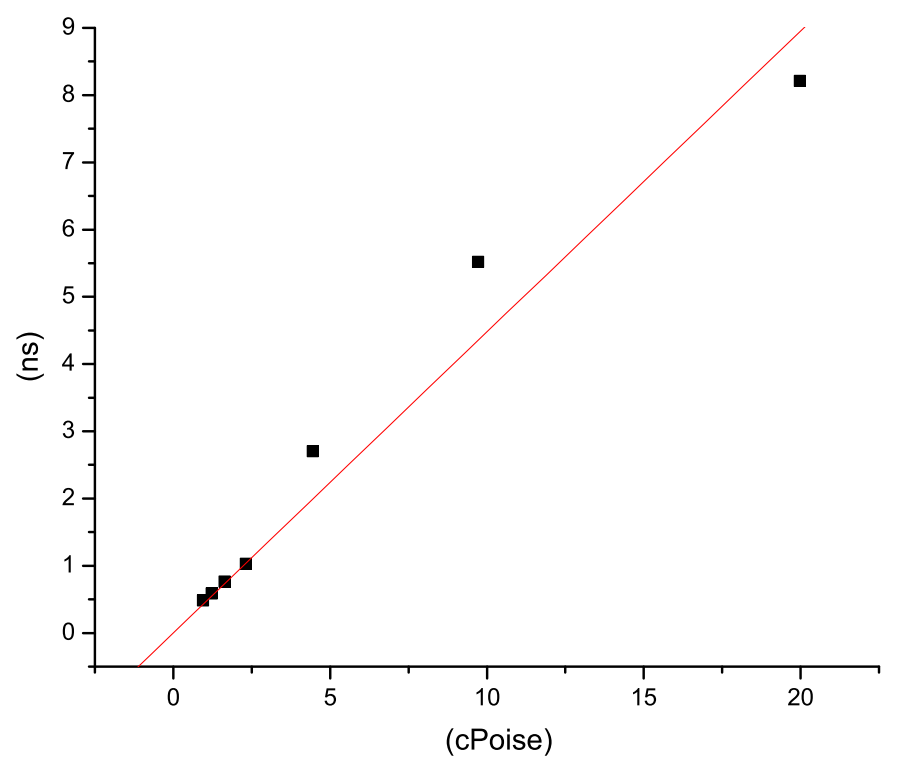

Figura 4.16. Tempo de correlação rotacional $\theta$ versus viscosidade $\eta$ do Abz-Bk.

Sob o mesmo tipo de mistura de solventes água e glicerina é refeita a experiência, desta vez com o Abz-Bk no lugar do Abz isolado. O comprimento de onda da excitação foi ajustado para $330 \mathrm{~nm}$ e a emissão foi tomada em $420 \mathrm{~nm}$. O gráfico da figura 4.16 nos mostra os resultados obtidos para a plotagem de $\theta$ versus $\eta$.

A bradicinina apresenta um volume maior do que o do Abz, e isso deve se traduzir em movimentos rotacionais bem mais lentos do que a deste. Isso pode ser claramente observado nos tempos de correlação rotacional do Abz-Bk, bem maiores do que aqueles obtidos para o $\mathrm{Abz}$ isolado. Entretanto, é necessário fazer algumas ressalvas quanto aos valores obtidos para as diferentes misturas 
de água e glicerina, pois tais variações podem estar causando alterações nas propriedades do solvente capazes de alterar a forma estrutural da bradicinina e conseqüentemente o volume. O volume e respectivo raio obtido para o Abz-Bk se acham na tabela que se segue.

\begin{tabular}{cccc}
\hline Amostra & Volume $\left(\AA^{3}\right)$ & Raio $(\AA ̊)$ & Raio comparativo $(\AA)$ \\
\hline \hline o-Abz & 60,7 & 2,4 & $3,0^{*}$ \\
\hline Abz-Bk & 1823,4 & 7,6 & $7,35^{* *}$ \\
\hline
\end{tabular}

Tabela 4.9. Resultados comparativos do Abz-Bk e Abz isolado. * Mataga, 1963. ** Souza et al, 1999.

Fazendo-se a aproximação da molécula da bradicinina por uma esfera, obtém-se o raio de 7,58 Angstroms, o que corresponde a um diâmetro de 15,16 Angstroms. Tal valor é próximo de uma das distâncias $(14,7 \mathrm{~A})$ entre os terminais da molécula de bradicinina observada por meio do modelo de transferência de energia de ressonância de Forster [6]. Neste trabalho, aos terminais da bradicinina foram ligados o abz como doador e o EDDnp como aceitador, e tendo por solvente tampão fosfato com pH 7,4. Outras distâncias também foram observadas para este peptídeo, sendo elas 10,3 Å e 19,0 Å. Deve-se observar no entanto, que enquanto o modelo da transferência de energia (FRET) lida com as distâncias entre os terminais de uma molécula sem fazer qualquer menção quanto à forma do volume, a equação de Perrin assume tal volume como sendo esférico.

\subsubsection{Abz ligado a aminoácidos}

O mesmo tipo de experimento foi repetido ainda para o Abz ligado aos aminoácidos leucina e fenilalanina (figura 4.17). As figuras 4.18 e 4.19 a seguir apresentam os gráficos contendo os tempos de correlação rotacional em função da viscosidade, obtidos para tais amostras. 


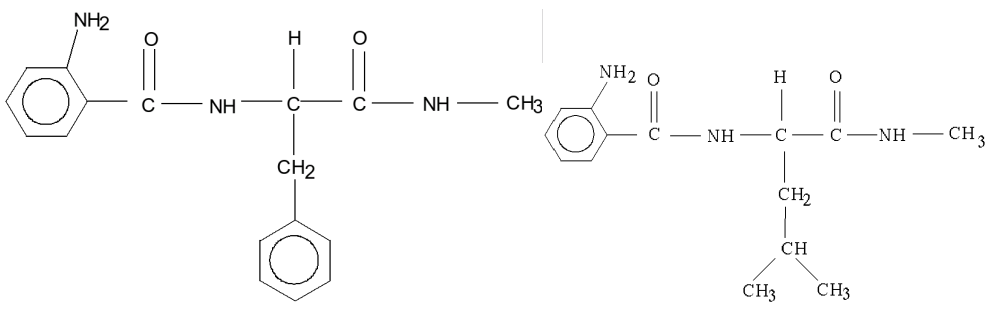

Figura 4.17. $\mathrm{Abz}-\mathrm{Phe}-\mathrm{NH}\left(\mathrm{CH}_{3}\right)$ e $\mathrm{Abz}-\mathrm{Leu}-\mathrm{NH}\left(\mathrm{CH}_{3}\right)$.

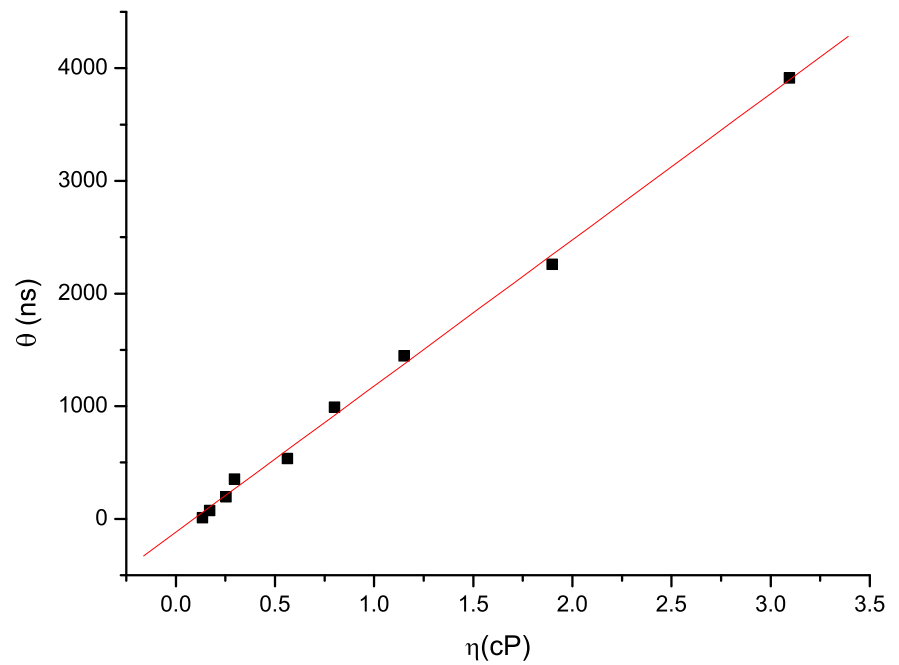

Figura 4.18. Tempo de correlação rotacional $\theta$ versus viscosidade $\eta$ do $\mathrm{Abz}-\mathrm{Phe}-\mathrm{NH}\left(\mathrm{CH}_{3}\right)$. 


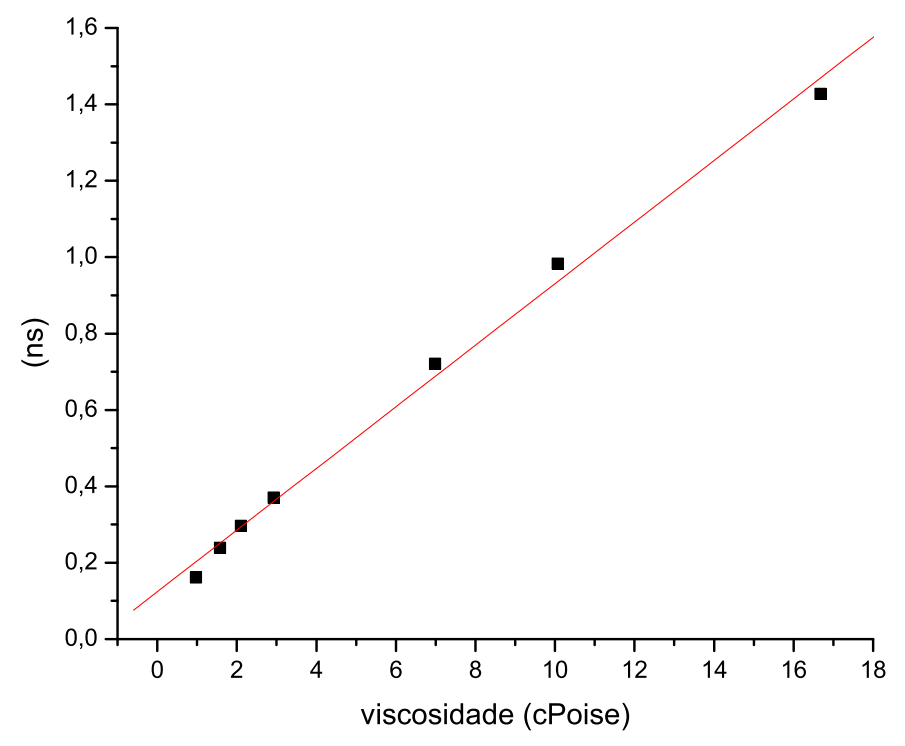

Figura 4.19. Tempo de correlação rotacional $\theta$ versus viscosidade $\eta$ do Abz-Leu-NH(CH3).

Aplicando-se o mesmos procedimentos apresentados anteriormente, obteve-se os seguintes resultados:

\begin{tabular}{ccc}
\hline Amostra & Volume $\left(\AA^{3}\right)$ & Raio ( $(\AA)$ \\
\hline \hline Abz-Phe- $\mathrm{NH}\left(\mathrm{CH}_{3}\right)$ & 328,4 & 4,28 \\
\hline $\mathrm{Abz}-\mathrm{Leu}-\mathrm{NH}\left(\mathrm{CH}_{3}\right)$ & 302,0 & 4,16 \\
\hline
\end{tabular}

Tabela 4.10. Resultados comparativos do Abz-Phe e Abz-Leu.

A semelhança entre as estruturas do $\mathrm{Abz}-\mathrm{Phe}-\mathrm{NH}\left(\mathrm{CH}_{3}\right)$ e do $\mathrm{Abz}-\mathrm{Leu}-\mathrm{NH}\left(\mathrm{CH}_{3}\right)$ nos sugere que as duas moléculas possuam dimensões muito próximas, o que pode ser verificado nos resultados obtidos na tabela 4.10. Observa-se também, a coerência em relação aos valores obtidos anteriormente, pois ambas as moléculas apresentam dimensões maiores do que aquelas obtidas para o o-Abz isolado e muito menores do que as da bradicinina, que se constitui de 9 aminoácidos. As diferenças entre os dois compostos devem estar relacionadas aos arranjos 
espaciais distintos que as moléculas podem assumir em vista das diferenças entre os grupos laterais da Phe e da Leu.

Os resultados obtidos permitiram observar uma boa proximidade dos valores experimentais em relação àqueles previstos teoricamente, ou calculados por outros modelos. Isso mostra a validade do modelo utilizado, baseado na equação de Perrin ao permitir determinar dimensões aproximadas de moléculas. É importante observarmos também que ao variarmos a mistura de água e glicerina, podemos estar alterando certas propriedades do solvente, tais como o $\mathrm{pH}$ e o caráter prótico. Tais fatores exercem uma importância muito grande, pois pode inibir a formação de ligações de hidrogênio intermoleculares responsáveis pela forma estrutural da molécula e conseqüentemente da sua dimensão.

\subsection{Cálculos ab-initio}

\subsubsection{Otimização de estrutura do o-Abz e seus derivados}

O o-Abz, por possuir os grupo amina e ácido carboxílico tal qual os aminoácidos [10, 51], apresenta um caráter de protonações semelhante. Conforme já observado experimentalmente através de experimentos de titulação [8] como os da seção 4.1.2, quando se encontra em um em solvente aquoso, o-Abz apresenta protonações nos grupos amina e ácido carboxílico nos pH's abaixo de 4,5 e 1,9, respectivamente. Assim, estes dois pK's separam três intervalos de pH's onde prevalecem configurações diferentes quanto às protonações, que são caracterizadas na figura 4.20. Na tentativa de se reproduzir os efeitos de pH sobre o o-Abz em água, todas as diferentes configurações de protonações do o-Abz foram otimizadas através de cálculos ab-initio, através da Teoria do Funcional de Densidade (DFT), onde se utilizou o método B3LYP e base 6-311-G+(d), implementados no pacote de programas Gaussian 03 [52]. Da mesma forma também 
foram otimizados os rotâmeros das formas neutras, entendendo-se que tal forma deve se manifestar em um solvente não aquoso ou no vácuo.

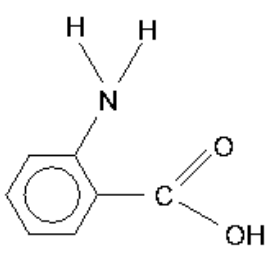

neutro

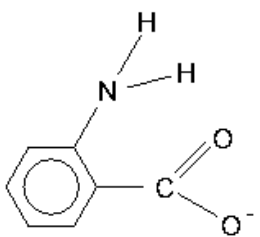

aniônico

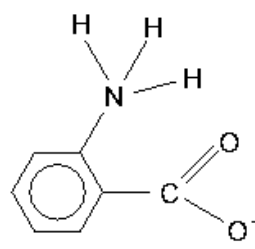

zwiteriônico

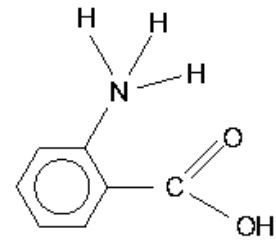

catiônico

Figura 4.20. Estados de protonação do o-Abz.

Nas conformações neutra e catiônica, o o-Abz apresenta dois rotâmeros devido à rotação do grupo ácido carboxílico (isômeros I e II) . A forma aniônica apresenta uma simetria no seu grupo ácido indiferente à rotação e portanto não possui outra forma isomérica. Já a forma zwitteriônica, por sua vez tende a assumir uma configuração onde um dos três hidrogênios do grupamento amina forma uma poderosa ligação intramolecular com um dos átomos de Oxigênio do grupo ácido, cuja distância é próxima às das ligações covalentes nas formas normal e catiônica (distâncias $\mathrm{R}(\mathrm{O}-\mathrm{H})$ na tabela 4.12). O que a primeira vista pode parecer uma configuração neutra como a dos outros dois isômeros é na verdade uma molécula com acentuado momento de dipolo, por volta de $7 \mathrm{D}$, valor comparável às das moléculas carregadas. Na tabela

\begin{tabular}{ccccccc}
\hline & Neutro(I) & Neutro(II) & Zwiteriônico & aniônico & catiônico(I) & catiônico(II) \\
\hline$\Delta \mathrm{E}(\mathrm{kcal} / \mathrm{mol})$ & 0 & 2,60 & 8,59 & 341,49 & $-219,90$ & $-214,08$ \\
$\mu(\mathrm{D})$ & 1,33 & 3,27 & 7,08 & 8,38 & 4,65 & 7,65 \\
\hline
\end{tabular}

Tabela 4.11. Diferentes formas protonadas do o-Abz e seus isômeros.

A tabela 4.12 resume as distâncias e os ângulos mais relevantes que envolvem o grupo amina e o grupo ácido carboxílico. Com exceção da forma zwitteriônica, observamos a tendência dos grupos ácido carboxílico e amina em perma- 
necer no mesmo plano do anel aromático, conferindo à molécula uma forma planar. Na tabela 4.11, onde tomamos o o-Abz como referência, verificamos que a energia interna das moléculas tende a diminuir, seguindo a seqüência aniônica, zwitteriônica e catiônica. Embora tais otimizações sejam feitas para a molécula no vácuo, contabilizam os efeitos do $\mathrm{pH}$ da água. Nos momentos de dipolo, observamos os maiores valores nas formas carregadas, onde as formas aniônica e catiônica apresentam módulos maiores do que a espécie zwitteriônica. Embora tal fato possa parecer contraditório, devemos entender que a separação entre as cargas é pequena, pois se dá entre os grupos que ocupam posições adjacentes no anel aromático e o hidrogênio extra do grupo amina chega a estabelecer uma ligação intramolecular com o oxigênio desprotonado do ácido carboxílico.

\begin{tabular}{ccccccc}
\hline$R(\AA) / \theta\left({ }^{\circ}\right)$ & Neutro(I) & Neutro(II) & zwitteriônico & aniônico & catiônico(I) & catiônico(II) \\
\hline \hline $\mathrm{R}(\mathrm{C}=\mathrm{O})$ & 1,222 & 1,211 & 1,207 & 1,247 & 1,226 & 1,193 \\
$\mathrm{R}(\mathrm{C}-\mathrm{O})$ & 1,359 & 1,373 & 1,337 & 1,268 & 1,323 & 1,380 \\
$\mathrm{R}(\mathrm{O}-\mathrm{H})$ & 0,969 & 0,969 & 0,994 & - & 0,972 & 0,972 \\
$\mathrm{R}(\mathrm{C}-\mathrm{N})$ & 1,361 & 1,372 & 1,454 & 1,390 & 1,488 & 1,492 \\
$\Theta(\mathrm{C}-\mathrm{C}-\mathrm{N})$ & 122,449 & 123,989 & 119,484 & 120,926 & 119,052 & 120,869 \\
$\Theta(\mathrm{C}-\mathrm{C}=\mathrm{O})$ & 126,057 & 125,615 & 121,258 & 116,268 & 123,457 & 125,180 \\
$\Theta(\mathrm{C}-\mathrm{C}-\mathrm{O})$ & 113,886 & 114,614 & 117,175 & 116,255 & 113,917 & 113,064 \\
$\Theta(\mathrm{H}-\mathrm{N}-\mathrm{C}-\mathrm{C})$ & 0,000 & 13,119 & 119,924 & 15,316 & 0,020 & - \\
\hline
\end{tabular}

Tabela 4.12. Distâncias (R) e ângulos ( $\theta$ )internos obtidos para diferentes conformações protonadas e isoméricas do o-Abz.

Fazendo uso do mesmo método ab-initio, procedemos também aos cálculos de estrutura dos três derivados, cujos resultados são apresentados na tabela que se segue. Dentre os possíveis rotâmeros de cada derivado, consideramos aquelas que envolviam a rotação do plano formado pela carbonila e a amina. 


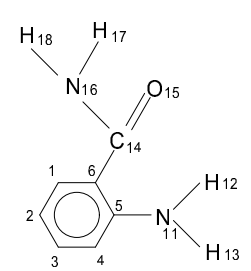

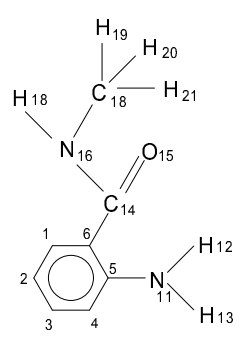

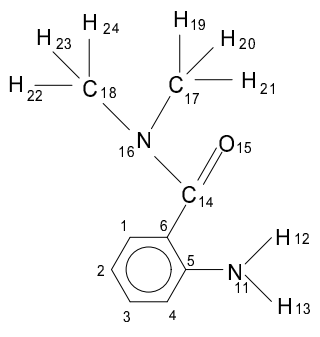

III

Figura 4.21. Derivados do o-Abz: $\mathrm{Abz}-\mathrm{NH}_{2}, \mathrm{Abz}-\mathrm{NH}\left(\mathrm{CH}_{3}\right)$ e $\mathrm{Abz}-\mathrm{N}\left(\mathrm{CH}_{3}\right)_{2}$.

\begin{tabular}{|c|c|c|c|c|c|c|}
\hline$R(\AA) / \theta\left({ }^{\circ}\right)$ & $\begin{array}{c}\mathrm{Abz}-\mathrm{NH}_{2} \\
\text { (I) }\end{array}$ & $\begin{array}{c}\mathrm{Abz}-\mathrm{NH}_{2} \\
\text { (II) }\end{array}$ & $\begin{array}{c}\mathrm{Abz}-\mathrm{NH}\left(\mathrm{CH}_{3}\right) \\
\text { (I) }\end{array}$ & $\begin{array}{c}\mathrm{Abz}-\mathrm{NH}\left(\mathrm{CH}_{3}\right) \\
\text { (II) }\end{array}$ & $\begin{array}{c}\mathrm{Abz}-\mathrm{N}\left(\mathrm{CH}_{3}\right)_{2} \\
\text { (I) }\end{array}$ & $\begin{array}{c}\mathrm{Abz}-\mathrm{N}\left(\mathrm{CH}_{3}\right)_{2} \\
\text { (II) }\end{array}$ \\
\hline$R(C 6-C 14)$ & 1,48 & 1,5 & 1,49 & 1,50 & 1,50 & 1,50 \\
\hline$R(C 14-O 15)$ & 1,23 & 1,22 & 1,23 & 1,22 & 1,23 & 1,22 \\
\hline$R(C 14-N 11)$ & 1,37 & 1,38 & 1,37 & 1,37 & 1,37 & 1,38 \\
\hline$R(C 5-N 11)$ & 1,37 & 1,40 & 1,38 & 1,37 & 1,38 & 1,39 \\
\hline$\theta(C 5-C 6-C 14)$ & 120,2 & 125,3 & 120,0 & 125,5 & 119,5 & 122,8 \\
\hline$\theta(O 15=C 14-N 16)$ & 119,9 & 120,9 & 120,4 & 121,4 & 120,9 & 121,3 \\
\hline$\theta(C 6-C 5-N 11)$ & 122,2 & 122,5 & 121,9 & 122,1 & 121,3 & 121,8 \\
\hline$\theta(C 5-C 6-C 14-N 16)$ & 161,57 & 22,9 & $-155,9$ & $-25,5$ & $-142,1$ & 55,5 \\
\hline$\theta(C 6-C 5-N 11-H 12)$ & 19,1 & 37,1 & $-21,7$ & $-41,7$ & $-29,4$ & $-19,9$ \\
\hline$\Delta \varepsilon(\mathrm{kcal} / \mathrm{mol})$ & 0 & 3,08 & 0 & 3,13 & 0 & 3,85 \\
\hline$\mu(\mathrm{D})$ & 2,03 & 4,22 & 1,98 & 4,28 & 2,16 & 4,75 \\
\hline
\end{tabular}

Tabela 4.13. Distâncias (R) e ângulos ( $\theta$ )internos obtidos para diferentes rotâmeros de derivados do o-Abz.

Da tabela 4.13, observamos que os rotâmeros de menor energia correspondem àquelas onde o oxigênio se encontra mais próximo da amina, tendo a diferença de energia entre eles se mantido por volta de $3 \sim 4 \mathrm{kcal} / \mathrm{mol}$. 


\subsection{Simulação de Monte Carlo do Espectro de absorção do o-Abz em água}

\subsubsection{Termalização e Equilíbrio}

A simulação de Monte Carlo para a obtenção das configurações soluto+solvente foi realizada através do programa DICE, cuja implementação já fora mostrada no capítulo anterior. Assim como o-Abz, a molécula individual da água também foi otimizada pelo método B3LYP/6-311G+(d). O processamento de todos os cálculos foi dividido entre três microcomputadores com processadores Intel Pentium IV, com sistema operacional Linux Debian, cujas configurações eram: 2GHz, 1Gbyte RAMBUS, HD 80Gbyte; 3,4GHz, 2Gbyte DDR400 dual channel, HD 250Gbytes sata150; 3,0 GHz, 2Gbyte DDR400 dual channel, HD 150Gbyte sata150. A partir das coordenadas xyz da configuração optimizada do o-Abz aniônico e da molécula da água, procedemos à montagem do arquivo de entrada para a simulação de Monte Carlo, no ensemble NPT. Dentre os parâmetros configurados, a pressão foi fixada em $1 \mathrm{~atm}$, a densidade em $1 \mathrm{~g} / \mathrm{cm}^{3}$, a temperatura em $300 \mathrm{~K}$ e o número total de moléculas em 401 (400 de $\mathrm{H}_{2} \mathrm{O}+1$ de o-Abz). Como o o-Abz apresenta um estado de desprotonação em seu grupo ácido carboxilíco quando em pH 7,4, adotamos a sua configuração aniônica. Utilizamos o potencial de interação (equação 3.59), onde os parâmetros $\sigma$ e $\varepsilon$ são extraídos do conjunto OPLS (Optmized Parameter for Liquid Simulation) elaborada pelo grupo de Jorgensen [53]. Já as cargas utilizadas pelo potencial de Coulomb são extraídas dos resultados dos cálculos de optimização ab-initio já mencionados.

No estágio inicial da simulação, as primeiras configurações geradas encontram-se fora do equilíbrio, com energia elevada, o que exige um processo de termalização. A fim de se acelerar o processo de equilíbrio, forçamos a redução de energia, num processo que consiste em tomar somente as configurações que diminuam 


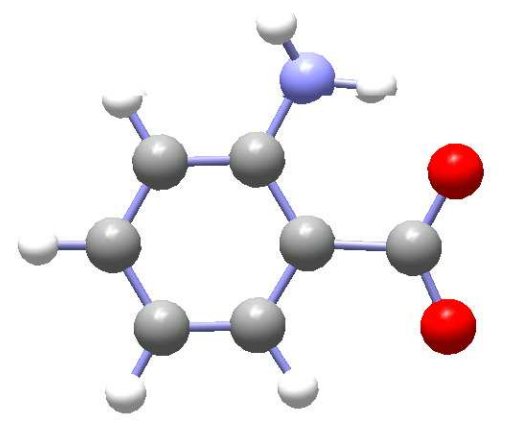

Figura 4.22. Estrutura optimizada do Ácido orto-Aminobenzóico obtida por B3LYP /6-311G+.

a energia em relação à anterior. Assim, sendo a energia da configuração dada por U:

$$
\begin{array}{ll}
U_{i+1}<U_{i} & \text { aceita } \\
U_{i+1} \geq U_{i} & \text { rejeita }
\end{array}
$$

Definimos o número de passos de resfriamento forçado como 150 e o número total para termalização como 30000, produto dos parâmetros vstep (3)e nstep (10000), que correspondem respectivamente aos números de tentativas de mudanças do volume e das coordenadas. Os gráficos que se seguem foram obtidos da interface gráfica Dicewin, que permite visualizar os resultados do DICE.

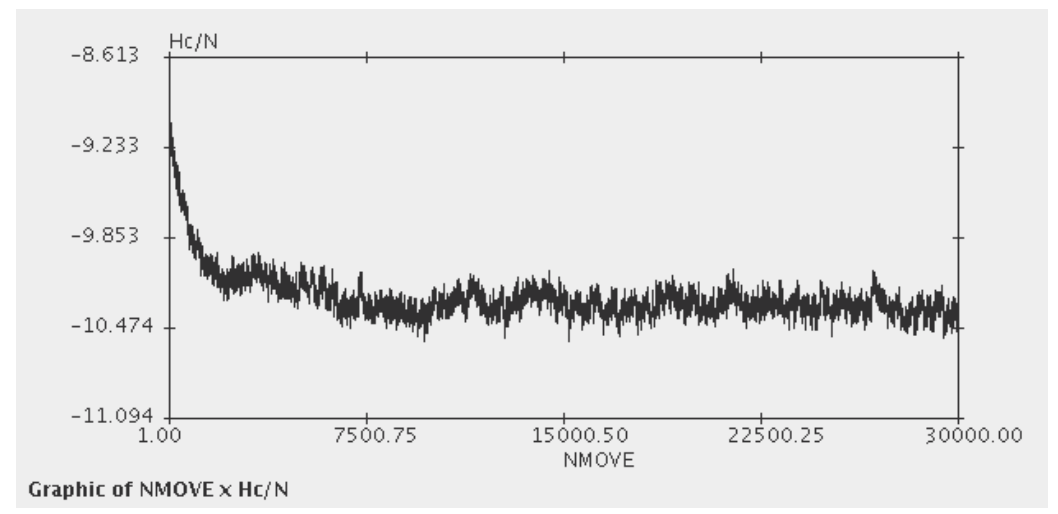

Figura 4.23. Termalização do o-Abz em água. Durante esta fase da simulação, somente as configurações que diminuem a energia são aceitas. 
Na figura 4.23, observamos que o equilíbrio é atingido após 7500 movimentos. Após este estágio inicial, passamos então para a fase de geração das configurações do sistema soluto+solvente, já no estágio de equilíbrio, através da Técnica de Amostragem de Metrópolis. Fixamos o número de passos para mudança de coordenadas nstep em 28000 e o número de tentativas de mudança de volume vstep em 3, totalizando um produto de 84000 movimentos. Entretanto, as configuração obtidas sempre tendem a apresentar fortes correlações em relação às configurações próximas, quanto ao número de movimentos. Faz se necessário então, definir um intervalo de movimentos entre as configurações, onde haja pouquíssima ou nenhuma correlação entre elas[54, 55]. Assim, através da equação de auto-correlação (equação 4.6), observamos o decaimento da auto-correlação da energia em relação ao número de configurações, e a esses pontos fazemos o ajuste de um função exponencial (equação 4.7), onde calculamos o "tempo" de decaimento $\tau$. Na verdade, não há nenhum tempo físico relacionado ao decaimento da correlação; $\tau$ corresponde ao número de configurações que precisamos gerar, afim de que não haja nenhuma correlação entre as configurações.

$$
\begin{gathered}
C(t)=\frac{\left\langle f_{i} f_{i+t}\right\rangle-\left\langle f_{i}\right\rangle\left\langle f_{i+t}\right\rangle}{\left\langle\delta f^{2}\right\rangle} \\
C(t)=\sum_{i}^{n} c_{i} e^{-t / \tau_{i}} \quad\left(\tau_{1}>\tau_{2}>\cdots>\tau_{n}>0\right) .
\end{gathered}
$$




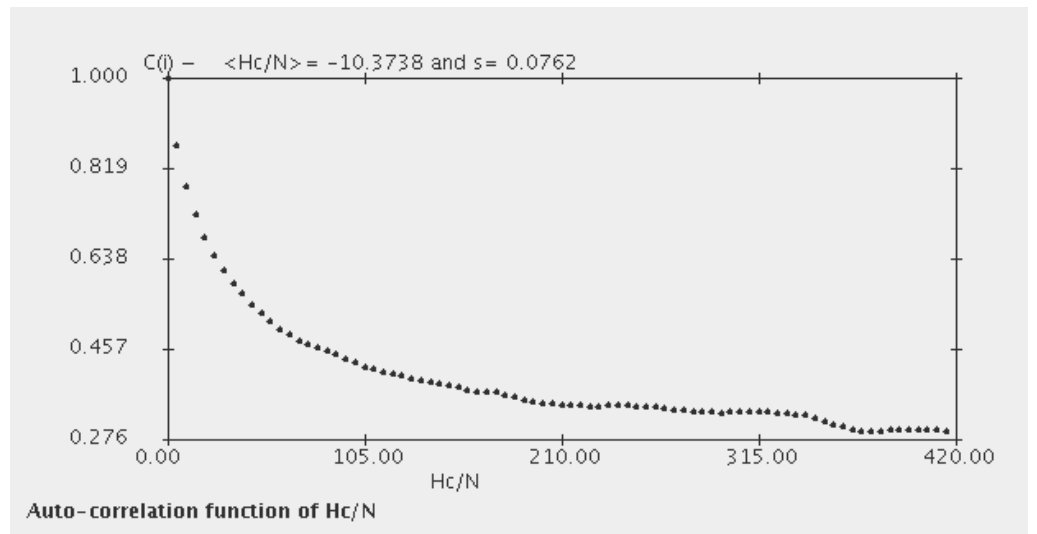

Figura 4.24. Função de auto-correlação de energia.

Do ajuste, obtemos o valor de $\tau \cong 550$. A fim de garantirmos um resultado mais confiável (configurações não correlacionadas), adotamos um intervalo de $2 \tau \cong 1200$ entre as configurações; devemos colher uma a cada 1200 configurações geradas aleatoriamente. De um total de 84000 configurações geradas, havíamos salvado uma a cada 100, o que resultou em um arquivo de saída contendo 840 configurações. Assim, para o cálculo quântico das energias de transição entre os estados, pegamos uma configuração a cada 12 durante a análise das camadas de solvatação, gerando 70 configurações não correlacionadas, que correspondiam a 1/1200 do total de 84000 configurações.

\subsubsection{Solvatação do o-Abz}

A princípio, poderíamos agora partir para o cálculo das energias de transição do o-Abz envolvido pelas 400 moléculas de água nas suas 840 configurações, mas há ainda a barreira das limitações computacionais, mesmo em se tratando de métodos semi-empíricos, que demandam menor exigência de CPU. Podemos então, realizar os cálculos considerando as primeiras camadas de solvatação, onde dependendo da situação, os efeitos da água bulk já tendem a se manifestar de forma constante a partir da $3^{a}$ camada de solvatação. Cabe agora determinar tais camadas. 


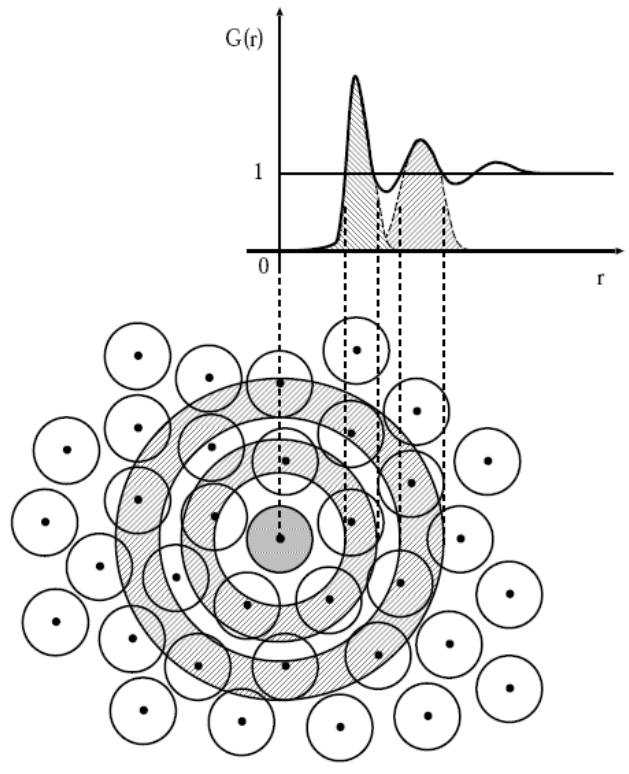

Figura 4.25. Distribuição de centros de massas em torno de um ponto central.

Através do programa ORDER, que integra o pacote de programas do DICE, é possível montar as configurações do o-Abz com cada uma das camadas de solvatação. O ORDER, como o próprio nome sugere, faz uma seleção das moléculas que desejamos observar, conforme os critérios definidos em seu arquivo de entrada. Faz também a contagem e a medição das distâncias entre cada átomo do soluto e do solvente, e isso permite obter o conhecimento não somente das camadas de solvatação, como também da estatística das ligações de hidrogênio.

\section{Determinação das camadas de Solvatação}

Na figura 4.26, observamos as populações das moléculas de água em relação à distância ao centro de massa do o-Abz. Os picos definem as distâncias onde se posicionam o maior número de centros de massa, e os mínimos definem onde eles estão menos presentes. Conforme a figura 4.25 sugere, os locais de mínimo definem uma região de transição entre uma camada de solvatação e a seguinte. Assim, da esquerda para a direita, somamos o número de moléculas presentes até o ponto de mínima, e obtemos então o número total de moléculas na camada 
de solvatação. Identificamos então, quatro camadas de solvatação: a $1^{a}$ camada de solvatação, com 21 moléculas, a $2^{a}$ com 47 moléculas, a $3^{a}$ com 88 moléculas e a $4^{a}$, com 153 moléculas.

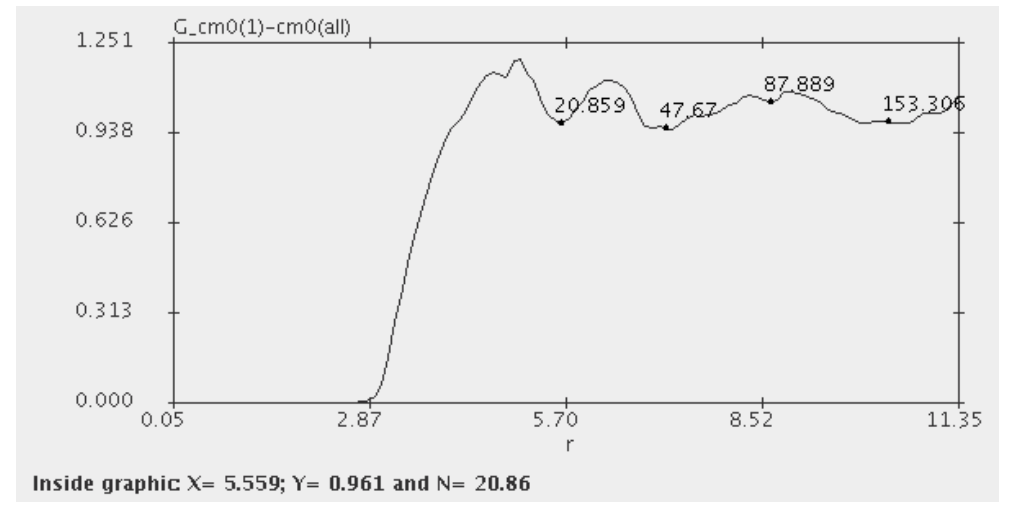

Figura 4.26. Número de moléculas de água pela distância de Centros de massa. Podemos identificar a $1^{a}$ camada de solvatação (21 moléculas), a $2^{a}$ (47 moléculas), a $3^{a}$ (88 moléculas) e a $4^{a}$ (153 moléculas).

É importante ressaltar que a solvatação do o-Abz já se deu na presença das 400 moléculas de água, quando foram geradas as configurações aleatórias através do DICE; o que fazemos agora, através do programa ORDER é selecionar a molécula do soluto juntamente com as sucessivas camadas de solvatação, desprezando o restante das moléculas do solvente. Das 840 configurações, selecionamos uma a cada 12, e formatamos então um arquivo de entrada para os cálculos quânticos de energia, que conterá as coordenadas de 70 configurações do soluto com as camadas de solvatação. A figura 4.27 ilustra a molécula de o-Abz aniônico rodeado pelas 88 moléculas de água que compõem a $3^{a}$ camada de solvatação.

\section{Estatística das ligações de Hidrogênio}

As ligações de hidrogênio se caracterizam pela formação de uma "ponte" entre dois átomos eletronegativos, onde a mesma se dá através do hidrogênio "pertencente" a um deles, o chamado doador, para o que o receberá, o aceitador. Esses átomos são o Oxigênio, Flúor e Nitrogênio. Os critérios que definem uma ligação 


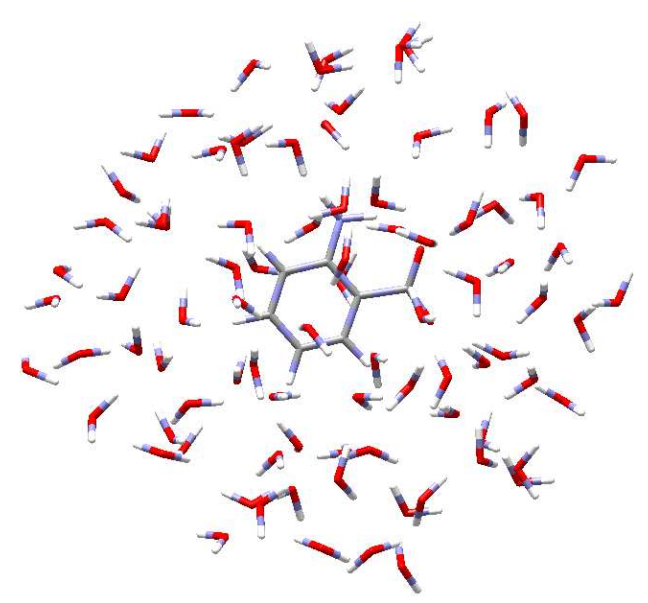

Figura 4.27. o-Abz solubilizado em 88 moléculas de $\mathrm{H}_{2} \mathrm{O}$, correspondentes à terceira camada de solvatação.

de hidrogênio são a distância entre o átomo de hidrogênio e o átomo aceitador por volta de $\sim 2 \AA$, o alinhamento da ligação em relação ao eixo da ligação covalente do hidrogênio ao seu doador e a energia da ligação que pode variar de -1 Kcal/mol para as ligações mais fracas até -15 Kcal/mol nas ligações mais fortes[56]. No nosso caso, adotamos a distância entre átomos aceitadores e doadores $R_{O O} \leq 3,6$, ângulo da ligação em relação ao eixo da ligação entre doador e hidrogênio $\Theta_{O O H} \leq 30^{\circ}$ e energia da ligação $\varepsilon \leq-1 k c a l / m o l$.

\begin{tabular}{|c|c|c|c|c|c|c|c|c|c|}
\hline Aceitadores & total & média & $R_{O H}(\AA)$ & $\varepsilon(\mathrm{kcal} / \mathrm{mol})$ & Doadores & total & média & $R_{O H}(\AA)$ & $\varepsilon(\mathrm{kcal} / \mathrm{mol})$ \\
\hline$O_{12}$ & 212 & 3,03 & $1,85 \pm 0,26$ & $-11,3 \pm 1,9$ & $N_{14}-H_{16}$ & 2 & 0,03 & $2,53 \pm 0,05$ & $-12,0 \pm 1,5$ \\
\hline$O_{13}$ & 184 & 2,63 & $1,83 \pm 024$ & $-11,2 \pm 2,1$ & $N_{14}-H_{15}$ & 12 & 0,17 & $2,30 \pm 0,16$ & $-2,3 \pm 0,7$ \\
\hline$N_{14}$ & 60 & 0,86 & $1,96 \pm 0,22$ & $-5,6 \pm 1,8$ & & & & & \\
\hline
\end{tabular}

Tabela 4.14. Estatísticas das Ligações de Hidrogênio entre o-Abz e a água.

Na figura 4.28 observamos os tipos de ligações de hidrogênio intermoleculares que o o-Abz forma com o solvente. Os valores $R_{O H}$ apresentados referem-se às distâncias entre o átomo aceitador e o Hidrogênio. De acordo com a contagem das ligações de hidrogênio definidas pelos critérios, os átomos de Oxigênio 
pertencentes ao ácido carboxílico tendem a receber uma média de três ligações de hidrogênio e o Nitrogênio do grupo amina aproximadamente uma ligação. Observa-se no entanto que as ligações sobre os átomos de Oxigênio tendem a ser mais fortes do que as do Nitrogênio, pois além de $R_{O H}$ serem mais curtas, as suas energias de ligação correspondem ao dobro das que pertencem a este último (vide tabela 4.14). E dada a baixa freqüência com que ocorrem, as ligações do tipo doadoras providas pelo Nitrogênio do grupo amina podem ser praticamente desprezadas. A energia maior da ligação de hidrogênio com os átomos de Oxigênio se deve em grande parte à forte eletronegatividade destes últimos, e acaba acentuada pela desprotonação de um deles, quando em pH neutro. Por serem ligações fortes, ocorre aí uma estabilização no estado fundamental da molécula e isso é claramente observado no deslocamento para o azul no espectro experimental de absorção óptica do o-Abz isolado, e em pH 7,4 $(\lambda=310 \mathrm{~nm})$.

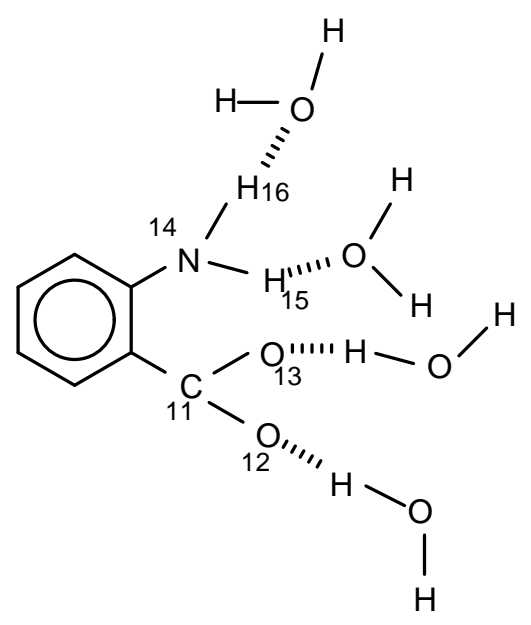

Figura 4.28. Possíveis ligações de hidrogênio intermoleculares no o-Abz aniônico.

\section{Espectros de Absorção Óptica}

Para cada tipo de camada de solvatação, fazemos o cálculo quântico das energias de transição para os estados excitados, através do método semi-empírico 
ZINDO (Zerner's Intermediate Neglect of Differential Overlap) com parametrização espectroscópica, cujo programa é incluído no pacote GAUSSIAN 03. Para avaliar o grau dos efeitos da solvatação sobre o o-Abz, fizemos um cálculo preliminar da transição da energia para os três primeiros estados excitados. Entretanto, não foi possível concluir os cálculos da energia para a configuração com 153 moléculas de água devido às limitações na capacidade de processamento. Na tabela 4.15, verificamos pouca alteração nos efeitos da solvatação da segunda camada para a terceira. Embora se observe um deslocamento substancial para o azul no comprimento de onda mais longo $(\lambda=313 \mathrm{~nm})$, com o acréscimo de camadas de solvatação, o comprimento de onda predominante correspondente à transição para o segundo estado excitado $(\lambda \cong 297 \mathrm{~nm})$ apresenta pouca variação entre a configuração de duas camadas para a de três. Assim, optamos por fazer uma análise mais completa do o-Abz solvatado até a terceira camada, por ser suficiente para a observação dos efeitos de solvente nos deslocamentos espectrais relevantes.

\begin{tabular}{ccccccc}
\hline num. átomos & $\lambda_{1}(\mathrm{~nm})$ & $\mathrm{f} 1$ & $\lambda_{2}(\mathrm{~nm})$ & $\mathrm{f} 2$ & $\lambda_{3}(\mathrm{~nm})$ & $\mathrm{f} 3$ \\
\hline \hline $21\left(1^{a}\right.$ camada) & 313,0298 & 0,0055 & 296,7580 & 0,0684 & 282,2308 & 0,0056 \\
$47(2$ camada) & 311,2990 & 0,0076 & 297,0888 & 0,0695 & 280,5084 & 0,0051 \\
$88\left(3^{a}\right.$ camada) & 308,3273 & 0,0128 & 297,1292 & 0,0694 & 276,9182 & 0,0043 \\
\hline
\end{tabular}

Tabela 4.15. Energias de transição para os três primeiros estados excitados e respectivas forças de oscilador.

Assim, para simular o espectro de absorção óptica, fazemos o cálculo das transições entre o estado fundamental e 20 estados excitados, e os respectivos valores da força de oscilador. Calculamos as médias das energias nas 70 configurações, ponderadas pelo valor da força de oscilador, e temos então os valores médios para as 20 transições calculadas (vide tabela 4.17).

Dos valores da tabela 4.17 simulamos o espectro de absorção do o-Abz, fazendo uma soma de gaussianas centradas nos valores das energias de transição 


\begin{tabular}{cccccccc}
\hline$\lambda(\mathrm{nm})$ & $\mathrm{f}$ & $\lambda(\mathrm{nm})$ & $\mathrm{f}$ & $\lambda(\mathrm{nm})$ & $\mathrm{f}$ & $\lambda(\mathrm{nm})$ & $\mathrm{f}$ \\
\hline \hline 308,3286 & 0,0128 & 218,8768 & 0,1717 & 198,2794 & 0,0935 & 181,4069 & 0,0156 \\
297,1294 & 0,0693 & 212,4487 & 0,1963 & 189,4874 & 0,0034 & 179,7454 & 0,0103 \\
276,9174 & 0,0043 & 209,7089 & 0,1470 & 183,3589 & 0,0106 & 177,2543 & 0,0459 \\
266,1171 & 0,0889 & 209,4978 & 0,1581 & 182,9070 & 0,0111 & 174,8271 & 0,0580 \\
224,9147 & 0,7419 & 207,0400 & 0,1653 & 182,2985 & 0,0060 & 173,0190 & 0,0247
\end{tabular}

Tabela 4.17. Valores médios para energia de transição e respectiva força de oscilador obtidos das configurações do o-Abz solvatado por 88 moléculas de água.

convertidas em números de onda $\left(\mathrm{cm}^{-1}\right)$, com a amplitude dada pelos valores da força de oscilador. Para cada gaussiana estipulamos uma largura arbitrária entre 3000 e $5000 \mathrm{~cm}^{-1}$. Para fins de comparação do resultado simulado com espectros experimentais, fazemos a conversão da energia em numero de onda $\left(\mathrm{cm}^{-1}\right)$ para comprimento de onda $(\mathrm{nm})$ e procedemos uma normalização sobre ambos espectros.

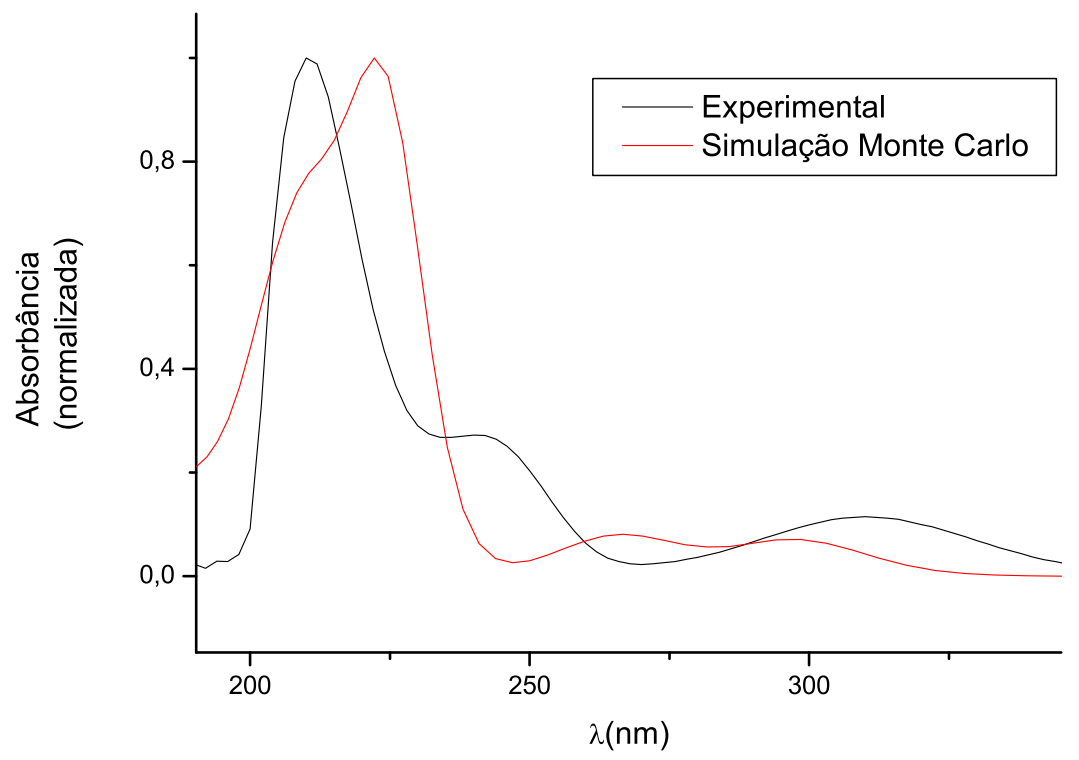

Figura 4.29. Comparativo entre espectros normalizados de absorção óptica do o-Abz em água obtidos experimentalmente e via simulação de Monte Carlo. 
Na figura 4.29, observamos a presença de um pico pronunciado na região próxima de $\lambda_{\max }=210 \mathrm{~nm}$ e outro menos intenso porém bem definido, ao redor de $310 \mathrm{~nm}$, com coeficiente de absorção molar experimental $\epsilon_{\max }$ de $3000 \mathrm{M}^{-1} \mathrm{~cm}^{-1}$. Observamos ainda, junto à direita da primeira banda uma borda bem definida, por volta de $230 \mathrm{~nm}$, que configuraria um outro pico. De acordo com a literatura [21], o benzeno diluído em hexano possui três bandas de absorção: $184 \mathrm{~nm}\left(\epsilon_{\max }\right.$ $\left.60.000 \mathrm{M}^{-1} \mathrm{~cm}^{-1}\right), 204 \mathrm{~nm}\left(\epsilon_{\max } 7.900 \mathrm{M}^{-1} \mathrm{~cm}^{-1}\right)$ e $256 \mathrm{~nm}\left(\epsilon_{\max } 200 \mathrm{M}^{-1} \mathrm{~cm}^{-1}\right)$. Estas três bandas originam-se de transições $\pi \rightarrow \pi^{*}$. As bandas em $184 \mathrm{~nm}$ e em 204 nm são também chamadas de bandas $E$ (etilênicas) e a banda em $256 \mathrm{~nm}$ de banda $B$ (benzênicas). O acréscimo de um grupo auxocrômico $(\mathrm{OH}, \mathrm{NH} 2$, etc.) ao benzeno desloca as bandas $E$ e $B$ para comprimentos de onda maiores, freqüentemente com intensificação da banda $B$ e perda da estrutura fina, devido à conjugação $n-\pi$. A adição de uma amina ao benzeno, que o transforma na Anilina, por exemplo, desloca as bandas com $\lambda_{\max }$ em $204 \mathrm{~nm}$ e $256 \mathrm{~nm}$ para $230 \mathrm{~nm}\left(\epsilon_{\max } 8.600 \mathrm{M}^{-1} \mathrm{~cm}^{-1}\right)$ e $280 \mathrm{~nm}\left(\epsilon_{\max } 1.430 \mathrm{M}^{-1} \mathrm{~cm}^{-1}\right)$, respectivamente. Por outro lado, a ligação de um grupo cromóforo ao anel benzênico produz também um deslocamento para o vermelho intenso da banda $B$ e o aparecimento de uma outra banda, denominada $K$, na região entre 200 e $250 \mathrm{~nm}$, que se superpõem às bandas $E$. Assim, no caso do ácido benzóico, onde se adicionou uma carboxila ao benzeno, se observam uma banda $K$ com $\lambda_{\max }$ em $230\left(\epsilon_{\max } 10.000 \mathrm{M}^{-1} \mathrm{~cm}^{-1}\right)$ e a banda $B$ em $270 \mathrm{~nm}\left(\epsilon_{\max } 800 \mathrm{M}^{-1} \mathrm{~cm}^{-1}\right)$. No caso do o-Abz, temos uma combinação destes dois efeitos que deslocam a banda $B$ para o vermelho, assim como aumentam consideravelmente a sua constante de absorção molar $\epsilon_{\max }$, para $3000 \mathrm{M}^{-1} \mathrm{~cm}^{-1}$ em $\lambda_{\max }=310 \mathrm{~nm}$.

Para efeito de comparação, o espectro experimental do o-Abz em um solvente apolar (ciclohexano) é confrontado com uma simulação de espectro no vácuo (figura 4.30). Como os cálculos de optimização através do método B3LYP/6-311G+(d) já demonstraram, o rotâmeros cujo grupo $\mathrm{OH}$ se encontrava mais distante do 


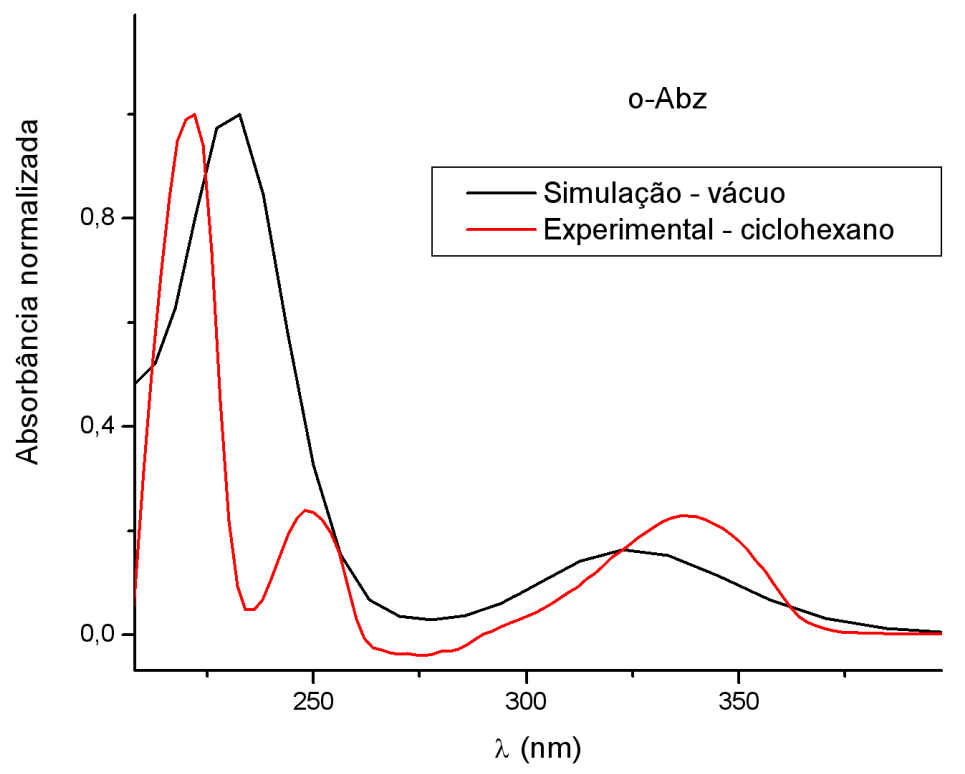

Figura 4.30. Comparativo entre espectros de absorção óptica do o-Abz obtido experimentalmente em solução ciclohexano e calculado no vácuo através de ZINDO.

grupo amina apresentou uma conformação de menor energia [58]. Tal foi a conformação (rotâmero I) escolhida para a simulação de espectro no vácuo. Observa-se nestes espectros a mesma concordância quanto a natureza dos picos de absorção. No espectro experimental, observamos a presença dos mesmos picos na simulação, o mais intenso devido à banda $K$ e outro menor atribuído a $B$, além de um pico adicional por volta de $250 \mathrm{~nm}$, que deve corresponder à banda intermediária do benzeno. Das análises dos dados obtidos dos cálculos, observamos a grande presença de orbitais $\pi$ na composição dos estados envolvidos nas transições relativas a banda de menor $\lambda_{\max }$ e por outro lado, observamos também uma certa conjugação $n-\pi$ nos orbitais HOMO envolvidos nas transições das bandas de comprimento de onda maiores.

Da comparação com o resultado para a simulação na água (figura 4.29), fica evidente a observação de um deslocamento espectral para o azul no espectro 
da água, tanto simulado quanto experimental, em relação ao solvente apolar e vácuo. Tal deslocamento é contrário ao efeito geral que se espera de um cromóforo na presença de um solvente polar, pois moléculas cujo momento de dipolo é maior no estado excitado em relação ao estado fundamental tendem a apresentar deslocamentos para o vermelho, conforme o aumento na polaridade do solvente [59]. Há nesse caso um forte efeito específico que pode ser atribuído ao $\mathrm{pH}$ da água, além de seu caráter prótico. Por ser um ácido, o o-Abz possui o comportamento característico de doador de prótons, quando diluído em água. Em experimentos de titulação de $\mathrm{pH}$ do o-Abz, através da espectroscopias de absorção óptica, fluorescência estática e temporal, foi verficado um comportamento similar ao dos aminoácidos, que apresentam três estados de protonações, devido à presença do grupo amina, que tende a aceitar prótons. Na presente situação, o o-Abz possui o grupo ácido carboxílico desprotonado quando em $\mathrm{pH}$ neutro, o que o torna aniônico e aumenta o seu momento de dipolo; uma vez sendo a água um solvente polar, isso estabiliza o seu estado fundamental e deve tornar necessário um maior dispêndio de energia na sua excitação, o que leva ao deslocamento para o azul na absorção.

\subsubsection{Solvatação de derivados do o-Abz}

Todo o procedimento de simulação descrito anteriormente para o o-Abz foi aplicado para a os derivados aminado e metilados do o-Abz: $\mathrm{Abz}-\mathrm{NH}_{2}, \mathrm{Abz}-\mathrm{NH}\left(\mathrm{CH}_{3}\right)$. Assim como no o-Abz isolado, as conformações dos rotâmeros escolhidos para a simulação em água foram aqueles de menor energia.

As tabelas 4.18, 4.19 e 4.20 apresentam as estatísticas para as possíveis ligações de hidrogênio formadas entre a água e os derivados. É importante observar que nesta metodologia não se contabilizam as ligações de hidrogênio intramoleculares, mas apenas as intermoleculares. 

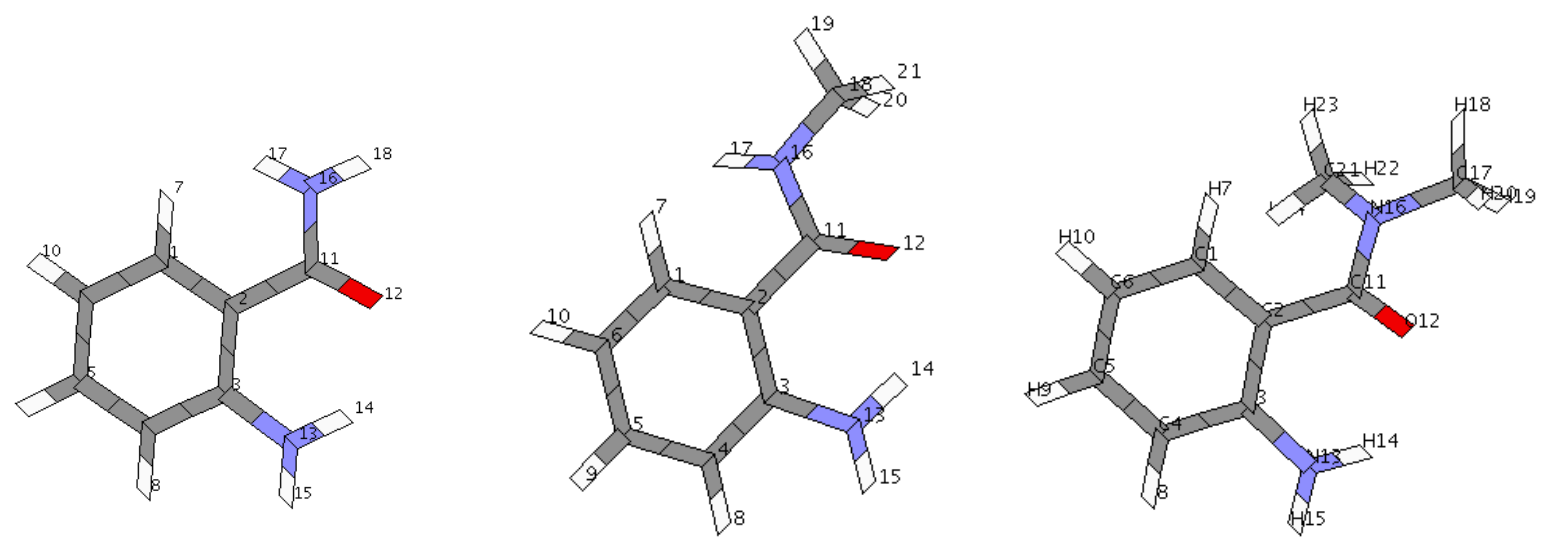

Figura 4.31. $\mathrm{Abz}-\mathrm{NH}_{2}, \mathrm{Abz}-\mathrm{NH}\left(\mathrm{CH}_{3}\right)$ e $\mathrm{Abz}-\mathrm{NH}\left(\mathrm{CH}_{3}\right)_{2}$.

\begin{tabular}{cccccccccc}
\hline Aceitadores & total & média & $R_{O H}(\AA)$ & $\varepsilon(\mathrm{kcal} / \mathrm{mol})$ & Doadores & total & média & $R_{O H}(\AA)$ & $\varepsilon(\mathrm{kcal} / \mathrm{mol})$ \\
\hline \hline$O_{12}$ & 116 & 1,66 & $1,88 \pm 0,20$ & $-5,6 \pm 1,2$ & $N_{13}-H_{15}$ & 51 & 0,73 & $2,09 \pm 0,17$ & $-3,5 \pm 1,0$ \\
$N_{13}$ & 45 & 0,65 & $2,05 \pm 0,27$ & $-3,1 \pm 1,1$ & $N_{13}-H_{14}$ & 21 & 0,30 & $2,29 \pm 0,22$ & $-2,3 \pm 1,1$ \\
$N_{16}$ & 3 & 0,04 & $2,14 \pm 0,23$ & $-1,9 \pm 0,5$ & $N_{16}-H_{17}$ & 28 & 0,40 & $2,25 \pm 0,20$ & $-3,5 \pm 1,1$ \\
& & & & & $N_{16}-H_{18}$ & 41 & 0,59 & $2,09 \pm 0,20$ & $-3,5 \pm 1,1$ \\
\hline
\end{tabular}

Tabela 4.18. Estatísticas das Ligações de Hidrogênio entre $\mathrm{Abz}-\mathrm{NH}_{2}$ e a água.

\begin{tabular}{|c|c|c|c|c|c|c|c|c|c|}
\hline Aceitadores & total & média & $R_{O H}(\AA)$ & $\varepsilon(\mathrm{kcal} / \mathrm{mol})$ & Doadores & total & média & $R_{O H}(\AA)$ & $\varepsilon(\mathrm{kcal} / \mathrm{mol})$ \\
\hline$O_{12}$ & 52 & 0,74 & $2,02 \pm 0,18$ & $-3,6 \pm 0,8$ & $N_{13}-H_{15}$ & 45 & 0,64 & $2,13 \pm 0,18$ & $-2,8 \pm 0,9$ \\
\hline$N_{13}$ & 100 & 1,43 & $1,90 \pm 023$ & $-4,8 \pm 1,2$ & $N_{13}-H_{14}$ & 8 & 0,11 & $2,36 \pm 0,18$ & $-3,4 \pm 1,6$ \\
\hline$N_{16}$ & 1 & 0,01 & $2,69 \pm 0,00$ & $-1,75 \pm 0,00$ & $N_{16}-H_{17}$ & 48 & 0,69 & $2,13 \pm 0,23$ & $-3,7 \pm 1,1$ \\
\hline
\end{tabular}

Tabela 4.19. Estatísticas das Ligações de Hidrogênio entre $\mathrm{Abz}-\mathrm{NH}\left(\mathrm{CH}_{3}\right)$ e a água.

\begin{tabular}{|c|c|c|c|c|c|c|c|c|c|}
\hline Aceitadores & total & média & $R_{O H}(\AA)$ & $\varepsilon(k c a l / m o l)$ & Doadores & total & média & $R_{O H}(\AA)$ & $\varepsilon(\mathrm{kcal} / \mathrm{mol})$ \\
\hline$O_{12}$ & 48 & 0.69 & $1,98 \pm 0,24$ & $-3,8 \pm 1,1$ & $N_{13}-H_{15}$ & 55 & 0,79 & $2,15 \pm 0,27$ & $-3,0 \pm 0,8$ \\
\hline$N_{13}$ & 118 & 1,69 & $1,91 \pm 0,23$ & $-5,2 \pm 1,4$ & $N_{13}-H_{14}$ & 7 & 0,10 & $2,35 \pm 0,28$ & $-4,3 \pm 1,8$ \\
\hline$N_{16}$ & 1 & 0,01 & $2,75 \pm 0,00$ & $-4,24 \pm 0,00$ & & & & & \\
\hline
\end{tabular}

Tabela 4.20. Estatísticas das Ligações de Hidrogênio entre $\mathrm{Abz}-\mathrm{N}\left(\mathrm{CH}_{3}\right)_{2}$ e a água. 
Repetimos aqui também os cálculos das energias de transições dos estados eletrônicos, através do método semi-empírico ZINDO e simulamos os seus espectros de absorção óptica. Nas figuras 4.32 e 4.33, observamos claramente as bandas de absorção referentes às bandas $K$ e $B$, assim como no o-Abz isolado. Nas simulações percebe-se ainda a presença de um pico intermediário entre as duas bandas mencionadas, por volta de $270 \mathrm{~nm}$.

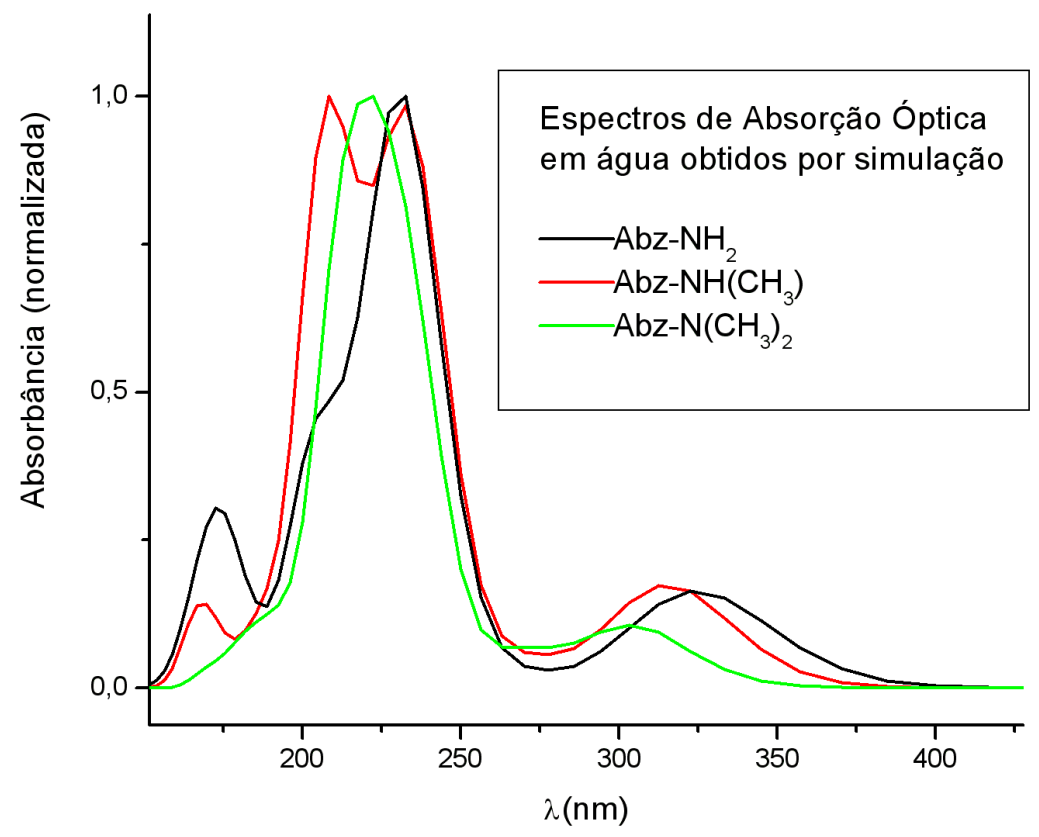

Figura 4.32. Espectros simulados de absorção óptica para $\mathrm{Abz}-\mathrm{NH}_{2}, \mathrm{Abz}-\mathrm{NH}\left(\mathrm{CH}_{3}\right)$, $\mathrm{Abz}-\mathrm{NH}\left(\mathrm{CH}_{3}\right)_{2}$ solvatados em água.

Apesar das bandas relativas à $K$ terem apresentado uma certa discrepância quanto ao comprimento de onda no máximo, verificamos uma razoável concordância em relação às bandas $B$, quanto às posições espectrais. Percebemos nos espectros simulados a mesma tendência ao deslocamento para o azul nas 
bandas de absorção destas transições observada nos espectros experimentais diante da adição das metilas.

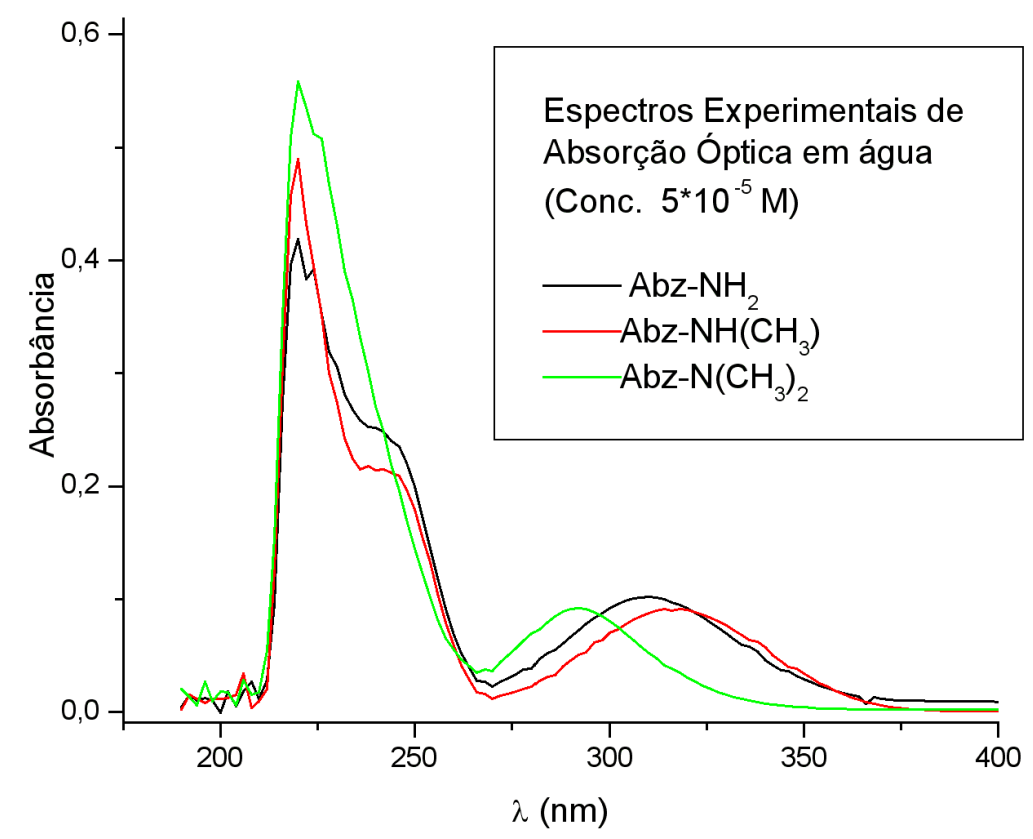

Figura 4.33. Espectros experimentais de absorção óptica para $\mathrm{Abz}-\mathrm{NH}_{2}, \mathrm{Abz}-\mathrm{NH}\left(\mathrm{CH}_{3}\right)$, $\mathrm{Abz}-\mathrm{NH}\left(\mathrm{CH}_{3}\right)_{2}$ solvatados em água, sob $\mathrm{pH} 7,4$.

É importante observar que as geometrias utilizadas tanto para as moléculas do soluto como dos solventes foram otimizadas individualmente em vácuo através dos cálculos ab-initios e foram mantidas rígidas. Observando-se estas limitações, os resultados obtidos foram bons.

Ao fazermos uma análise das ligações de hidrogênio (tabelas 4.18, 4.19 e 4.20), o que chama a atenção é o fato da energia das ligações de hidrogênio sobre o átomo de Oxigênio diminuirem para a metade, assim como a sua freqüência, em relação ao o-Abz isolado e na forma aniônica. Outra observação importante diz respeito aos grupos aminas, que passam a apresentar uma afinidade maior 
em doar as ligações de hidrogênio. São fatos que parecem estar relacionados diretamente à ausência da oxila do grupo ácido carboxílico do o-Abz isolado.

As maiores contribuições das interações específicas entre solutos e solventes sobre os efeitos de solventes são aquelas devidas às ligações de hidrogênio entre a molécula do soluto e solventes próticos como alcoóis, água e ácidos carboxílicos. Tal situação é parecida com a que ocorre com a Anilina [60], onde o Nitrogênio da amina, que possui um par isolado de elétrons (lone pair), recebe uma forte ligação de hidrogênio de uma molécula do solvente. No estado excitado, ocorre uma transferência da carga eletrônica do Nitrogênio para o anel aromático. Nesta situação em particular, ao contrário do que ocorre quando em solventes apróticos, há uma diminuição da variação do momento de dipolo do estado excitado em relação ao estado fundamental $\left(\Delta \mu_{g}>\Delta \mu_{e}\right)$. Assim, há uma menor estabilização do estado excitado, e no caso particular da Anilina, ocorre um deslocamento anômalo para o azul na banda de absorção óptica que mescla transições do tipo $l \rightarrow \pi^{*}$ e $\pi \rightarrow \pi^{*}$, onde orbitais $l$ são aqueles relacionados aos elétrons não ligantes do par isolado (lone-pair). No o-Abz e os derivados, devemos observar um fenômeno semelhante, devido à presença do grupo amina. Das tabelas $4.18,4.19$ e 4.20 contendo a estatística das ligações de hidrogênios, verificamos que as ligações de hidrogênio do tipo aceitadoras sobre o grupo amina apresentam energia de ligação maior com o acréscimo das metilas. Conforme a intensidade das energias destas ligações, verifica-se uma certa correspondência quanto ao deslocamento para o azul nos comprimentos de onda nos máximos de absorção óptica 4.7. Por outro lado, junto com o acréscimo das metilas acompanhou uma diminuição na soma de todas as ligações de hidrogênio formadas entre soluto-solvente, que no caso da água pode ser interpretado como aumento de hidrofobicidade, devido a fatores estéricos e ao fato das metilas possuírem um certo caráter hidrofóbico. 


\section{Capitulo 5}

\section{Conclusões}

Verificamos experimentalmente que as bandas de absorção e de emissão do Ácido orto-Aminobenzóico (o-Abz) e dos derivados Abz-NH2, Abz- $\mathrm{NH}(\mathrm{CH} 3)$ e Abz-N(CH3)2 apresentam deslocamentos espectrais dependentes da interação com o meio solvente. O modelo que considera o solvente como meio contínuo, prevendo uma dependência linear entre deslocamento de Stokes e a orientação de polarizabilidade do solvente não se mostrou adequado para interpretar todos os dados experimentais. Os resultados mostraram que ocorrem interações específicas entre os compostos e os solventes classificados como doadores de prótons (próticos) segundo a escala de polaridade de solventes de Kamlet-Taft. Algumas das características que fazem do o-Abz uma boa sonda fluorescente permaneceram presentes quando ligado a outros compostos, como o elevado rendimento quântico e a sensibilidade à polaridade ambiente. Os compostos $\mathrm{Abz}-\mathrm{NH} 2 \mathrm{e}$ $\mathrm{Abz}-\mathrm{NH}(\mathrm{CH} 3)$ mostraram decaimentos bi ou tri-exponencial, com tempos médios acima de $7 \mathrm{~ns}$, exceto para os solventes clorofórmio, benzeno e acetonitrila. Embora as interações específicas influenciem o deslocamento de Stokes, não produzem um efeito direto sobre os processos de desexcitação dos dois compostos. Por outro lado, os processos não radiativos exercem papel relevante no composto $\mathrm{Abz}-\mathrm{NH}(\mathrm{CH} 3)_{2}$, diminuindo consideravelmente o rendimento quântico e os tempos de decaimento das amostras.

Das simulação da caixa d'água contendo o-Abz e derivados, observamos um 
aumento na energia das ligações de hidrogênio do tipo aceitadoras sobre o grupo amina, ante a adição das metilas nos derivados. Tal fato contribui com um deslocamento para o azul nos espectros de absorção, verificado experimentalmente.

Os espectros de absorção ótica obtidos via simulação demonstraram concordância razoável com os resultados experimentais e foi possivel uma atribuição quantitativa dos orbitais envolvidos nas transições, preenchendo uma lacuna na interpretação dos espectros, que baseavam-se em considerações qualitativas. Houve boa concordância quanto à definição das bandas oriundas das transições $\pi \rightarrow \pi^{*}$, apesar das aproximações feitas em relação às geometrias fixas das moléculas do cromóforo. Foi possivel identificar as ligações de hidrogênio intermoleculares formadas com o solvente. Experimentalmente, já havia sido verificada a tendência do o-Abz em apresentar deslocamentos para o vermelho nas transições do tipo $\pi \rightarrow \pi^{*}$, especificamente a banda $B$, ante o aumento da polaridade do solvente. Tal é o efeito geral de solvente comum a fluoróforos que apresentem momentos de dipolos que são maiores nos estados excitados em relação aos estados fundamentais.

Na simulação dos espectros de absorção da forma aniônica do o-Abz, verificou -se um deslocamento para o azul em relação à simulação no vácuo, o que é condizente com resultados já observados experimentalmente. A forma aniônica incrementa a eletronegatividade dos átomos de Oxigênio, e deve aumentar a energia das ligações de hidrogênio com esses átomos. Essas ligações mais intensas, juntamente com as que envolvem também o grupo amina acabam por estabilizar mais o estado fundamental do o-Abz, e isso contribui para um deslocamento para azul no espectro de absorção. Da simulação, verificou-se também que na forma aniônica há uma inibição das ligações de hidrogênio do tipo doadoras por parte do grupo amina. Nos derivados, o deslocamento no máximo da excitação para o azul com o acréscimo das metilas acompanha um aumento na energia da ligação de hidrogênio do tipo aceitador sobre os átomos de Nitrogênio 
da amina, condizente com observações da literatura onde tais ligações tendem a gerar esse mesmo efeito hipsocrômico em moléculas de Anilina.

O uso conjunto de técnicas de simulação computacional com práticas experimentais espectroscópicas de absorção óptica, fluorescências estáticas e resolvidas no tempo se mostrou bastante válido no estudo de sistemas soluto + solvente, ao permitir análises qualitativas mais precisas. As simulações, que mesclaram a mecânica quântica com a mecânica molecular, apresentaram uma boa razão custo/benefício, onde por custo se entende a demanda computacional. O DICE se mostrou um valioso instrumento, não só na geração das configurações soluto+solvente mas também na análise das ligações de hidrogênio intermoleculares, que costumam ter sempre um papel relevante em sistemas biológicos.

O o-Abz, além de ter apresentado boas qualidades como sonda fluorescente, se mostrou também um interessante modelo para simulações, juntamente com seus derivados. Como perspectiva de trabalhos futuros fica a possibilidade de se incluir nas simulações os seus espectros de emissão fluorescente, através do método de interação de configuração (CI) no cálculo de estados excitados. Uma molécula compacta como o o-Abz, que possua uma boa correlação entre dados experimentais e resultados de simulação é um bom modelo para o desenvolvimento de simulações e cálculos teóricos. 


\section{Bibliografia}

[1] Marquezin, C.A., Hirata, L.Y., Juliano, L., Ito, A.S., "Tryptophan as a probe for acid-base equilibria in peptides”, Biopolimers, 71 (5): 569-576, 2003.

[2] Amaral, M.S., Loss, M., Ito A.S., "A QM/MM hybrid simulation of 5-hydroxytryptophan in solution", International Journal of Quantum Chemistry, 95 (3): 289-294, 2003.

[3] Turchiello RF, Lamy-Freund MT, Hirata IY, Juliano L, Ito AS, "Ortho-Aminobenzoic Acid As A Fluorescent Probe For The Interaction Between Peptides And Micelles."Biophysical Chemistry 73, 217-225, 1998.

[4] Ito, A. S.; Turchiello, R. D.; Hirata, I. Y.; Cezari, M. H.; Juliano, L. "Fluorescent Properties of Amino Acids Labeled with Ortho-Aminobenzoic Acid”. Biospectroscopy, 4, 6, 395-402, 1998.

[5] Takara, M ; Ito, AS. "General and specific solvent effects in optical spectra of ortho-Aminobenzoic Acid”, Journal of Fluorescence, 15 (2), 171-177, 2005.

[6] Souza, E.S., Hirata, I.Y., Juliano, L. and Ito, A.S. "End-to-end distance distribution in bradykinin observed by Forster resonance energy transfer." Biochimica et Biophysica Acta, Amsterdam, v. 1474, p. 251-261, 2000.

[7] C. A. Marquezin, I. Y. Hirata, L. Juliano and A. S. Ito. Spectroscopic characterization of 2-amino-N-hexadecyl-benzamide (AHBA), a new fluorescence probe for membranes. Biophysical Chemistry. 124, 125-133, 2006.

[8] Takara, M. "Efeitos de Solventes na absorção óptica e na emissão fluorescente do Ácido orto-Aminobenzóico.", dissertação de mestrado, Instituto de Física , USP, 2001.

[9] Cantor,C.R., Schimmel,P.R., "Biophysical Chemistry", vol.2, cap. 8.2, W.H.Freeman and Company, 1980 
[10] Voet D. , Voet, J.G., "Biochemistry", second edition, cap. 2, John Wiley \& Sons, 1995

[11] Melhuish, W.H. "Quantum Efficiences of Fluorescence of Organic Substances: Effects of Solvent and Concentration of the Fluorescent Solute." J. Phys. Chem - US, 65, (2), 229-235, 1961

[12] Hirata I.Y., Sedenho M.H.C., Boschcov P. , Garratt R.C.,Oliva G., Ito A.S., Spisni A., Franzoni L. and Juliano L. "Reductionof ortho-aminobenzoyl-proline fluorescence and formation of pyrrolobenzodiazepine-5,11-dione". Lett. Pept. Sci. 5, 1-10.(1998)

[13] C.A. Southern,D.H. Levy,G.M. Florio,A. Longarte,T.S. Zwier;"Electronic and infrared spectroscopy of anthranilic acid in a supersonic jet”, Journal ouf Physical Chemistry; A 107 (20): 4032-4040, 2003.

[14] Lippert, E., Z. Naturforsch., A: Phys. Sci., 10, 541, 1955.

[15] Mataga, N.; Kaifu, Y; Koizumi, M. "Solvent Effects upon Fluorescence Spectra and the Dipolemoments of Excited Molecules". B. CHEM. SOC. JPN 29: (4) 465-470 1956.

[16] Mataga, N., "Solvents effects on the absorption and fluorescence spectra of naphtthylamines and isomerics aminobenzoic acids”. Vol.36, n.36, 654-662, Bul. of the Chem. Soc. of Japan, 1963.

[17] Onsager L., "Eletric Moments of Molecules in Liquids", J. Am. Chem. Soc. , 58, 1486, 1936.

[18] Kirkwood J. G. , “The Dieletric Polarization of Polar Liquids”, J. Chem. Phys., 7, 911-919, 1939.

[19] -Bueno, W.A., "Ligação de Hidrogênio", McGraw-Hill do Brasil, 1978

[20] Jeffrey, G.A., Saenger, W., "Hidrogen Bonding in Biological Structures, Springer, 1991.

[21] Silverstein, R.M., Bassler, G.C., Morrill, T.C., "Identificação Espectrométrica de Compostos Orgânicos”, cap. 5, Guanabara Koogan, 1979.

[22] Cantor, C.R., Schimmel, P.R., "Biophysical Chemistry", part II, "Techniques for the Study of Biological Structure and Function”, capítulo 8, W.H. Freeman and Company, 1980.

[23] Lakowicz, J.R., "Topics in Fluorescence Spectroscopy", vol.2, Principles, cap.3, Plenum Press, 1991. 
[24] J. R. Lakowicz. "Principles of Fluorescence Spectroscopy", Plenum Press, cap.3, 1983.

[25] Lakowicz, J.R., "Topics in Fluorescence Spectroscopy", vol.1, Techniques, Plenum Press, 1991

[26] Born M. , Oppenheimer R. ,"Zur Quantentheorie der Molekeln”, Annalen der Physik, 389 (20), 457-484, 1927.

[27] Szabo, A., Ostlund, N.S.; "Modern Quantum Chemistry”; Mcgraw-Hill; 1989.

[28] Vianna, J.D.M., Fazzio, A., Canuto, S.;" Teoria Guântica de Moléculas e Sólidos”; Editora Livraria da Física, São Paulo, 2004.

[29] Roothaan, C.C.J., "New Developments in Molecular Orbital Theory", Reviews of Modern Physics, 23, 69-89, 1951.

[30] Lowdin,P. O. , “Advances in Chemical Physics”, 2, 207-322, 1959.

[31] Ehrenfest, P., T. Ehrenfest; "The Conceptual Foundations of the Statistical Approach in Mechanics”, Trad. by M. J. Moravicsik, Cornell U.P. ,1959.

[32] Marion J. B. and Thornton S., "Classical Dynamics of Particles \& Systems", Saunders College Publishing, third ed., 1988.

[33] Landau, L., Lifchitz, E. "Curso de Física: Mecânica”, Hemus, 2004.

[34] Coutinho, K.; “Método de Monte Carlo aplicado à Simulação de Líquidos”, apostila, IF-USP, 2003.

[35] K.Coutinho and S. Canuto, "DICE: A Monte Carlo program for molecular liquid simulation”, University of São Paulo, Brazil, 2003.

[36] Metropolis, N., A. W. Rosenbluth, M. N. Rosenbluth, A. H. Teller and E. Teller; J. Chem. Phys., 21, 1087 (1953).

[37] Chung, K. L.; Markov Chains with Stationary State Probability, vol. 1.Springer, Heidelberg (1960).

[38] Kamlet, M.J.; Minesinger, R. R.; Kayser, E. G.. "Hydrogen Bonding by Hydroxylic Solvents to Aromatic Amines. Effects on Spectra and Relative Basicities of Some N-(4-Nitrophenyl)polymethylenimines" . J. Org. Chem., vol. 36, No. 25, 1971.

[39] Kamlet, M.J.; Kayser, E.G.; Eastes, J.W.; Gilligan, W. H.; "Hydrogen Bonding by Protic Solvents to Nitro Oxigens. Effects on Eletronic spectra of Nitro Derivatives". Journal of the Am. Chem. Soc., 95:16, 5210, 1973.

[40] Kamlet, M.J.; Abboud; J. L., Taft, R.W.. "The Solvatochromic Comparison Method. 
6. The $\pi^{*}$ Scale of Solvent Polarities". Journal of the Am. Chem. Soc., 99:18, 6027, 1977.

[41] Kamlet, M.J.; Taft, R.W.. "The Solvatochromic Comparison Method. I. The $\beta$-Scale of Solvent Hydrogen-Bond Acceptor (HBA) Basicities". Journal of the Am. Chem. Soc., 98:2, 377, 1976.

[42] Kamlet, M.J.; Taft, R.W. "The Solvatochromic Comparison Method. 2. The $\alpha$-Scale of Solvent Hydrogen-Bond Donor (HBD) Acidities". Journal of the Am. Chem. Soc., 98:10, 2886, 1976.

[43] Reichardt, C., "Solvents and Solvent Effects in Organic Chemistry", cap. 6, $\mathrm{VCH}, 1990$.

[44] Southern CA, Levy DH, Stearns JA, Florio GM, Longarte A, Zwier TS, "Spectroscopic consequences of localized electronic excitation in anthranilic acid dimer", Journal of Physical Chemistry A; 108 (21): 4599-4609, 2004.

[45] He ,Y., Wu, C., Kong, W, “Theoretical and Experimental Studies of Water Complexes of p- and o-Aminobenzoic Acid”, J. Phys. Chem. A, 109, 2809-2815, 2005.

[46] Dorsey , N.E.; "Properties of Ordinary Water-Substance", New York, 1940.

[47] Regoli, D. ; Barabe, J.; "Pharmacology of bradykinin and related kinins, Pharmacol. Rev.” 32 ,1-46, 1980.

[48] Coutinho, K., Saavedra N., Serrano, A., Canuto, S., "A Monte Carlo-quantum mechanics study of the spectroscopy properties of molecules in solution”, J. Molecular. Struct (Theochem); 539, 171-179; 2001.

[49] Stewart, J.M.; "Bradykinin antagonists: development and applications", Biopolymers, 37, 143-155, 1995 .

[50] Proud, D; Reynolds, C.J.; Lacapra, S; Kagey-Sobotka. A; Lichtenstein, L.M.; Naclerio, R.M.; "Nasal provocation with bradykinin inducessymptoms of rhinitis and a sore throat”, Am. Rev. Respir. Dis. 137, 613-616, 1988.

[51] Nelson, D.L.,Cox, M.M., "Lehninger Principles of Biochemistry", 3rd Edition, W. H. Freeman, 2000.

[52] Gaussian 03, Revision B.04, M. J. Frisch, G. W. Trucks, H. B. Schlegel, G. E. Scuseria,M. A. Robb, J. R. Cheeseman,J. A. Montgomery, Jr.,T. Vreveaussian 03, Revision B.04, M. J. Frisch, G. W. Trucks, H. B. Schlegel, G. E. Scuseria,M. A. Robb, J. R. Cheeseman,J. A. Montgomery, Jr.,T. Vreven,K. N. Ku- 
din,J. C. Burant,J. M. Millam,S. S. Iyengar,J. Tomasi,V. Barone,B. Mennucci,M. Cossi,G. Scalmani,N. Rega,G. A. Petersson,H. Nakatsuji,M. Hada,M. Ehara,K. Toyota,R. Fukuda,J. Hasegawa,M. Ishida,T. Nakajima,Y. Honda,O. Kitao,H. Nakai,M. Klene, X. Li,J. E. Knox,H. P. Hratchian,J. B. Cross,C. Adamo,J. Jaramillo,R. Gomperts,R. E. Stratmann,O. Yazyev,A. J. Austin, R. Cammi,C. Pomelli, J. W. Ochterski, P. Y. Ayala,K. Morokuma, G. A. Voth, P. Salvador, J.J.Dannenberg, V.G.Zakrzewski,S. Dapprich,A. D. Daniels,M. C. Strain,O. Farkas,D. K. Malick,A. D. Rabuck,K.Raghavachari, J.B.Foresman,J. V. Ortiz, Q. Cui,A. G. Baboul,S. Clifford,J. Cioslowski,B. B. Stefanov,G.Liu, A.Liashenko,P.Piskorz, I.Komaromi,R. L. Martin, D. J. Fox, T.Keith, M. A. Al-Laham,C. Y. Peng,A. Nanayakkara,M. Challacombe,P. M. W. Gill,B. Johnson, W. Chen,M. W. Wong,C. Gonzalez, and J. A. Pople,Gaussian,Inc.,Pittsburgh PA, 2003.

[53] Jorgensen, W.L.;Maxwell, D.S.;Tirado-Rives, J;"Development and Testing of the OPLS All-Atom Force Field on Conformational Energetics and Properties of Organic Liquids”, J. Am. Chem. Soc., 118 (45): 11225-11236, 1996.

[54] Rocha, W.R, Martins, V.M, Coutinho, K, Canuto, S; "Solvent effects on the electronic absorption spectrum of formamide studied by a sequential Monte Carlo/quantum mechanical approach”, Theoretical Chemistry Accounts, 108 (1), 2002.

[55] Coutinho K., Canuto S,"The sequential Monte Carlo-quantum mechanics methodology. Application to the solvent effects in the Stokes shift of acetone in water", Journal of molecular Structure-THEOCHEM, 632: 235-246, 2003.

[56] Jeffrey, G. A.,"An Introduction to Hydrogen Bonding (Topics in Physical Chemistry)". Oxford University Press, USA (March 13, 1997).

[57] Sobolewski, A.L., Domcke, W., "Intramolecular hydrogen bonding in the S-1(pi-pi*) excited state of anthranilic acid and salicylic acid: TDDFT calculation of excited-state geometries and infrared spectra”, Journal of Physical Chemistry A 108 (49): 10917-10922, 2004.

[58] He Y.G., Wu C.Y., Kong W.,"Theoretical and experimental studies of water complexes of p- and o-aminobenzoic acid"; Journal of Physical Chemistry A; 109 (12): 2809-2815; 2005. 
[59] Suppan, P.; Ghoneim N.. "Solvatochromism". The Royal Society of Chemistry, 1997.

[60] Suppan, P, "Solvatochromic shifts: The influence of the medium on the energy of eletronic states", Journal of Photobiology A, Chemistry, 50, 293-330, 1990.

[61] Lide, D.R. ,"CRC Handbook of Chemistry and Physics”, 79 edition, RC-Press, 1998.

[62] A.L. Sobolewski, W.Domcke ," On the mechanism of rapid non-radiative decay in intramolecularly hydrogen-bonded pi systems”, Chemical Physics Letters, Volume 300, Number 5, 533-539(7), 1999. 